\title{
SEISMIC BEHAVIOUR OF PRECAST SANDWICH WALL PANELS OF STEEL FIBRE REINFORCED CONCRETE LAYERS AND FIBRE REINFORCED POLYMER CONNECTORS
}

Rodrigo Lameiras*1, Joaquim A. O. Barros ${ }^{2}$, Isabel B. Valente ${ }^{2}$, Elisa Poletti ${ }^{2}$, Matilde Azevedo ${ }^{2}$, Miguel

\section{Azenha $^{2}$}

${ }^{1}$ PECC, ENC, UnB - Univ. de Brasília. Brasília, DF, Brazil. E-mail adress: rmlameiras@gmail.com.

${ }^{2}$ ISISE, Universidade do Minho, Campus de Azurém. 4800-058. Guimarães, Portugal.

\begin{abstract}
In recent past, the authors developed an innovative modular system for low rise building made by structural sandwich panels. This system was conceived with the focus on the rationalization of the construction process and on the thermal efficiency of the building. Thus, the precast panels comprise two outer Steel Fibre Reinforced Self-Compacting Concrete (SFRSCC) layers, a thermal insulation material and Glass Fibre Reinforced Polymer (GFRP) connectors. Studies previously made by the authors have proved the viability of the proposed solution when subjected to flexural loads (out-of-plane loads). However, the in-plane biaxial cyclic behaviour of these type of panels has not yet been assessed. Therefore, to investigate the response of these panels to loading conditions that can occur in a seismic event, an experimental program was carried out. This program was composed of almost real-scale panels $(2.0 \mathrm{~m}$ by $2.0 \mathrm{~m})$, with and without openings, which were subjected to a constant vertical load representative of the load transferred by the slab to the panel, while horizontal reversed cyclic loading was imposed to the top of the panel. The in-plane cyclic behaviour of the panels was evaluated in terms of strength, stiffness, ductility and energy dissipation. The results have shown that the tested prototypes were able to withstand high values of lateral loads, namely $212 \mathrm{kN}$ and $155 \mathrm{kN}$ in the prototypes without and with opening, respectively.
\end{abstract}

KEYWORDS: Glass Fibre Reinforced Polymer (GFRP), Steel Fibre Reinforced Self-Compacting Concrete (SFRSCC), sandwich panel, seismic behaviour.

*- corresponding author. 


\section{INTRODUCTION}

Different construction techniques have been proposed in the last years aiming to decrease the installation time and increase the energy efficiency without increasing significantly the overall building cost. Among these, there is the modular solution proposed by Lameiras et al. [1-4], which is composed by structural sandwich wall panels consisting of Steel Fibre Reinforced Self Compacting Concrete (SFRSCC) layers, a thermal insulation core layer material, and an innovative Glass Fibre Reinforced Polymer (GFRP) connector (herein designated by PERFOFRP). In the proposed system, developed for low rise residential buildings, the sandwich panels have to resist to both the vertical and lateral loads.

A main concern in the case of structural walls that have the main function of resisting to the lateral loads, is their seismic performance. It is highly desirable that this type of panels exhibits a ductile behaviour, by presenting a shear capacity capable of favouring the occurrence of flexural ductile failure mode [5].

In fact, design codes for seismic resistance of concrete buildings are more conservative for wall systems than for frame structures [6]. This is mainly attributed to the fact that shear plays a superior role in the seismic response of walls in consequence of the smaller experimental-based knowledge on wall systems. An aggravating factor in the case of the proposed system is the fact that the panels are precast and do not include conventional steel reinforcement. The design of precast/prefabricated systems generally is even more conservative.

Since the 1950s, some research has been developed to access the behaviour of prestressed/reinforced concrete walls under monotonic or simulated earthquake loading [5, 7-13]. Nonetheless, few attention was given on the use of precast/prefabricated wall systems as primary lateral load resisting system for seismic regions [14-17]. The seismic performance of precast/prefabricated structural wall systems is still not well understood due to the relative scarce information derived from experimental tests on walls in consequence of the high costs and difficulties on executing this type of tests [18]. Moreover, most of these studies are focused on the behaviour of slender cantilever walls, having been given relatively few attention to concrete walls with a height to length ratio of less than 2, hereinafter referred as squat walls.

Currently, there is still a lack of studies on the mechanical behaviour of structural concrete sandwich panels. The few works in this field are mainly dealing with the out-of-plane behaviour of panels [19-22]. The works developed by Pavese and Bournas [18] and by Ricci et al. [23] are dedicated to the assessment of the behaviour of single reinforced concrete cast-in-place squat sandwich panels under pseudo-static (cyclic) loadings. The behaviour of the complete structural system under earthquake (dynamic) loadings was investigated by Rezaifar 
et al. [24] and Palermo et al. [25]. Nonetheless, the geometry, reinforcement of concrete layers, connections between concrete layers, and constructive aspects of the sandwich panels tested in those researches are completely different from the solution proposed by Lameiras et al. [1-4]. The main differences that can be pointed out are the traditional materials (concrete reinforced with steel rebars and electro-welded meshes) and the cast-in-place technology for the sandwich panels, as well as steel connectors to link the outer and inner RC concrete layers.

The investigation presented in this paper was undertaken with the main aim of attaining a better insight of the inplane cyclic behaviour of the sandwich panels comprising SFRSCC layers and PERFOFRP connectors. Experimental results of quasi-static in-plane cyclic tests performed on almost real scale sandwich panels were obtained, including failure modes, hysteresis diagrams and shear behaviour. The option for the quasi-static inplane cyclic tests relies on the available experimental facilities. Furthermore, stiffness degradation, ductility and energy dissipation capacity were also assessed from the experimental tests carried out.

\section{RESEARCH SIGNIFICANCE}

This paper presents the experimental results of four almost full-scale squat Steel Fibre Reinforced SelfCompacting Concrete (SFRSCC) sandwich panels under in-plane cyclic loading. The tested panels include innovative Glass Fibre Reinforced Polymer (GFRP) connectors, herein designated as PERFOFRP, to keep both SFRSCC layers working together without occurrence of thermal bridge. The obtained results presented herein contribute to the state-of-the-art and provide a better insight on the mechanical behaviour of these innovative structural elements. Moreover, these results can be used for appraising the predictive performance of advanced FEM-based numerical models on the simulation of the behaviour of the building system recently proposed by the authors, composed by this type of panels..

\section{DESCRIPTION OF THE BUILDING SYSTEM}

The developed construction system is based on the use of precast sandwich panels that are intended to be the envelope for the building. The proposed sandwich panels are composed of two SFRSCC flat layers and a rigid thermal insulation material core, e.g.; Expanded Polystyrene (EPS) and Extruded Polystyrene (XPS) foams.

The panels are intended to act as load-bearing panels, eliminating the need for beams and columns along exterior walls. They must accommodate and transfer to foundations the vertical loads acting on the slabs, their selfweight and also lateral loads deriving mainly from wind loadings, temperature gradients and seismic loadings. 
For the sake of aesthetics, in the proposed building system the slabs are supported by the internal SFRSCC layers of the wall panels, therefore the external layer is higher than the internal layer (see Figure 1 and Figure 2). In the construction site, the precast structural concrete panels are positioned one beside the other in accordance with the architectural design of the building (see Figure 1 and Figure 2). The wall panels are designed to span from the foundation to the slab (i.e.; the interstorey height), as shown in Figure 1 and Figure 2. The foundation can be executed using cast in place or prefabricated foundations like the one represented in Figure 1. In the case of the prefabricated solution, the wall-footing connection is ensured using grout or concrete. In this case, the walls cantilever from the foundation until the pre-slab is positioned. The pre-slabs are joined together to the walls with the cast-in-place composite topping (in situ concrete), as shown in the detail of the wall-slab connections of Figure 2. Horizontal connections between the horizontal faces of the adjoining wall and floor panels are accomplished by means of starter longitudinal steel bars projected from the inner SFRSCC layer of the wall panel (see Figure 2). These horizontal connections tie the walls to the slabs, allowing the later to act as diaphragms, distributing horizontal loads to the walls and giving robustness to the structural system.

The role of SFRSCC is related to the inherent benefits of using this material instead of concrete with conventional reinforcement. Firstly, it allows reducing the volume of concrete necessary to produce the external layers, since the requirement of minimum concrete cover for the reinforcements in conventional reinforced concrete (RC) structures is not applicable to SFRSCC elements. So, more structurally efficient and lightweight elements can be obtained. Moreover, SFRSCC technology eliminates the tasks of placing the reinforcement (mesh or bars), and compacting/levelling concrete, thus allowing easier standardization of the production tasks. Furthermore, since the proposed panels are supposed to constitute the building envelope, it should be ensured that the width of the cracks in these elements is small enough to satisfy requirements concerning serviceability (functionality and appearance) and durability of the structure. In this context, SFRSCC has several properties that makes it attractive: it generally presents high crack-width control capacity, ductility, impact resistance, and water tightness due to the fibre reinforcement mechanisms provided by fibres bridging the microcracks, and the relatively high content of fine constituents. Furthermore, the costs of maintenance derived from corrosion of conventionally reinforced concrete layers are suppressed, since corrosion effects in SFRSCC have been reported to be negligible or even non-existent if crack width is limited to $0.3 \mathrm{~mm}[26,27]$.

The connection between the two SFRSCC layers of a sandwich panel is assured by discrete or continuous oneway GFRP connectors. While the continuous connectors extend along the full height or length of the panel, the 
discrete connectors have much lower length than the in-plane dimensions of the panels, and are strategically positioned to ensure optimized strength/stiffness benefits.

Since these connectors are the main load transfer mechanism between both SFRSCC layers, they must resist to the forces resulting from loadings the panel may be subjected. It should be noticed that, if the panels are stripped from the horizontal position, their connectors must be designed to resist the tensile forces caused by the selfweight of the lower wythe, which also happens during the lift up movement of the panel. Moreover, the connectors are also mobilized to transfer the shear stresses caused by the out-of-plane flexural loading (like wind pressure), as well as the stresses due to temperature variation and shrinkage. Finally, they also attend the stresses due to seismic loading.

The thickness of the thermal insulation material is defined in order to meet the energy requirements for the building, what depends on the climate characteristics of the place where the building is going to be located and on the prescriptions of regulations to be followed.

\section{TEST PROGRAMME}

Almost real-scale tests with single walls were performed under static horizontal cyclic loading and constant vertical loading (corresponding to the load transmitted by the upper stories for a low-rise residential building). In a simplified manner, these tests on single walls can simulate the seismic action expected on the wall during an earthquake [28].

The tests were performed with four prototypes, two of them without openings (NO) and the remaining two with a central opening (OP). These tests were carried out in the Laboratory of the Structural Division of the University of Minho.

\subsection{Material properties}

The materials used for prototypes were SFRSCC for the concrete layers, Expanded Polystyrene (EPS) for the thermal insulation core, and GFRP for the PERFOFRP connectors. Material tests were performed on SFRSCC and on GFRP.

4.1.1 - Steel Fibre Reinforced Self-Compacting Concrete (SFRSCC)

The SFRSCC consisted of ordinary Portland cement (C), type CEM I 42.5 R according to EN 197 [29], fine river sand (FS), coarse river sand (CS), limestone filler (LF), crushed limestone coarse aggregate with $12 \mathrm{~mm}$ maximum size (LA), water (W), SIKA ViscoCrete 3005 superplasticizer (SP) and hooked-end steel fibres (SF). The steel fibres were characterized by a length $\left(L_{f}\right)$ equal to $35 \mathrm{~mm}$, a diameter $\left(d_{f}\right)$ equal to $0.55 \mathrm{~mm}$, and an 
aspect ratio $\left(\lambda_{f}=L_{f} / d_{f}\right)$ equal to 65 . According to the data given by the supplier, their yield stress ranges between 1244 and $1446 \mathrm{MPa}$.

The SFRSCC was produced in a precast concrete plant by a vertical axis planetary concrete mixer. The present research was carried out considering data from tests performed with panels obtained from different castings, but made with similar SFRSCC. They consist of same constituent materials with slightly different water contents, as shown in Table 1. The differences in the water content among different castings were caused by adjustments to compensate the different moisture condition of aggregates.

The flow spread diameter $\left(D_{f l}\right)$ of SFRSCC from each casting, shown in Table 2, was obtained in the fresh state by using the inverted Abram's cone and following the recommendations of EFNARC [30]. An average flow spread of $661 \mathrm{~mm}$ was obtained. The smallest value of $D_{f l}$ was registered in the SFRSCC of panel P01 due to the lowest water content and highest period of time between its mixing phase and the flow test amongst all the SFRSCC compositions.

From each concrete batch, four $150 \times 300 \mathrm{~mm}$ (diameter $\times$ height) cylinders, and at least three $150 \times 150 \times 600 \mathrm{~mm}$ prisms were prepared

The compressive strength was obtained by executing compression tests in three cylinders according to the recommendations of EN 12390-3 [31], while elastic modulus was determined by performing two tests following the Portuguese standard LNEC E397 [32]. The tests of specimens from different castings were carried out at the ages indicated in Table 2. The average values and respective coefficient of variation $(\mathrm{CoV})$ obtained for the compressive strength $\left(f_{c m}\right)$ and the elastic modulus $\left(E_{c m}\right)$ are presented in Table 2. The specimens and the wall panels were cured under the same laboratory temperature and humidity conditions. The results of the compressive strength indicate a maximum deviation from the average of $21 \%$ for the SFRSCC used in the panel P01. The average values and respective coefficient of variations $(\mathrm{CoV})$ obtained for the compressive strength and elastic modulus of SFRSCC were equal to $57.5 \mathrm{MPa}(\mathrm{CoV}$ equal to $12 \%)$ and $37.6 \mathrm{GPa}(\mathrm{CoV}$ equal to $9 \%)$, respectively.

The post-cracking behaviour of SFRSCC was characterized by performing three-point bending test of a notched beam according to EN 14651 [33]. The prismatic specimens were tested at 28 days of age using a closed loop test system by applying two Linear Variable Differential Transformers (LVDTs) to the lateral faces of the beam, at the notch, to measure the crack mouth opening displacement (CMOD) at the height corresponding to the notch tip. The tests were operated under displacement control in a servo-hydraulic testing machine at a constant rate of $0.2 \mathrm{~mm} / \mathrm{min}$ until the deflection of $1 \mathrm{~mm}$, and then increased to $0.4 \mathrm{~mm} / \mathrm{min}$ until the CMOD reached at least 
$4 \mathrm{~mm}$. Based on the experimentally determined stress $\times$ CMOD relationship, residual flexural strengths $f_{R, i}$ were evaluated in order to identify the post-cracking behaviour of SFRSCC. Four residual flexural strengths, namely $f_{R, 1}, f_{R, 2}, f_{R, 3}$ and $f_{R, 4}$. were determined corresponding to the $C M O D_{i}$ values of $0.5,1.5,2.5$ and $3.5 \mathrm{~mm}$, respectively. These values were obtained following the recommendations of the fib Model Code [34], as schematically shown in Figure 3. The experimental load-CMOD of the SFRSCC used in different castings and panels are shown in Figure 4. The residual strengths were calculated by using the Eq. (1).

$$
f_{R, i}=\frac{3}{2} \frac{F_{R, i} \cdot l}{b \cdot h_{s p}{ }^{2}}
$$

where:

$f_{R, i}$ is the residual flexural tensile strength corresponding to $C M O D_{i}$;

$F_{R, i}$ is the load corresponding to $C M O D_{i}$;

$l$ is the span length (nominal value: $550 \mathrm{~mm}$ );

$b$ is the width of the specimen's cross section (nominal value: $150 \mathrm{~mm}$ );

$h_{s p}$ is the distance from the notch tip to the top of the specimen (nominal value: $125 \mathrm{~mm}$ ).

The average values for the residual flexure strengths $f_{R, 1}, f_{R, 2}, f_{R, 3}$ and $f_{R, 4}$ for the SFRSCC of the different batches are presented in Table 3 . It is also indicated the limit of proportionality, $f_{f c t, L}$.

\subsection{2 - GFRP connectors}

The GFRP connectors were fabricated with $2.0 \mathrm{~mm}$ of thickness obtained by stacking five Chopped Strand Mat (CSM) sheets consisting of $450 \mathrm{~g} / \mathrm{m}^{2}$ of E-glass fibres impregnated by Polyester resin matrix. This laminate was chosen for the connectors because previous researches made by the authors already shown to be an adequate material for this purpose [1-4]. The Vacuum Assisted Resin Transfer Moulding (VARTM) process [35] was the selected one to the produce the connectors. The piece was cured at room temperature and, once hardened, the parts were cut and drilled to obtain the final geometry of the connectors.

Six specimens of CSM laminate were tested in tension following the procedures described in ASTM 3039 standard [36]. The tensile stress was assumed as the ratio between the applied load and the average crosssectional area of specimen, while the engineering axial strain was determined by using a clip-gauge transducer with a reference length of $50 \mathrm{~mm}$ attached to the mid-span of the specimens. The elastic limit stress, ultimate tensile stress, the corresponding strains and the elastic modulus were obtained from these tests. The stress-strain 
relationships obtained from tests are given in Figure 5. The obtained average values and the respective coefficient of variations are provided in Table 4.

Shear properties of CSM laminate were obtained by the standard Iosipescu shear test following the procedures described in ASTM D5379 [37]. From the tests it was obtained a shear strength of $139.60 \mathrm{MPa}$, an ultimate shear strain of $19510 \mu \varepsilon$, and a shear modulus of $3.97 \mathrm{GPa}$, with a coefficient of variation of $1.2 \%, 16.4 \%$ and $2.5 \%$, respectively.

\subsection{3 - EPS}

EPS was used as the insulation material since it is a relatively economic solution, and is readily available. According to data supplied by the manufacturer, the expanded polystyrene adopted in the middle layer has an apparent density of $15 \mathrm{~kg} / \mathrm{m}^{3}$, a flexural strength of $100 \mathrm{kPa}$ obtained following the EN 12089 [38], and a compressive stress of $15 \mathrm{kPa}$ and $60 \mathrm{kPa}$ at, respectively, $2 \%$ and $10 \%$ of strain, determined according to EN 826 [39].

\subsection{Geometry and execution of prototypes}

Figure 6 shows the dimensions and details of the prototypes used in the cyclic tests. All the prototypes have length $\left(l_{w}\right)$ and height $\left(h_{w}\right)$ equal to $2000 \mathrm{~mm}\left(h_{w} / l_{w}=1.0\right)$. The thermal insulation material, the inner and the outer SFRSCC layers have an equal thickness of $60 \mathrm{~mm}$. The thickness of the inner SFRSCC layer was increased for $90 \mathrm{~mm}$ in a strip of $400 \mathrm{~mm}$ of height along the top boundary of panel. This solution reduces locally the thickness of thermal insulation, which could jeopardize the thermal efficacy of the sandwich panel, but it was the easier way to guarantee a suitable contact area to support the sandwich panel composing the slab. For the OP panels, a square opening of a length edge of $900 \mathrm{~mm}$ was executed in the centre of the panel to simulate the effect of a window. A solid SFRSCC zone with height equal to $150 \mathrm{~mm}$ was produced in the base of the panel corresponding to the depth of the panel that is embedded into the foundation (see Figure 1 and Figure 6). This solid zone along the bottom edge of the wall panel aims to reproduce the effect of the cast-in-place foundation proposed for the system, and also to increase the in-plane shear stiffness of the panel.

Based on the numerical modelling of the sandwich panels and on the strength capacity of the connections [2], it was chosen to use discrete connectors (length equal to $400 \mathrm{~mm}$ ) regularly distributed along the panel and arranged as shown in Figure $6 a$ and b, designated by $\mathrm{C} 40$. All the connectors were positioned with their length parallel to the height of wall panel. In panels with opening, a connector was applied in the proximity of each 
corner, as presented in Figure 6. Four connectors with length equal to $600 \mathrm{~mm}$, hereinafter called C60, were positioned along the base of panel with $100 \mathrm{~mm}$ embedded in the SFRSCC solid zone (see Figure 6b).

Due to the support conditions of the panel in the test setup, four square holes were produced immediately above the solid zone, through the all thickness of panel (see Figure 6). The holes were produced using EPS prisms positioned appropriately before the panels be cast.

A wooden placeholder was used to materialize the opening in the panels, as shown in Figure 7. The thicker SFRSCC zone was materialized reducing the thickness of the thermal insulation to $30 \mathrm{~mm}$ in a strip of $400 \mathrm{~mm}$ of height along the top boundary of the panel.

The execution of prototypes followed the same sequence of procedures: (1) the mould and the placeholders were previously mounted; (2) the first SFRSCC layer was poured; (3) the thermal insulation plates (EPS plates) and lifting inserts were placed; (4) the connectors were positioned prior the SFRSCC set time; (5) the second SFRSCC layer was poured; and (6) after the initial curing (approximately 16h covered by a wet blanket), the panel was removed from the mould and stocked, being cured under laboratory temperature and humidity conditions until the date of test.

All the prototypes were cast in the horizontal position, as shown in Figure 7. For the sake of simplicity on the manufacturing of sandwich panels, the connectors were positioned after the casting of the first SFRSCC layer. As mentioned in Lameiras et al. [1-4], this procedure reduces the probability of obtaining fibres passing through the holes of the perforated GFRP connectors corresponding to the outer layer. Nonetheless, it disregards the use of temporary supports to keep the connectors positioned and held firmly while the first SFRSCC layer is poured. In the adopted procedure the connectors are positioned in slots previously made in the EPS plates (see Figure 7). In order to guarantee the specified SFRSCC cover (nominal distance between the GFRP connector and the mould equal to $15 \mathrm{~mm}$ ), spacers made with the same GFRP used in the connectors were glued as shown in Figure 7c.

\subsection{Test setup, instrumentation and test procedure}

Figure 8 illustrates the test setup used in the experimental program. It was conceived in order to assess the response of the sandwich wall segments to seismic loading type. The prototypes were laterally loaded in reversed cyclic configuration and displacement controlled, by using a loading system consisting of a tension-compression servo-hydraulic-actuator acting in a rectangular loading area equal to $250 \mathrm{~mm} \times 90 \mathrm{~mm}$ (height $\times$ width) with the gravity center passing $125 \mathrm{~mm}$ from the top surface of prototype (see Figure 8c). The actuator has a maximum capacity in terms of displacement and load equal to $100 \mathrm{~mm}$ and $\pm 250 \mathrm{kN}$, respectively. The loads and 
corresponding displacements are considered positive when the prototype is pushed (Figure 8c). The actuator was connected to the reaction wall by means of a three-dimensional hinge, and to the prototype by using a twodimensional hinge (see Figure $8 \mathrm{~b}$ ). To impose the cyclic displacements to the prototype, the thicker part of the internal SFRSCC layer was confined by two steel plates connected through four sufficiently stiff steel threaded bars of $40 \mathrm{~mm}$ nominal diameter (Figures $8 \mathrm{a}$ and $8 \mathrm{~b}$ ).

The vertical load was applied by three hydraulic cylinders with pressure automatically self-adjusted. This load was spread in the top boarder of the panel by using a IPN 200 steel profile. For this purpose, each hydraulic cylinder applied the load directly to the steel beam, acting against a T-shaped steel plate that is connected to the lower steel beam by using four vertical steel threaded bars of $17.5 \mathrm{~mm}$ nominal diameter (Figures $8 \mathrm{a}$ and $8 \mathrm{~b}$ ). This configuration allows the actuators to follow the horizontal movement of the wall during the cyclic tests. For an adequate distribution of the vertical loading, steel plates were welded to the top of the steel beam positioned in the top of the wall. The surface of the wall's top boarder that received the distributed load was levelled and regularized using a thin layer of high strength mortar. Finally, for a better distribution of load, one strip of $2 \mathrm{~mm}$ thick rigid rubber was positioned between the steel beam and the wall's regularization mortar layer.

The prototype was connected to the bottom steel profile in 4 points in order to prevent the vertical movement of the solid SFRSCC zone (see Figure 8). For practical purposes, two different fastening systems were used to prevent the vertical movement of the prototypes, as shown in Figure 8. Near the extremities of the prototype a system composed of high strength bolts was positioned in the solid SFRSCC zone. In the middle of panel steel bars of rectangular section passing throughout the holes produced during the casting of prototypes were used for this purpose (see Figure 8). Furthermore, the horizontal movement of the solid zone was restrained in the direction of the load, by using two steel profiles fixed to the bottom steel profile, as shown in see Figure 8 . The out-of-plane displacements were prevented through means of punctual steel rollers distributed along the upper part of the prototype, on the both sides of the wall (see Figure 8a).

The displacements of the prototypes were measured using linear variable differential transformers (LVDT), as shown in Figure 9. Different instrumentation was used on the tests with NO and OP prototypes. In the specific tests of the prototypes without openings, 7 LVDTs were used to capture the horizontal displacement of these prototypes at different elevations (LVDTs 5 to 11, as presented in Figure 9a). Horizontal displacements were registered in both SFRSCC layers for capturing any relative displacement that could occur due to the mode adopted to apply the load to the prototype (in one of the two SFRSCC layers). LVDT 16 was devoted to measure 
horizontal slip between the wall and the steel beam located in the base, LVDTs 13 to 15 were utilized to measure vertical displacement at the bottom and top of wall (rocking displacement), LVDTs 1 and 2 were used to register displacements at the diagonal of the prototype, LVDTs 3 and 4 were adopted to register the displacement at the vertical boarders of the prototype, and LVDT 12 was applied to evaluate any eventual tendency for the separation of the SFRSCC layers in the middle height of the prototype. It is worth underlining that the horizontal displacements of the prototype were depurated (parasitic contribution was removed) from the horizontal rigidbody displacements of the solid SFRSCC zone, registered by LVDT 16.

Two different arrangements of LVDTs were used for the prototypes with openings. For both OP prototypes, their horizontal displacements at different elevations were obtained with LVDTs 5 to 8, the horizontal slip between the prototype and the bottom steel beam was measured by LVDT 16, and the rocking displacements by LVDTs 13 to 15 . Moreover, the vertical displacement along the height of these prototypes was registered by one LVDT at the same position (LVDT 9 for OP 01 and LVDT 12 for OP 02). Nonetheless, while the LVDTs 1 to 4 were used in prototype OP 01 to evaluate shear deformations (see Error! Reference source not found.), in prototype OP 02 the same LVDTs were used to register the crack opening displacements in the corners of the opening (see Figure 9c), in panel OP 02 the same LVDTs were used to register the crack opening displacements in the corners of the opening (see Figure 9b). Furthermore, the LVDTs 10 and 11 were used to measure the horizontal displacements just above the opening (to estimate axial deformation and curvature) in prototype OP 01, as shown in (see Figure 9b). In prototype OP 02 the LVDTs 9, 10 and 11 were positioned in the faces of the vertical edges of the prototype in an attempt of registering the opening of horizontal cracks that had appeared in the first test with this type of prototype.

A constant vertical load of $45 \mathrm{kN}$ (i.e., $22.5 \mathrm{kN} / \mathrm{m}$ ) was applied to all the tested prototypes. The applied vertical load was calculated according to Eurocode 1 [40], considering a dead load of $4.3 \mathrm{kN} / \mathrm{m}^{2}$, a live load of $2.0 \mathrm{kN} / \mathrm{m}^{2}$ and assuming a slab of $10 \mathrm{~m}$ of one way span (the maximum value considered for the modular construction in this research project), simply supported on sandwich wall panels at its extremities. The partial safety coefficients were considered to be equal to 1.3 and 1.5 for dead and live loads, respectively. A total vertical load of $15 \mathrm{kN}$ was applied by each of the three hydraulic cylinders for materializing the total load in the prototype. In the case of the horizontal load, the cyclic procedure adopted during the tests was based on the ISO protocol [41] and adapted for the specific prototype. In summary, the lateral load procedure consisted of successive cycles progressively increasing in each direction of loading, according to predefined target drift ratios (i.e., ratio between the lateral displacement and the prototype's height). A total of nine target interstorey drifts were applied 
to investigate a wide range of phenomena from initial elastic phase up to the ultimate conditions, namely: $0.07 \%$, $0.14 \%, 0.27 \%, 0.41 \%, 0.54 \%, 0.68 \%, 0.81 \%, 1.08 \%$ and $1.35 \%$. To investigate the strength and stiffness degradation due to loading-unloading damage, the loading protocol consisted of three cycles at each level of displacement, as suggested by the ISO protocol and done by Poletti and Vasconcelos [42], Pavese and Bournas [18] and Ricci et al. [23]. Figure 10 shows the cyclic load history. The loading rate was $0.3 \mathrm{~mm} / \mathrm{s}$, controlled by the LVDT positioned horizontally and aligned with the actuator (LVDT 6, shown in Figure 9).

\section{EXPERIMENTAL RESULTS}

\subsection{Deformational features and typical damage patterns}

Figure 11 and Figure 12 show the typical cracking patterns for each type of test performed. By observing the final aspect of the prototypes in Figure 11, no shear cracking pattern was detected in the prototypes without openings (type NO). In these prototypes, cracks are horizontal and concentrated at the transition between the solid zone and the sandwiched part (see Figure 11). These horizontal cracks started in the two corners, at drift equal to $0.41 \%$, and they are mainly caused by the applied flexural loading conditions. No additional cracks appeared during the test, and the crack pattern alteration was resumed to the widening of the cracks in the base during the progress of test. The observed behaviour is strongly related to the specific constructive details at the part of the prototypes where the abrupt transition from a solid zone to a sandwiched type section favour the localization and concentration of these type of cracks. Possibly, the use of conventional steel reinforcement in the lateral corners of the prototype could control the crack opening in these regions and, therefore, increase the panel's lateral load carrying capacity by mobilizing more effectively its relatively high shear strength. The main issues related to the use of conventional reinforcement along the base of the panels are related to the decrease of the thermal efficacy of the sandwich panels and also to the activities related to the preparation and installation of the steel bars (i.e., cutting, bending and positioning) that were avoided when using only fibre reinforced concrete. Alternatively, the connectors embedded in the solid zone (C60) could be done with higher content of fibres aligned in the prototype's height, increasing their load capacity along this direction and keeping this horizontal crack controlled, allowing to explore even more the shear capacity of these sandwich walls. In fact, after the NO 02 prototype has been tested, it was dismantled and it was verified that the C60 connectors located near the extremities of specimen were ruptured in the section crossed by the main crack that appeared in the SFRSCC layers (see Figure 13a). 
Figure 12 shows the typical evolving and final cracking pattern in the prototypes with openings. In this case, due to the opening, the flexural cracks are less evident in respect to the prototypes without opening. As could be expected, inclined cracks concentrated around the opening have been formed. The first diagonal cracks appeared in the panels OP01 and OP02 for drifts equal to $0.54 \%$ and $0.41 \%$, respectively (see Figure 12). Nonetheless, in the panel OP01 the first crack appeared in the internal SFRSCC layer (i.e., with the thicker upper edge that receives the vertical load). In this prototype the cracks that opening in the external layer were thinner than the cracks formed in the internal layer until the end of test. In prototype OP02 the first crack appeared in the external layer and the cracking was more intense in the internal SFRSCC layer than in external SFRSCC layer along the test.

At $0.68 \%$ drift level, the diagonal cracks that appeared in the corners deviated towards the vertical direction in the nearby of GFRP connectors located in the proximity of corners of the central opening (see Figure 12). This observed behaviour indicates that the connector contributed to deviate the crack orientation and to limit the widening of the cracks formed in these zones. At drifts equal to $0.81 \%$ and $0.68 \%$, horizontal cracks were observed rising from outer vertical edges of panels to the corners of opening of panels OP01 and OP02, respectively. These cracks appeared first in the lower corners and later in the upper corners of the prototypes. For both prototypes, at a drift equal $1.08 \%$, the already opened cracks located above the opening became wider. At the same stage, sounds that seemed to be from the rupture of GFRP connectors were heard. After that, a clear rigid body movement (rotation) of the prototype was observed until the end of tests.

The prototypes were dismantled after have been tested in order to assess the final condition of GFRP connectors. It was observed that, in NO prototypes, the outmost C60 connectors (with $600 \mathrm{~mm}$ of length) were ruptured (see Figure 13a), while in all the other connectors no apparent damage was detected. In the prototypes with opening, the connectors $\mathrm{C} 40$ positioned in the nearby of opening corners, and the outmost C60 located in the beginning of horizontal cracking were ruptured (see Figure 13b). One of the outmost C60 connectors of prototype OP 01 was, however, not ruptured because it was capable of deviating the horizontal crack in order to pass immediately above to the interruption of this connector.

It is important to point out that no prototype have failed abruptly, presenting always a relatively gradual stiffness and strength degradation until the end of tests. Furthermore, all prototypes, with or without opening, displayed a moderate drift ratio at failure, of the order of $0.81-1.35 \%$. 


\subsection{Typical hysteretic diagrams}

The force-displacement hysteresis loops obtained in the tested prototypes are illustrated in Figure 14. The peak loads and corresponding drifts are summarized in Table 5, including: peak loads in two loading directions (pushing and pulling) and corresponding drift ratios.

From observation of Figure 14, it can be noted that all the tests presented some differences on their behaviour in positive and negative directions (pushing and pulling the prototype, respectively). Among different reasons that could be pointed out to the observed behaviour, the most acceptable are sliding of support. These differences are substantially higher in the test of NO 01 (the first one to be tested), due to the use of a steel plate with relative low stiffness to connect the actuator to the reaction wall of the laboratory (see Figure 8a). For the following tests this steel plate was replaced by an I-shaped steel profile, which has solved that issue (note the difference between the connection of actuator to the reaction wall, shown in Figure $8 \mathrm{a}$ and $8 \mathrm{~b}$. Thus, the parameters that define the idealized bilinear behaviour, the initial stiffness and ductility factor for test NO 01 presented in this paper are always related only to the pushing cycles.

Figure 14 shows that, for all prototypes, up to a drift equal to $0.41 \%$ (corresponding displacement in the top of wall equal to $8.2 \mathrm{~mm}$ ), the curves exhibits low hysteresis, indicating no significant damage in the panels. Furthermore, up to this stage the loading and unloading stiffness remain quite similar. In general, the hysteresis loops become larger from a drift of $0.54 \%$, indicating the occurrence of significant damage in the prototypes. The hysteresis cycles become larger, and a cyclic strength degradation is observed from drift of $0.81 \%$, for NO 01 panel and from drift of $1.08 \%$ for the other tested panels. At his stage, the peak loads reached at the third pushing cycle are reduced to $89 \%, 85 \%, 54 \%$ and $53 \%$ of the load reached at the first cycle for NO 01 , NO 02 , OP 01 and OP 02, respectively. This indicates that the damage in SFRSCC was increased along the repeated cycles. Furthermore, this damage was higher in OP panels. Considering the first cycles and the pushing portions, the maximum loads were equal to $208.2,217.2 \mathrm{kN}$ that were reached at $1.35 \%$ and $1.08 \%$ drifts, respectively for NO 01 and NO 02 panels, whilst they were reached 159.6 and $150.2 \mathrm{kN}$ at $0.81 \%$ drift for OP 01 and OP 02 panels, respectively.

The presence of the opening in the prototypes reduced considerably the lateral resistance and stiffness when compared to those of prototypes without opening. The opening in the OP prototypes resulted in an average decrease in the strength equal to $27 \%$ in comparison with the NO prototypes (considering $1^{\text {st }}$ cycles in pushing phase). Similarly, the stiffness of prototypes with opening was also affected, as can be observed in the hysteretic loops in Figure 14. 
The hysteretic curves obtained for the 4 tested prototypes are quite flat at the origin, which is justified by the fact that they experienced pinching in the cyclic response (see Figure 14), probably in consequence of slip between the specimen and the steel beam used as foundation and/or due to opening/closing of cracks.

The diagonal displacements for measuring the shear deformation were quite linear in the tests with prototypes without opening, as shown in Figure 15a for NO 02 prototype. This response reflects the fact that this prototype did not present any damage due to shear deformation during the test. Moreover, it is important to note that the maximum measured diagonal displacements in prototypes without opening represented only $1.0 \%$ of the corresponding lateral displacements imposed to the panels (average values obtained in NO 01 and NO 02).

Figure 15b and Figure 16a show comparisons between the lateral displacements read for both SFRSCC layers. From the observation of the hysteretic loops, it is noticed that the readings are quite similar, indicating that, although the load is imposed only to the internal SFRSCC layer (i.e., with the thicker SFRSCC layer in the upper border of the panel), both layers seem to work together, presenting very small relative lateral displacements.

From the analysis of Figure $15 \mathrm{c}$ and Figure $16 \mathrm{~b}$, it is verified that the prototypes developed a rocking mechanism, with significant uplifting of the solid zone from the base beam. This rocking mechanism is more evident for tests with prototypes without opening. The upper steel beam of OP 02 prototype uplift as much as $7.5 \mathrm{~mm}$ (see Figure 16b) while this value reached $18 \mathrm{~mm}$ in the test with NO 02 prototype (see Figure 15c), pointing out the important rotation experienced by the tested prototypes.

\subsection{Seismic performance}

\subsubsection{Monotonic envelope curves}

The monotonic envelopes are curves obtained from the hysteresis loops connecting the points of maximum load in each drift level. Since the test protocol consisted on the application of three repetitions for each drift level (first cycle and two stabilization ones), three monotonic envelope curves were obtained: corresponding to the first, second and third cycles. Figure 17 shows the monotonic envelopes of the force-displacement relationship for each of the three cycles. Since high variations were observed during tests among the three repetitions, the envelope curves of three cycles were considered for the calculations of idealized bilinear behaviour on the next section.

\subsubsection{Idealized bilinear behaviour}

Due to the reasons already exposed, only the results during pushing stage of cycles (i.e., positive displacements) are analysed in this section. In order to take into account the cyclic degradation caused by the stabilization 
cycles, bilinear curves corresponding to each of three different cycles were determined. The bilinearisation of the experimental curves was obtained based on the procedure adopted by Ricci et al. [23]. First, the initial stiffness, $k_{w}$, was set equal to the secant stiffness taking into account the origin and the load/displacement corresponding to the $0.27 \%$ drift (Figure 18). Thus, the pseudo yielding force, $F_{w y}$, was obtained through an energy criterion where the horizontal line segment of the idealized bilinear force-drift curve was located using an iterative graphic procedure that balanced the areas of the portions comprised between the real and the idealized curves above and below the horizontal line segment. The yielding displacement, $\delta_{w y}$, was defined as the intersection of the line corresponding to $F_{w y}$ and the initial slope, given by $F_{w y} k_{w}$ (see Figure 18). Finally, the ultimate displacement, $\delta_{w u}$, was set equal to the maximum imposed displacement (i.e., $21.6 \mathrm{~mm}$ for OP 01 prototype, and $27.0 \mathrm{~mm}$ for all the other prototypes). Table 6 presents the main parameters that define the obtained bilinear curves of all tested prototypes.

Figure 19 displays the experimental force-displacement envelope in the pushing stage for the three cycles of the tested prototypes, and their corresponding equivalent bilinear diagrams.

\subsubsection{Initial stiffness and stiffness degradation}

For comparison purposes, the initial stiffness of tested prototypes was calculated by two different methodologies. First, as made by Ricci et al. [23], the initial stiffness was taken equal to the secant stiffness taking into account the origin and a specific load-displacement point. In their work, Ricci et al. [23] calculated the secant stiffness considering at a load-displacement point corresponding to $0.10 \%$ drift. Nonetheless, $0.27 \%$ drift was chosen for the present work in order to overcome some type of initial nonlinearity observed in the load versus displacement responses associated to initial adjustments of specimen at the beginning of tests

The second methodology to calculate the initial stiffness is based on the ISO 21581 [41], where the lateral stiffness of the prototypes are calculated according to the following equation:

$$
k_{w 2}=\frac{0.3 F_{\max }}{\delta_{40 \% F \max }-\delta_{10 \% F \max }}
$$

where $F_{\max }$ is the maximum load attained in the test and $\delta_{40 \% \mathrm{Fmax}}$ and $\delta_{10 \% \mathrm{Fmax}}$ are, respectively, the displacement values obtained from the envelope curve corresponding to $40 \%$ and $10 \%$ of the displacement at maximum load. Table 7 summarizes the initial stiffness calculated by both methodologies, where it is verified that they provide similar values. On average, the initial stiffness evaluated at $0.27 \%$ drift, considering the pushing branches, was equal to 10.54 and $11.38 \mathrm{kN} / \mathrm{mm}$, respectively, for NO and OP prototypes. The respective values were equal to 10.35 and $10.81 \mathrm{kN} / \mathrm{mm}$ when the initial stiffness was computed by the Eq. (2). 
When only the pushing branches are considered, the prototypes with opening exhibit initial stiffness slightly lower than the prototypes without opening. On average, the initial stiffness of panels with openings corresponded to $98 \%$ and $95 \%$ of the values obtained for the panels without opening when the initial stiffness is computed at, respectively, $0.27 \%$ drift and according to the ISO 21581 recommendations.

For sandwich walls consisting on traditionally reinforced concrete layers, Ricci et al. [23] obtained values of initial stiffness in the interval of $35-40 \mathrm{kN} / \mathrm{mm}$, which are significantly higher than the values obtained in the current work. This difference can be attributed to the contribution of the following effects. Firstly, differently to what was done by Ricci et al. [23], in the present work the load was applied in only one of the SFRSCC layers. Secondly, the foundation proposed by Ricci et al. [23] for the prototypes consisted on a stiff reinforced concrete plate, monolithically connected to the wall layers, resulting on a stiff connection. However, in the current work, due to the precast nature of the prototypes, the connection between the wall panel and the foundation is not as stiff as the connection adopted by Ricci et al. [23].

To evaluate the degradation of stiffness experienced by the prototypes during the cyclic tests, the cyclic stiffness was computed for each drift ratio considering the average of the slopes of the line connecting the origin and the two points of loading corresponding to the maximum displacements (pushing and pulling). A schematic representation of the determination of cyclic stiffness is shown in Figure 20a. Figure 21 shows the variation of the cyclic stiffness with the drifts, which indicates that the stiffness of the prototypes without opening increased up to a drift ratio equal to $0.27 \%$ and decreased above this drift. In the case of the prototypes with opening, the overall stiffness starts to decrease from $0.14 \%$ drift. In general, the stiffness decrease was higher for panels with opening.

\subsubsection{Ductility}

The ductility of a wall subjected to in-plane loads can be defined as the capability of a structural system to undergo large amplitude of deformations without excessive strength deterioration. In other words, the ductility is the ability of the structural element to sustain several cycles of inelastic deformation without significant loss of strength. In earthquake-resistant design of structures, it is important to guarantee a ductile behaviour of the system and of the structural elements that are part of it.

In this work, the ductility is computed as the ratio between the ultimate displacement $\left(\delta_{w u}\right)$ and the pseudo-yield displacement $\left(\delta_{w y}\right)$ defined in the equivalent bilinear diagram. This is an index commonly adopted in similar works $[18,23]$. The ductility indexes computed considering each of the three cycles are presented in Table 8 . It 
is verified that the average values of ductility over cycles have ranged from 1.3 to 2.4 , and that the displacement ductility was unaffected by the presence of opening in the wall.

In general, the ductility of the sandwich panels was quite low. For instance, Ricci et al. [23] obtained ductility ratios ranging from 5.08 to 9.18 for cast-in-place sandwich panels consisting of $4 \mathrm{~cm}$ thick traditionally reinforced concrete layers and $10 \mathrm{~cm}$ thick layer of polystyrene foam.

\subsubsection{Ability to dissipate energy}

One major parameter usually adopted for the assessment of the seismic performance of prototypes is the ability of the structural element to dissipate energy during the cyclic test. According to FEMA-451 [43], the more energy dissipated per cycle without excessive strength deterioration, the better is the behaviour of the structure. The energy dissipated by the prototypes per drift ratio, $E_{d w}$, was calculated using the area of the enclosed loop in the load-displacement curve (Figure 20b). Figure 22 reports the variation of the dissipated energy by the prototypes for each drift level.

As can be observed, the dissipation of energy found for both types of wall tends to increase with larger lateral displacements. This behaviour was already expected because, per definition, the energy dissipation should be directly proportional to the lateral displacement imposed to the prototype. Nonetheless, from the observation of Figure 22 it can be noticed that the evolution of the dissipated energy was not directly proportional to the displacements, showing an exponential trend. This is a typical trend observed also in other typologies of infill walls $[44,45]$ and it is possibly associated with the damage growth and with the consequent development of nonlinear displacements.

As shown in Figure 22, after a drift ratio equal to $1.08 \%$, the dissipated energy per loop diminished for the test with panel OP 02 . This possibly happened due to the rupture of the panel prior to this drift.

In general, the results indicate that the energy dissipated by the proposed sandwich prototypes is rather low, when compared to sandwich walls in conventional reinforced concrete.

\subsubsection{Equivalent viscous damping}

To evaluate the level of effectiveness in terms of seismic resistance of the sandwich prototypes, the Equivalent Viscous Damping $\left(E V D_{w}\right)$ was also computed. It consists on a normalized energy dissipation capacity of panels that can be computed by the following equation [28]:

$$
E V D_{w}=\frac{E_{d w}}{2 \pi \cdot\left(E_{e w}{ }^{+}+E_{e w}{ }^{-}\right)}
$$


where $E_{d w}$ is the dissipated energy as discussed above and, $E_{e w}{ }^{+}$and $E_{e w}{ }^{-}$are the elastic energies of an equivalent viscous system calculated, respectively, at the maximum and minimum displacements reached in each loop (see Figure 20b).

Figure 23 illustrates how this property evolved with the increase of drift levels. Average values of the $E V D_{w}$ at $0.41 \%$ drift equal to $9.50 \%$ and $10.54 \%$ were achieved for NO and OP panels, respectively.

The elastic viscous damping ratio found for the prototypes without opening was almost constant between the $0.54 \%$ and $1.08 \%$ drift ratios, showing a trend to increase only between $0.14 \%$ and $0.41 \%$ drifts, and after $1.08 \%$ drift. In turn, the results for the prototypes with opening differed from the response of NO prototypes because their $E V D_{w}$ decreased between $0.54 \%$ and $0.81 \%$ and presented a rapid increase between $0.81 \%$ and $1.08 \%$ drifts. After the $1.08 \%$ drift the prototype OP 02 presented a decrease of $E V D_{w}$ when the second and third cycles are considered.

\section{CONCLUSIONS}

An experimental program was performed aiming at analysing the seismic behaviour of the developed precast sandwich wall consisting of two outer SFRSCC layers, GFRP connectors and EPS core. Its behaviour under inplane lateral forces was assessed by pseudo-static cyclic tests performed on almost real scale panels, with and without opening. From the results presented in this paper, the following conclusions can be pointed out:

- when subjected to in-plane lateral loads, the sandwich panels present a flexure-dominant failure mode;

- the damage in panels without opening is concentrated in the toe regions of the wall, without occurred of shear cracking. The premature failure mode observed in these panels could be avoided by using specific reinforcement to provide higher flexural capacity and toughness in the critical regions. Nonetheless, the use of conventional reinforcement was avoided in the proposed system in order to keep the manufacturing of panels as simple and fast as possible, and eliminate the probability of corrosion. A possibility is using in the critical regions FRP connectors of higher tensile capacity or larger percentage of adopted connectors;

- the initial stiffness of sandwich walls is approximately equal to $10 \mathrm{kN} / \mathrm{mm}$, apparently not being affected by the opening. This value is considerably less than the $30 \mathrm{kN} / \mathrm{mm}$ to $40 \mathrm{kN} / \mathrm{mm}$ achieved by Ricci et al. [23] and Pavese and Bournas [18] for typical squat conventional reinforced concrete (RC) sandwich panels with similar aspect ratios and vertical loads. For increasing the initial lateral stiffness of proposed panel's concept, experimental tests and advanced numerical simulations should be adopted 
by exploring the use of hybrid fibre reinforcement for assuring a composite material of tensile strain hardening character ;

- no prototype has failed abruptly, presenting always a relatively gradual stiffness and strength degradation until the end of tests;

- The opening in the sandwich panel has decreased in $27 \%$ its strength regarding the strength of the NO prototypes;

- Despite the actuator that has applied the lateral load and has limited this load be only concentrated in the internal layer, the experimental results have demonstrated a full composited action

- the tested prototypes were able to withstand high values of lateral loads. Their lateral load capacity was approximately equal to $212 \mathrm{kN}$ and $155 \mathrm{kN}$ in the prototypes without and with opening, respectively. Higher values, approximately equal to $300 \mathrm{kN}$, were attained by Ricci et al. [23] for sandwich panels made with conventional RC. A maximum strength equal to $280 \mathrm{kN}$ was reported by Hidalgo et al. [9] for conventional RC walls designed according to the ACI 318 [46] prescriptions;

- The sandwich panels without opening were able to withstand approximately $106 \mathrm{kN} / \mathrm{m}$, which is similar to the base shear strength required for mid-rise buildings according to the ASCE/SEI 7-05 [47, 48].

- the minimum ductility registered in the prototypes has ranged from 1.3 to 2.4 , apparently not being affected by the existence of opening in the prototype. This limitation should be overcome, which can be attained by using sandwich panels in critical regions of the proposed modular building with a fibre reinforcement system that assures strain hardening character for the FRC. 


\section{ACKNOWLEDGEMENTS}

The first author acknowledges the financial support provided by FAPDF. The second author acknowledges the financial support provided through the project ICoSyTec (POCI-01-0145-FEDER-027990) financed by Fundação para a Ciência e Tecnologia (FCT) and co-funded by FEDER through Operational Competitiveness and Internationalization Programme (POCI).

\section{Table captions}

Table 1: Composition of SFRSCC used in the experimental program (contents per $\mathrm{m}^{3}$ of SFRSCC).

Table 2: Flow spread in fresh state $\left(D_{f f}\right)$, compressive strength $\left(f_{c m}\right)$ and elastic modulus $\left(E_{c m}\right)$ of SFRSCC

Table 3: Post-cracking parameters for different castings of SFRSCC obtained from three-point bending tests.

Table 4: Properties of CSM laminate obtained from direct tensile tests.

Table 5: Peak loads and drifts corresponding to the peak loads

Table 6: Values of parameters that define the idealized bilinear behaviour for the tested prototypes.

Table 7: Values of initial stiffness calculated for the tested prototypes.

Table 8: Values of ductility factor for the tested prototypes. 


\section{Figure captions}

Figure 1: Details of construction system proposed: (a) internal view; (b) external view; (c) detail of cross-section with the wall supporting the slab; (c) placement of the pre-slab.

Figure 2: Typical wall-slab and wall-foundation connections in the building system.

Figure 3: Definition of fracture parameters of SFRSCC obtained from the Load-CMOD curve.

Figure 4: Experimental Load - CMOD relationships for SFRSCC, corresponding to the following panel/casting: (a) NO01/1, (b) NO2/1, (c) NO02/2, (d) OP01/1, (e) OP01/2 and (f) OP02/1.

Figure 5: Stress-strain response for the CSM laminate under direct tensile.

Figure 6: Prototype details: (a) without opening; (b) with opening; (c) connectors (dimensions in m).

Figure 7: Manufacturing of prototypes: (a) without opening; (b) with opening; (c) detail of connector with spacer.

Figure 8: Experimental setup: (a) perspective of test setup adopted in NO 01 panel; (b) lateral view of test setup adopted in NO 02, OP 01 and OP 02 prototypes; (c) schematic representation of loading system.

Figure 9: Schematic representation of instrumentation adopted: (a) prototypes without opening (NO); (b) prototypes with opening (OP). (dimensions in $\mathrm{m}$ ).

Figure 10: Test procedure used (pushing corresponds to a positive displacement).

Figure 11: Typical cracking pattern of prototypes without opening (NO).

Figure 12: Typical cracking pattern of prototypes with opening (OP).

Figure 13: Damaged prototypes: (a) NO 02, (b) OP 02.

Figure 14: Hysteretic curves for: (a) NO 01; (b) NO 02; (c) OP 01; (d) OP 02.

Figure 15: Force versus displacements for NO 02 prototype: (a) diagonal shear displacements; (b) lateral displacements in both SFRSCC layers; (c) rocking displacements; (c) vertical displacements.

Figure 16: Force versus displacements for OP 02 prototype: (a) lateral displacements in both SFRSCC layers; (b) vertical and rocking displacements; (c) cracking opening width in the corners of opening.

Figure 17: Envelopes of the force versus displacement responses: (a) NO 01; (b) NO 02; (c) OP 01; (d) OP 02..

Figure 18: Schematic representation of equivalent energy method used to obtain the equivalent bilinear curve.

Figure 19: Equivalent bilinear curves: (a) NO 01; (b) NO 02; (c) OP 01; (d) OP 02.

Figure 20: Evaluation of parameters: (a) overall stiffness (K); (b) Equivalent Viscous Damping $\left(E V D_{w}\right)$.

Figure 21: Overall stiffness degradation: (a) NO 01; (b) NO 02; (c) OP 01; (d) OP 02.

Figure 22: Dissipated energy per cycle: (a) NO 01; (b) NO 02; (c) OP 01; (d) OP 02.

Figure 23: Equivalent viscous damping: (a) NO 01; (b) NO 02; (c) OP 01; (d) OP 02. 


\section{Contents}

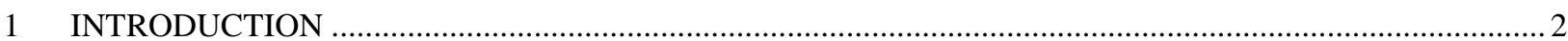

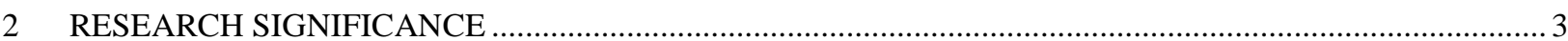

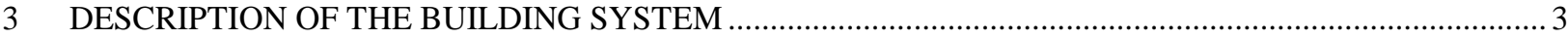

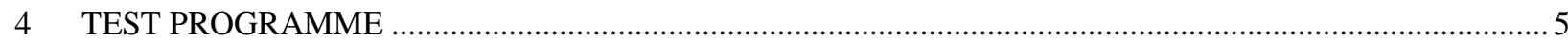

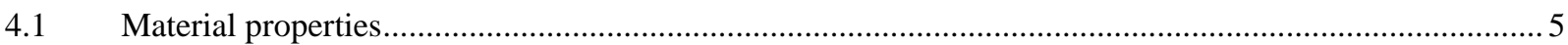

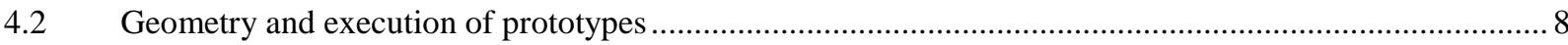

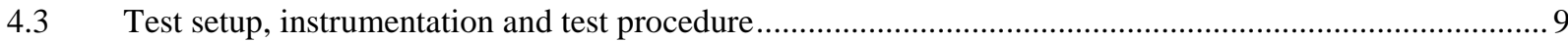

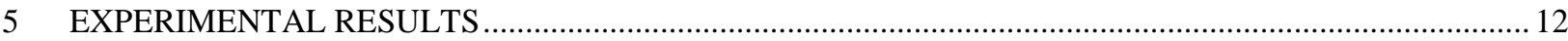

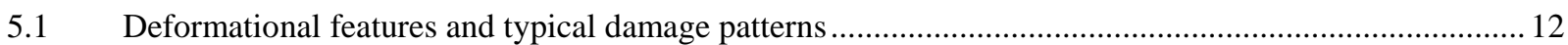

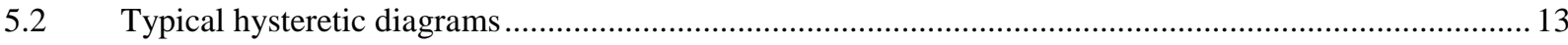

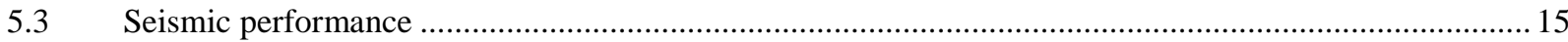

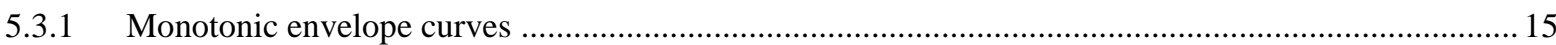

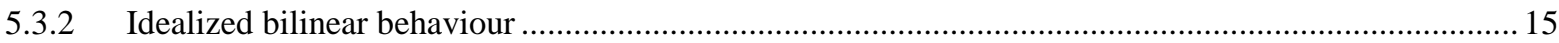

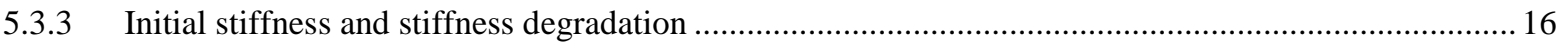

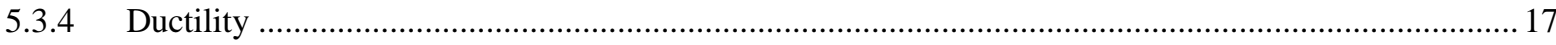

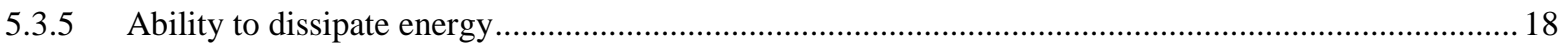

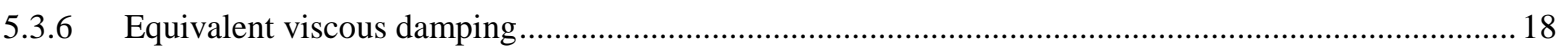

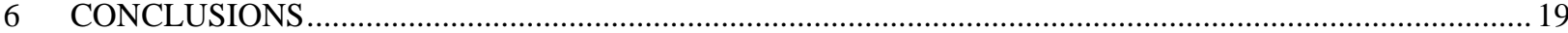

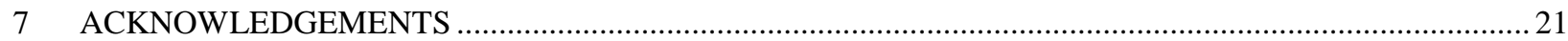




\section{REFERENCES}

[1] Lameiras R, Barros J, Azenha M, Valente IB. Development of sandwich panels combining fibre reinforced concrete layers and fibre reinforced polymer connectors. Part I: conception and pull-out tests. Composite Structures. 2013;105:446-59.

[2] Lameiras R, Barros J, Azenha M, Valente IB. Development of sandwich panels combining fibre reinforced concrete layers and fibre reinforced polymer connectors. Part II: Evaluation of mechanical behaviour. Composite Structures. 2013;105:460-70.

[3] Lameiras R, Valente IB, Barros JAO, Azenha M, Gonçalves C. Pull-out behaviour of GlassFibre Reinforced Polymer perforated plate connectors embedded in concrete. Part I: Experimental program. Construction and Building Materials. 2018;162:155-69.

[4] Lameiras R, Barros JAO, Valente IB, Xavier J, Azenha M. Pull-out behaviour of glass-fibre reinforced polymer perforated plate connectors embedded in concrete. Part II: Prediction of load carrying capacity. Construction and Building Materials. 2018;169:142-64.

[5] Paulay T, Priestley MJN, Synge AJ. Ductility in earthquake resisting squat shearwalls. ACI Journal. 1982;79:257-69.

[6] CEN. European standard EN 1998-3: Eurocode 8: design of structures for earthquake resistance. Brussels: European Committee for Standardization; 2005.

[7] Barda F, Hanson JM, Corley WG. Shear Strength of Low-Rise Walls with Boundary Elements. Special Publication. 1977;53.

[8] Kypros P, Amr E. Cyclic Behavior of RC Cantilever Walls, Part I: Experimental Results. Structural Journal. 1995;92.

[9] Hidalgo PA, Ledezma CA, Jordan RM. Seismic Behavior of Squat Reinforced Concrete Shear Walls. Earthquake Spectra. 2002;18:287-308.

[10] Cevdet K. Gulec ASW, Bozidar S. Shear Strength of Squat Rectangular Reinforced Concrete Walls. Structural Journal. 2008;105.

[11] Kuang JS, Ho YB. Seismic Behavior and Ductility of Squat Reinforced Concrete Shear Walls with Nonseismic Detailing. Structural Journal. 2008;105.

[12] Cevdet K. Gulec ASW, Bozidar S. Peak Shear Strength of Squat Reinforced Concrete Walls with Boundary Barbells or Flanges. Structural Journal. 2009;106.

[13] Massone L, Orakcal K, Wallace J. Modelling of squat structural walls controlled by shear. ACI Structural Journal. 2009;106: 646-55. 
[14] Crisafulli FJ, Restrepo JI, Park R. Seismic design of lightly reinforced precast rectangular wall panels. PCI Journal. 2002;47:104-21.

[15] Holden T, Restrepo J, Mander JB. Seismic performance of precast reinforced and prestressed concrete walls. Journal of Structural Engineering (ASCE). 2003;129:286-96.

[16] Perez FJ, Pessiki S, Sause R, Lu LW. Lateral Load Tests of Unbonded Post-Tensioned Precast Concrete Walls. Special Publication. 2003;211.

[17] Todut C, Dan D, Stoian V. Theoretical and experimental study on precast reinforced concrete wall panels subjected to shear force. Engineering Structures. 2014;80:323-38.

[18] Pavese A, Bournas DA. Experimental assessment of the seismic performance of a prefabricated concrete structural wall system. Engineering Structures. 2011;33:2049-62.

[19] Bush TD, Wu Z. Flexural Analysis of Prestressed Concrete Sandwich Panels with Truss Connectors. Precast/Prestressed Concrete Institute Journal. 1998;43:76-86.

[20] Pessiki S, Mlynarczyk A. Experimental Evaluation of the Composite Behavior of Precast Concrete Sandwich Wall Panels. Journal of Prescast/Prestressed Concrete Institute. 2003;48:5471.

[21] Benayoune A, Samad AAA, Trikha DN, Ali AAA, Ellinna SHM. Flexural behaviour of precast concrete sandwich composite panel - Experimental and theoretical investigations. Construction and Building Materials. 2008;22:580-92.

[22] Frankl BA, Lucier GW, Hassan TK, Rizkalla SH. Behavior of precast, prestressed concrete sandwich wall panels reinforced with CFRP shear grid. PCI journal. 2011;56:42-54.

[23] Ricci I, Palermo M, Gasparini G, Silvestri S, Trombetti T. Results of pseudo-static tests with cyclic horizontal load on cast in situ sandwich squat concrete walls. Engineering Structures. 2013;54:131-49.

[24] Rezaifar O, Kabir MZ, Taribakhsh M, Tehranian A. Dynamic behaviour of 3D-panel singlestorey system using shaking table testing. Engineering Structures. 2008;30:318-37.

[25] Palermo M, Ricci I, Silvestri S, Gasparini G, Trombetti T, Foti D et al. Preliminary interpretation of shaking-table response of a full-scale 3-storey building composed of thin reinforced concrete sandwich walls. Engineering Structures. 2014;76:75-89.

[26] Nemegeer D, Vanbrabant J, Stang H. Brite-Euram Program on Steel Fibre Concrete, Durability Corrosion Resistance of Cracked Fibre-Reinforced Concrete. In: Schnütgen B, Vandewalle L, editors. Test and Design Methods for Steel Fibre Reinforced Concrete- 
Background and Experiences RILEM Technical Committee 162, TDF Workshop, Proceedings Pro 312003. p. 47-66.

[27] Bernard ES. Durability of Fibre-Reinforced Shotcrete. Shotcrete: More Engineering Developments. Queensland, Australia: Taylor and Francis; 2004.

[28] Chopra AK. Dynamics of structures: theory and applications to earthquake engineering. Englewood Cliffs, New Jersey: Prentice-Hall; 1995.

[29] CEN. EN 197-1: Cement. Composition, specifications and conformity criteria for common cements. Brussels: European Committee for Standardization; 2011.

[30] EFNARC. The European guidelines for self-compacting concrete. 2005.

[31] CEN. EN 12390-3. Testing hardened concrete - Part 3: compressive strength of specimens. Lisbon: European Committee for Standardization (CEN); 2009. p. 21.

[32] LNEC. E397 Concrete: determination of the modulus of elasticity in compression. Lisbon1993.

[33] CEN. EN 14651:Test method for metallic fibered concrete - Measuring the flexural tensile strength (limit of proportionality (LOP), residual). Brussels: European Committee for Standardization; 2005.

[34] fib fidb. fib Model Code for Concrete Structures 2010. Berlin: Ernst \& Sohn; 2013.

[35] Advani SG, Hsiao K-T. Manufacturing techniques for polymer matrix composites (PMCs). Cambridge: Woodhead Publishing Limited; 2013.

[36] ASTM Standard D 3039/D 3039M. Tensile Properties of Polymer Matrix Composite Materials. West Conshohocken, PA: ASTM International; 2008.

[37] ASTM. D5379 - 12: Test method for shear properties of composite materials by the Vnotched beam method. West Conshohocken, PA: American Society for Testing and Materials (ASTM); 2012.

[38] CEN. EN 12089: Thermal insulating products for building applications. Determination of bending behaviour. European Committee for Standardization (CEN); 2013.

[39] CEN. EN 826: Thermal insulating products for building applications: Determination of compression behaviour. European Committee for Standardization (CEN); 2013.

[40] CEN. EN 1991: Eurocode 1 - Actions on structures. Brussels: European Committee for Standardization (CEN); 1991. 
[41] ISO. ISO 21581: Timber structures - Static and cyclic lateral load test method for shear walls. Geneva, Switzerland: International Organization for Standardization (ISO); 2010.

[42] Poletti E, Vasconcelos G. Seismic behaviour of traditional timber frame walls: experimental results on unreinforced walls. Bull Earthquake Eng. 2015;13:885-916.

[43] FEMA. FEMA-451: Recommended provisions: Design examples. Washington, USA: Federal Emergency Management Agency (FEMA); 2006.

[44] Pires F. Influence of masonry walls over the behaviour of reinforced concrete frames under horizontal actions: Thesis (in Portuguese). LNEC, Lisbon; 1990.

[45] Haach VG. Development of a Design Method for Reinforced Masonry Subjected to InPlane Loading Based on Experimental and Numerical Analysis. Guimaraes, Portugal: University of Minho; 2009.

[46] ACI Committee 318. Building code requirements for structural concrete: (ACI 318-95) and commentary (ACI 318R-95). Farmington Hills, Mich: American Concrete Institute; 1995.

[47] ASCE. Minimum design loads for buildings and other structures (ASCE/SEI 7-05). Reston, VA: American Society of Civil Engineers; 2006.

[48] Lindeburg M, McMullin KM. Seismic design of building structures: a professional's introduction to earthquake forces and design details. 10th. ed. Belmont, PA: Professional Publications; 2011. 
Table 9: Composition of SFRSCC used in the experimental program (contents per $\mathrm{m}^{3}$ of SFRSCC).

\begin{tabular}{ccccccccc}
\hline Panel/Casting & $\mathrm{C}$ & $\mathrm{W}$ & $\mathrm{SP}$ & $\mathrm{LF}$ & $\mathrm{FS}$ & $\mathrm{CS}$ & $\mathrm{LA}$ & $\mathrm{SF}$ \\
& {$[\mathrm{kg}]$} & {$[\mathrm{kg}]$} & {$[\mathrm{kg}]$} & {$[\mathrm{kg}]$} & {$[\mathrm{kg}]$} & {$[\mathrm{kg}]$} & {$[\mathrm{kg}]$} & {$[\mathrm{kg}]$} \\
\hline NO01/1 & & 148 & & & & & & \\
NO02/1 & & 182 & & & & & & \\
NO02/2 & & 182 & & & & & & \\
OP01/1 & 413 & 179 & & & & & & \\
OP01/2 & & 187 & & & & & & \\
OP02/1 & & 175 & & & & & & \\
\hline
\end{tabular}


Table 10: Flow spread in fresh state $\left(D_{f l}\right)$, compressive strength $\left(f_{c m}\right)$ and elastic modulus $\left(E_{c m}\right)$ of SFRSCC.

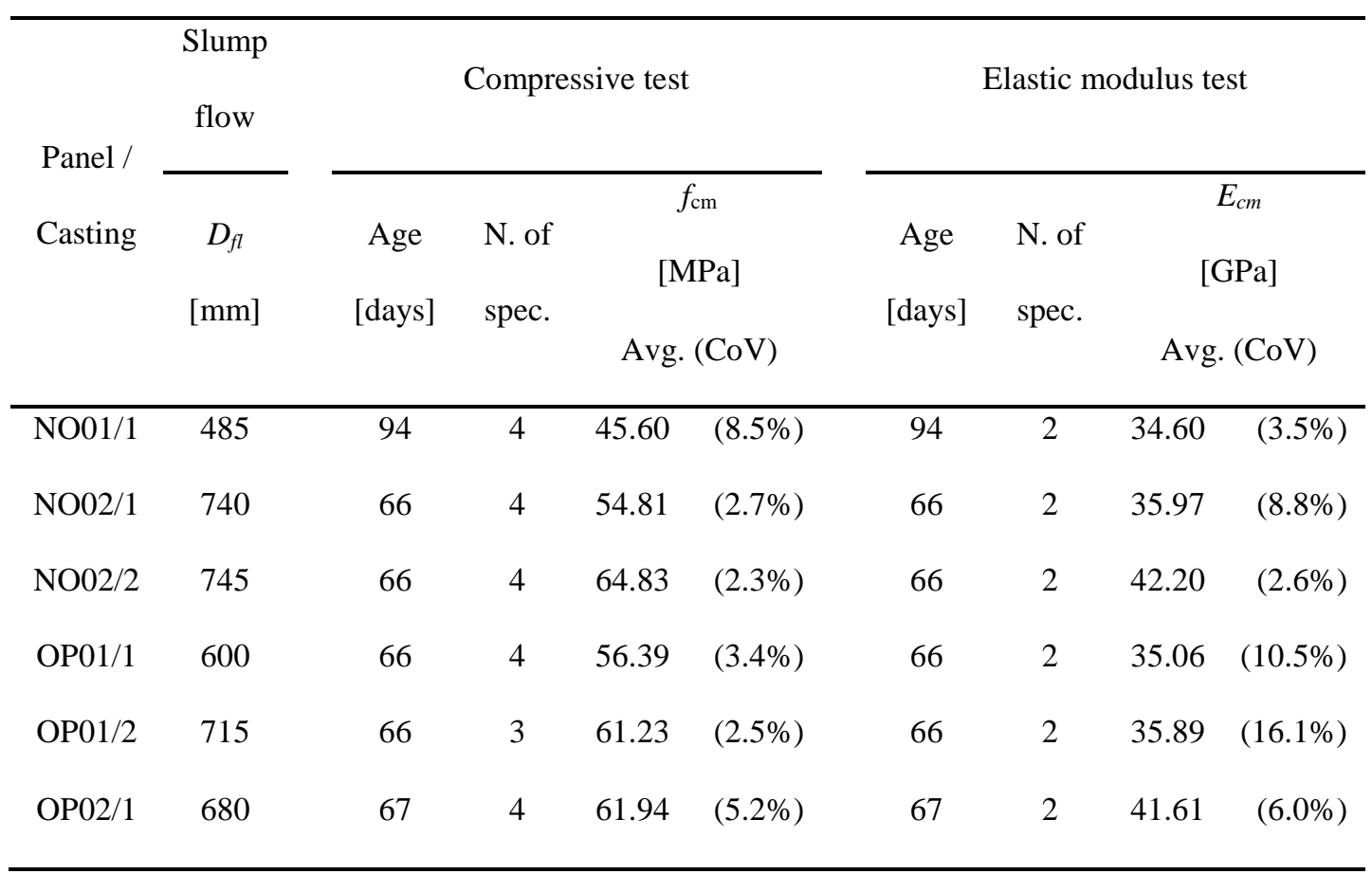


Table 11: Post-cracking parameters for different castings of SFRSCC obtained from three-point notched beam bending tests.

\begin{tabular}{|c|c|c|c|c|c|c|c|}
\hline \multirow{3}{*}{$\begin{array}{l}\text { Panel / } \\
\text { Casting }\end{array}$} & \multirow{3}{*}{$\begin{array}{l}\text { N. of } \\
\text { spec. }\end{array}$} & & \multirow{3}{*}{$\begin{array}{c}f_{f c t, L} \\
{[\mathrm{MPa}]}\end{array}$} & \multicolumn{4}{|c|}{ Residual flexural tensile strength } \\
\hline & & & & & $f_{R, 2}$ & $f_{R, 3}$ & \\
\hline & & & & {$[\mathrm{MPa}]$} & {$[\mathrm{MPa}]$} & {$[\mathrm{MPa}]$} & {$[\mathrm{MPa}]$} \\
\hline \multirow{2}{*}{ NO01/1 } & \multirow{2}{*}{5} & Avg. & 5.8 & 9.21 & 8.11 & 6.82 & 5.7 \\
\hline & & $(\mathrm{CoV})$ & $(13.30 \%)$ & $(13.80 \%)$ & $(15.40 \%)$ & $(15.70 \%)$ & $(18.50 \%)$ \\
\hline \multirow{2}{*}{$\mathrm{NO} 2 / 1$} & \multirow{2}{*}{5} & Avg. & 5.63 & 8.36 & 7.47 & 6.4 & 5.59 \\
\hline & & $(\mathrm{CoV})$ & $(7.90 \%)$ & $(7.40 \%)$ & $(7.20 \%)$ & $(9.60 \%)$ & $(11.40 \%)$ \\
\hline \multirow{2}{*}{$\mathrm{NO} 22 / 2$} & \multirow{2}{*}{5} & Avg. & 4.91 & 6.62 & 6.01 & 5.16 & 4.55 \\
\hline & & $(\mathrm{CoV})$ & $(10.90 \%)$ & $(16.00 \%)$ & $(13.70 \%)$ & $(12.60 \%)$ & $(13.70 \%)$ \\
\hline \multirow{2}{*}{ OP01/1 } & \multirow{2}{*}{3} & Avg. & 5.25 & 8.22 & 7.13 & 5.42 & 4.13 \\
\hline & & $(\mathrm{CoV})$ & $(0.90 \%)$ & $(4.20 \%)$ & $(2.70 \%)$ & $(10.70 \%)$ & $(19.40 \%)$ \\
\hline \multirow[b]{2}{*}{ OP01/2 } & \multirow[b]{2}{*}{7} & Avg. & 5.11 & 7.44 & 6.77 & 5.52 & 4.61 \\
\hline & & $(\mathrm{CoV})$ & $(13.20 \%)$ & $(27.20 \%)$ & $(24.60 \%)$ & $(28.60 \%)$ & $(26.30 \%)$ \\
\hline \multirow{2}{*}{ OP02/1 } & \multirow[b]{2}{*}{5} & Avg. & 5.23 & 6.82 & 6.25 & 5.38 & 4.69 \\
\hline & & $(\mathrm{CoV})$ & $(8.50 \%)$ & $(41.40 \%)$ & $(20.70 \%)$ & $(22.20 \%)$ & $(22.50 \%)$ \\
\hline
\end{tabular}


Table 12: Properties of CSM laminate obtained from direct tensile tests.

\begin{tabular}{|c|c|c|c|c|c|}
\hline $\mathrm{N}$ of & $\begin{array}{l}\text { Ultimate tensile } \\
\text { stress, } \sigma_{\text {pt.u }}\end{array}$ & $\begin{array}{l}\text { Ultimate tensile } \\
\text { strain, } \varepsilon_{\text {pt.u }}\end{array}$ & $\begin{array}{l}\text { Elastic limit } \\
\text { stress, } \sigma_{\text {pt.el }}\end{array}$ & $\begin{array}{l}\text { Elastic limit } \\
\text { strain, } \varepsilon_{\text {pt.el }}\end{array}$ & $\begin{array}{l}\text { Tensile modulus } \\
\text { of elasticity, } \mathrm{E}_{\mathrm{pt}}\end{array}$ \\
\hline spec. & $\begin{array}{l}\text { Avg. } \\
{[\mathrm{MPa}]}\end{array}$ & $\begin{array}{l}\text { Avg. } \\
{[\mu \varepsilon]}\end{array}$ & $\begin{array}{l}\text { Avg. } \\
{[\mathrm{MPa}]}\end{array}$ & $\begin{array}{l}\text { Avg. } \\
{[\mu \varepsilon]}\end{array}$ & $\begin{array}{l}\text { Avg. } \\
{[\mathrm{GPa}]}\end{array}$ \\
\hline 8 & $201.97 \quad(4.40 \%)$ & $17881 \quad(5.40 \%)$ & $201.97 \quad(4.40 \%)$ & $17881 \quad(5.40 \%)$ & $(3.70 \%)$ \\
\hline
\end{tabular}


Table 13: Peak loads and drifts corresponding to the peak loads.

\begin{tabular}{|c|c|c|c|c|c|c|c|c|c|c|c|c|}
\hline \multirow{3}{*}{$\begin{array}{c}\text { Specimen } \\
\text { Ref. }\end{array}$} & \multicolumn{6}{|c|}{ Peak load $[\mathrm{kN}]$} & \multicolumn{6}{|c|}{ Drift corresponding to the peak load [\%] } \\
\hline & \multicolumn{2}{|c|}{ 1st cycle } & \multicolumn{2}{|c|}{ 2nd cycle } & \multicolumn{2}{|c|}{ 3rd cycle } & \multicolumn{2}{|c|}{ 1st cycle } & \multicolumn{2}{|c|}{ 2nd cycle } & \multicolumn{2}{|c|}{ 3rd cycle } \\
\hline & push & pull & push & pull & push & pull & push & pull & push & pull & push & pull \\
\hline NO 01 & 208.2 & -185.7 & 195.6 & -173.9 & 183.5 & -171.8 & 1.35 & -1.35 & 1.08 & -1.35 & 1.08 & -1.35 \\
\hline NO 02 & 217.2 & -192.1 & 193.6 & -175.6 & 183.6 & -172.3 & 1.08 & -1.35 & 1.08 & -1.08 & 1.08 & -1.08 \\
\hline OP 01 & 159.6 & -154.3 & 152.9 & -137.1 & 149.3 & -136.5 & 0.81 & -1.08 & 0.81 & -0.81 & 0.81 & -0.81 \\
\hline OP 02 & 150.2 & -135.2 & 145.5 & -129.9 & 142.9 & -126.7 & 0.81 & -1.08 & 0.81 & -0.81 & 0.81 & -0.81 \\
\hline
\end{tabular}


Table 14: Values of parameters that define the idealized bilinear behaviour for the tested walls.

\begin{tabular}{ccccccccccc}
\hline \multirow{2}{*}{$\begin{array}{c}\text { Specimen } \\
\text { Ref. }\end{array}$} & \multicolumn{3}{c}{$F_{w y}[\mathrm{kN}]$} & \multicolumn{4}{c}{$\mathrm{d}_{w y}[\mathrm{~mm}]$} & \multicolumn{3}{c}{$\mathrm{d}_{w u}[\mathrm{~mm}]$} \\
\cline { 2 - 10 } & cycle & cycle & cycle & cycle & cycle & cycle & cycle & cycle & cycle \\
& & & & & & & & & & \\
\hline NO 01 & 206.0 & 195.5 & 174.0 & 21.4 & 21.4 & 18.7 & 27.0 & 27.0 & 27.0 \\
NO 02 & 167.0 & 158.2 & 152.0 & 14.6 & 13.3 & 12.8 & 27.0 & 27.0 & 27.0 \\
OP 01 & 132.2 & 114.1 & 110.2 & 12.5 & 11.1 & 11.2 & 27.0 & 27.0 & 27.0 \\
OP 02 & 117.5 & 98.3 & 90.3 & 11.7 & 9.1 & 8.5 & 27.0 & 27.0 & 27.0
\end{tabular}


Table 15: Values of initial stiffness calculated for the tested prototypes.

\begin{tabular}{|c|c|c|c|c|c|c|c|c|c|c|c|c|}
\hline \multirow{4}{*}{$\begin{array}{c}\text { Specimen } \\
\text { Ref. }\end{array}$} & \multicolumn{12}{|c|}{ Initial stiffness $\left(k_{w}\right)\left[10^{3} \mathrm{kN} / \mathrm{mm}\right]$} \\
\hline & \multicolumn{6}{|c|}{$\mathrm{F}_{0.27 \%} / \mathrm{d}_{0.27 \%}$} & \multicolumn{6}{|c|}{$30 \% \mathrm{~F}_{\max } /\left(\mathrm{d}_{40 \% \text { Fmax }}-\mathrm{d}_{10 \% \text { Fmax }}\right)$} \\
\hline & \multicolumn{2}{|c|}{ 1st cycle } & \multicolumn{2}{|c|}{ 2nd cycle } & \multicolumn{2}{|c|}{ 3rd cycle } & \multicolumn{2}{|c|}{ 1st cycle } & \multicolumn{2}{|c|}{ 2nd cycle } & \multicolumn{2}{|c|}{ 3rd cycle } \\
\hline & push & pull & push & pull & push & pull & push & pull & push & pull & push & pull \\
\hline NO 01 & 9.63 & - & 9.12 & - & 9.29 & - & 10.66 & - & 10.83 & - & 10.87 & - \\
\hline NO 02 & 11.46 & 14.15 & 11.88 & 13.86 & 11.87 & 13.65 & 11.58 & 15.07 & 12.18 & 16.55 & 12.14 & 17.13 \\
\hline OP 01 & 10.60 & 8.34 & 10.24 & 8.26 & 9.81 & 8.23 & 11.55 & 8.91 & 11.26 & 8.67 & 10.60 & 8.57 \\
\hline OP 02 & 10.02 & 8.51 & 10.75 & 8.28 & 10.67 & 8.41 & 9.94 & 7.61 & 10.79 & 7.61 & 10.69 & 7.69 \\
\hline
\end{tabular}


Table 16: Values of ductility factor for the tested walls.

\begin{tabular}{cccccccc}
\hline & \multicolumn{7}{c}{ Ductility factor $=\mathrm{d}_{w u} / \mathrm{d}_{w y}[-]$} \\
Specimen & 1st cycle & 2nd cycle & 3rd cycle & Average \\
\cline { 2 - 8 } Ref. & push & pull & push & pull & push & pull & over the \\
& & & & & & & cycles \\
\hline NO 01 & 1.26 & - & 1.26 & - & 1.44 & - & 1.3 \\
NO 02 & 1.85 & 2.17 & 2.03 & 2.35 & 2.11 & 2.42 & 2.2 \\
OP 01 & 1.73 & 1.29 & 1.94 & 1.27 & 1.93 & 1.25 & 1.6 \\
OP 02 & 2.30 & 1.72 & 2.95 & 2.05 & 3.19 & 2.26 & 2.4 \\
\hline
\end{tabular}




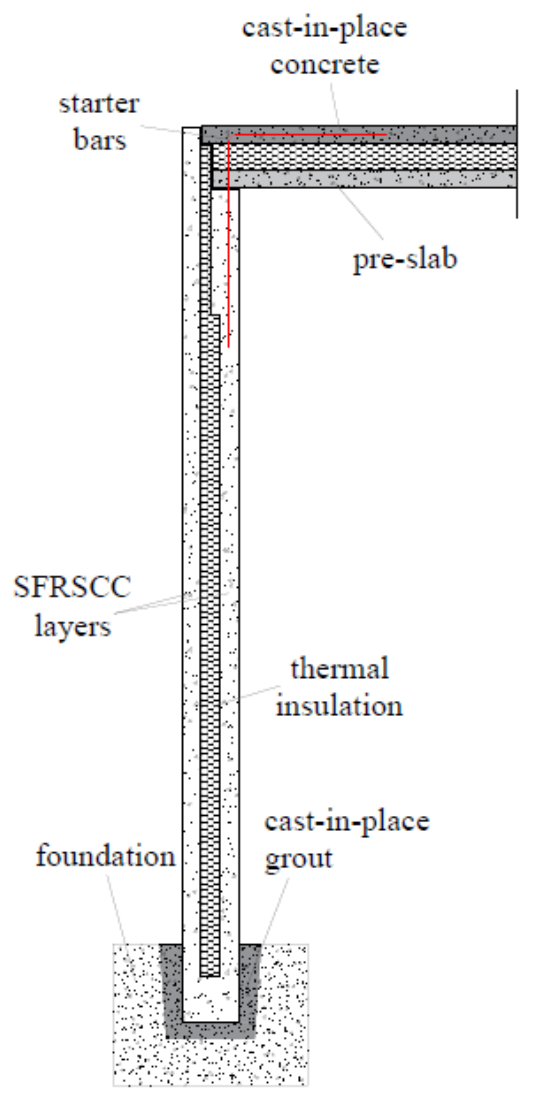

Figure 1: Typical wall-slab and wall-foundation connections in the building system. 


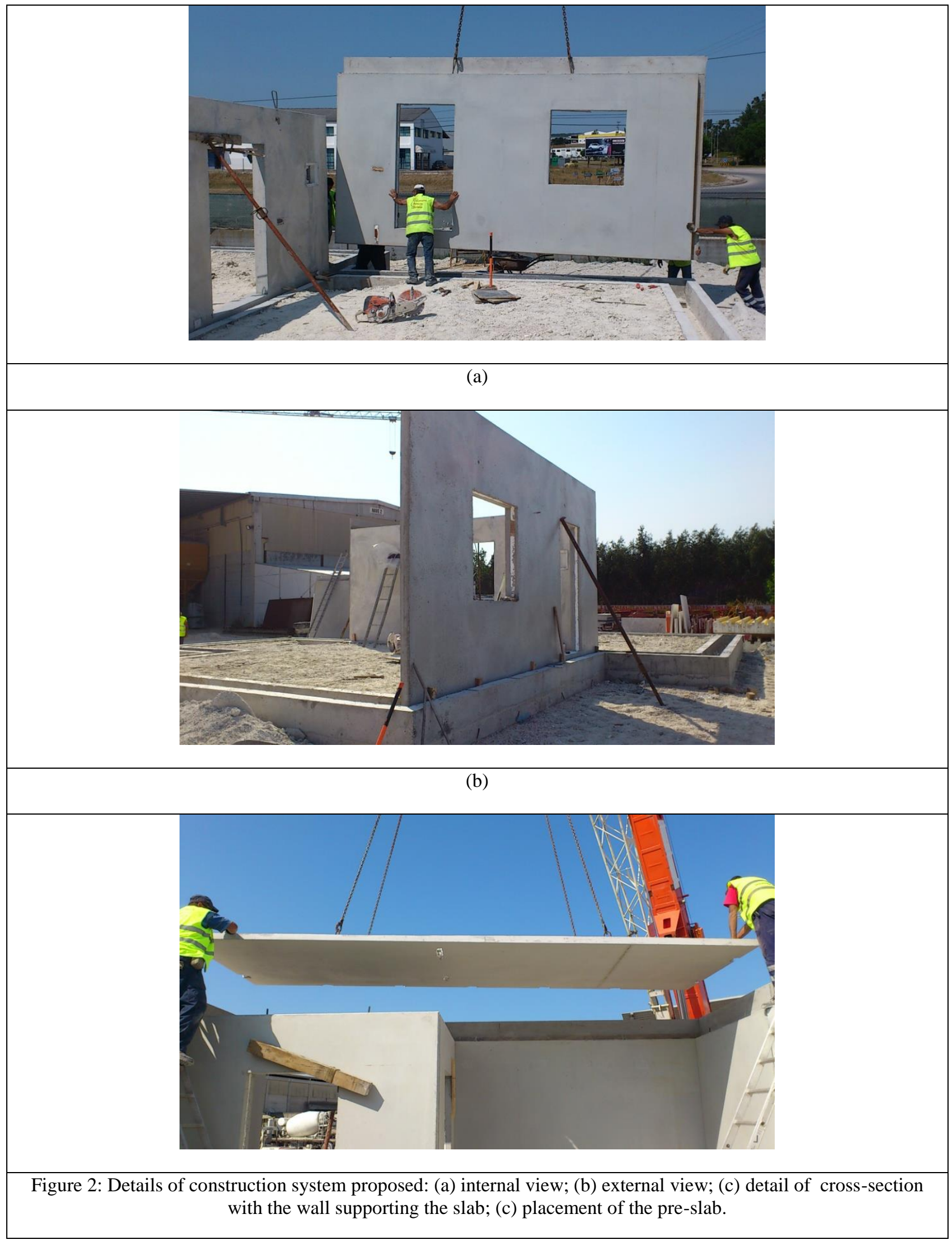



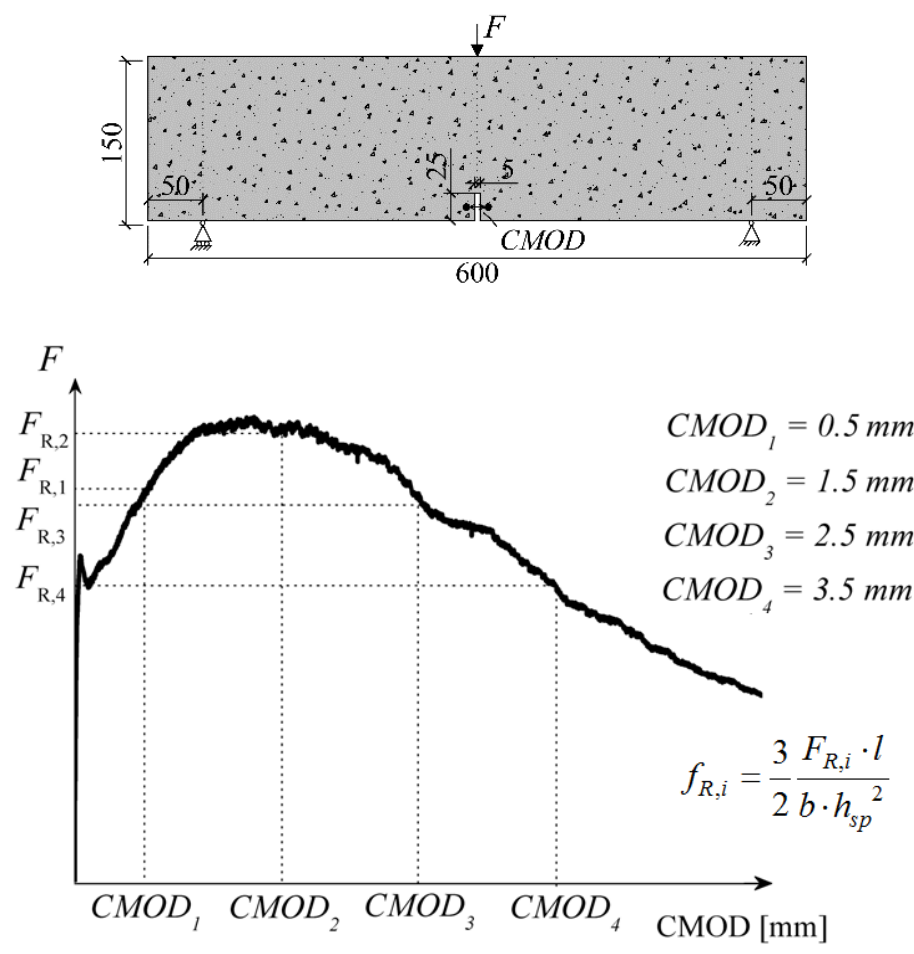

Figure 3: Characterization of the post-cracking behaviour of SFRSCC based on the Load-CMOD curve obtained from three point notched beam bending test. 


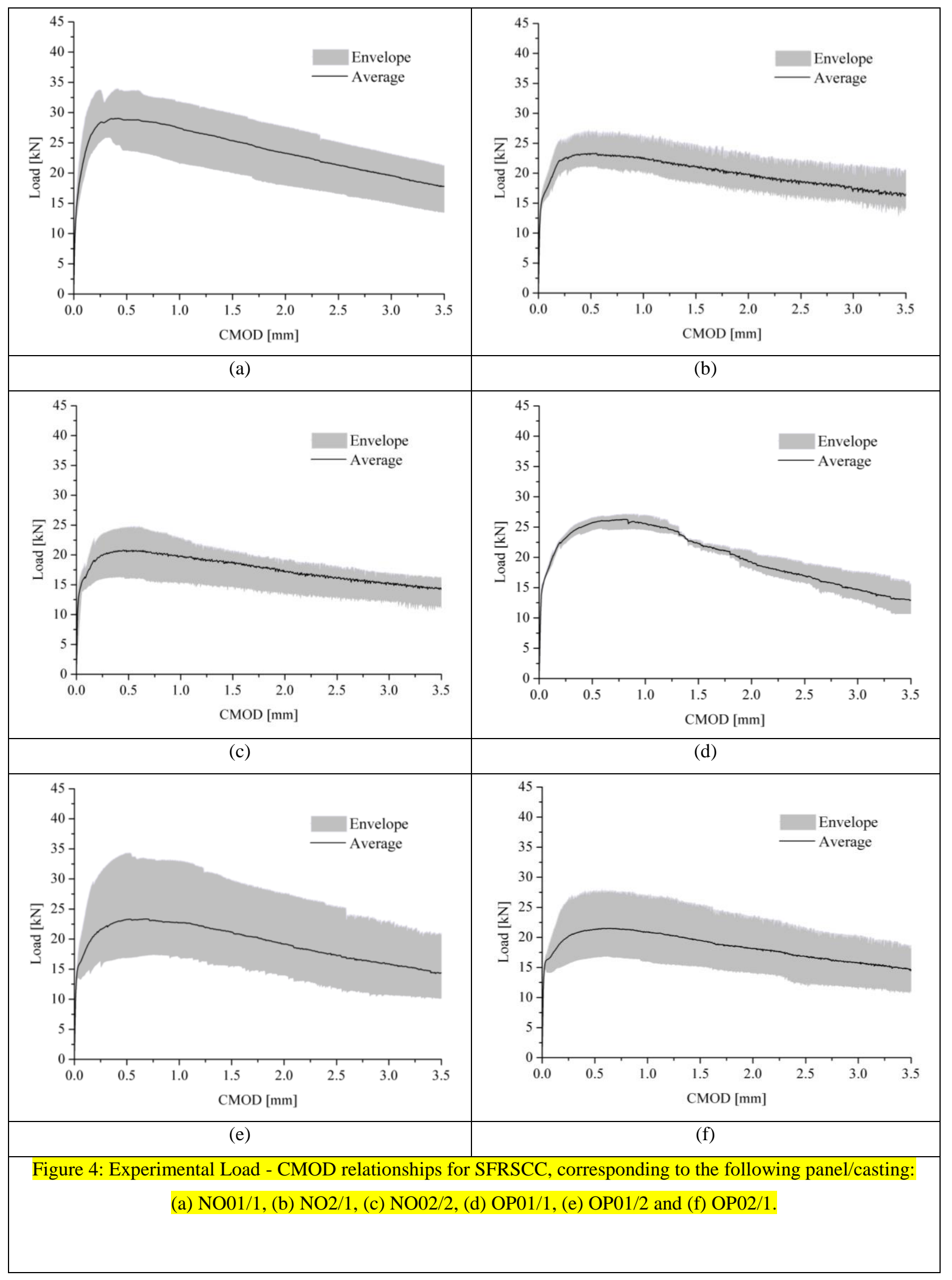




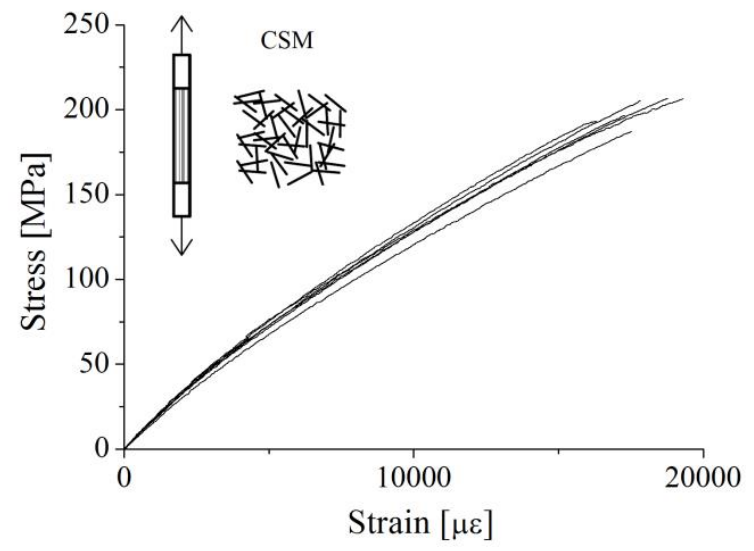

Figure 5: Stress-strain response for the CSM laminate under direct tension. 


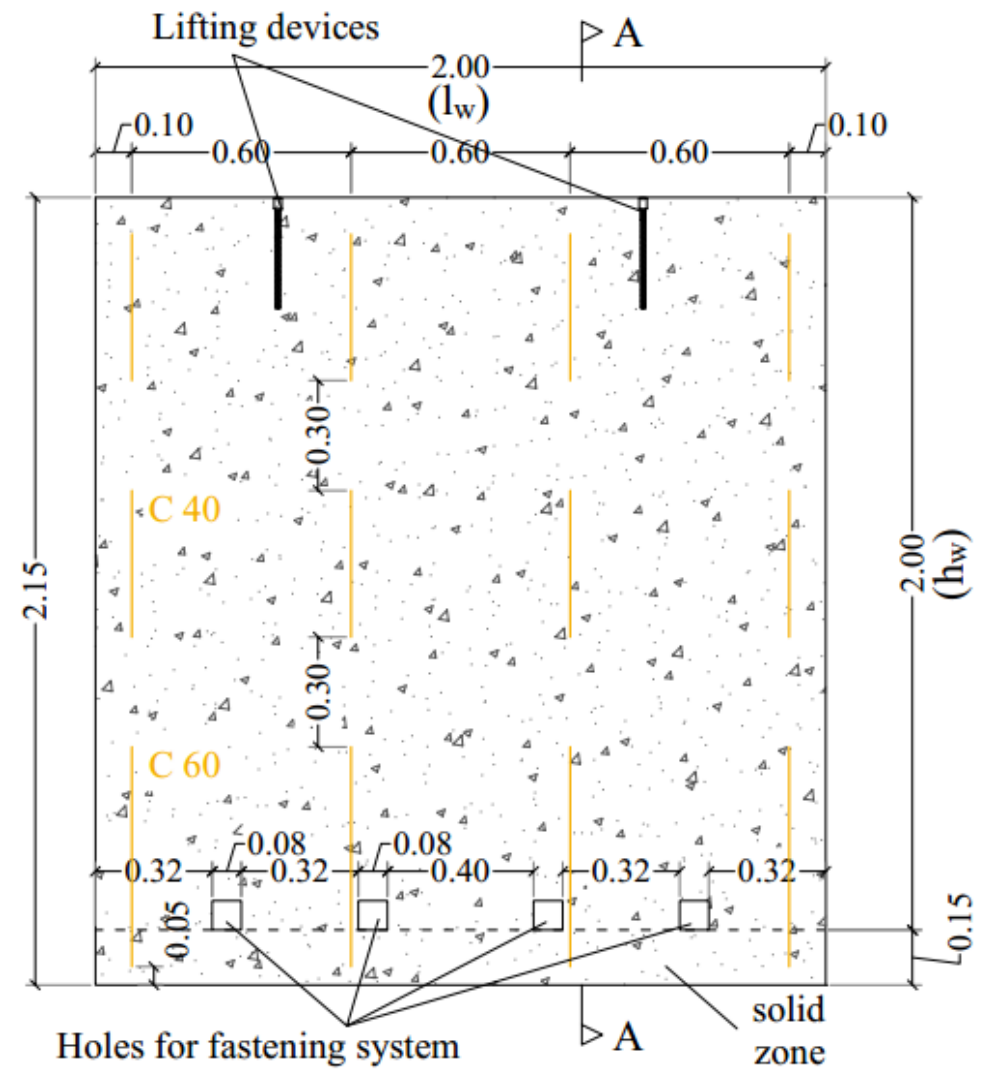

Section A-A

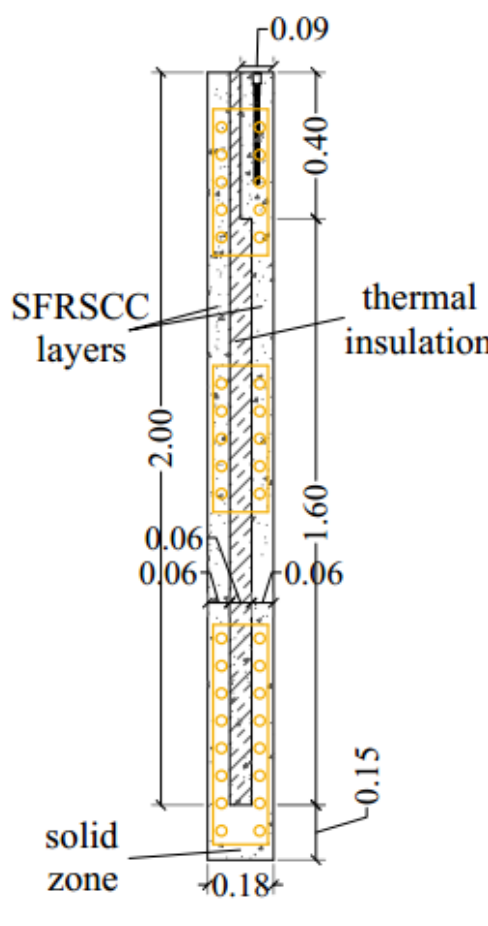

(a) 


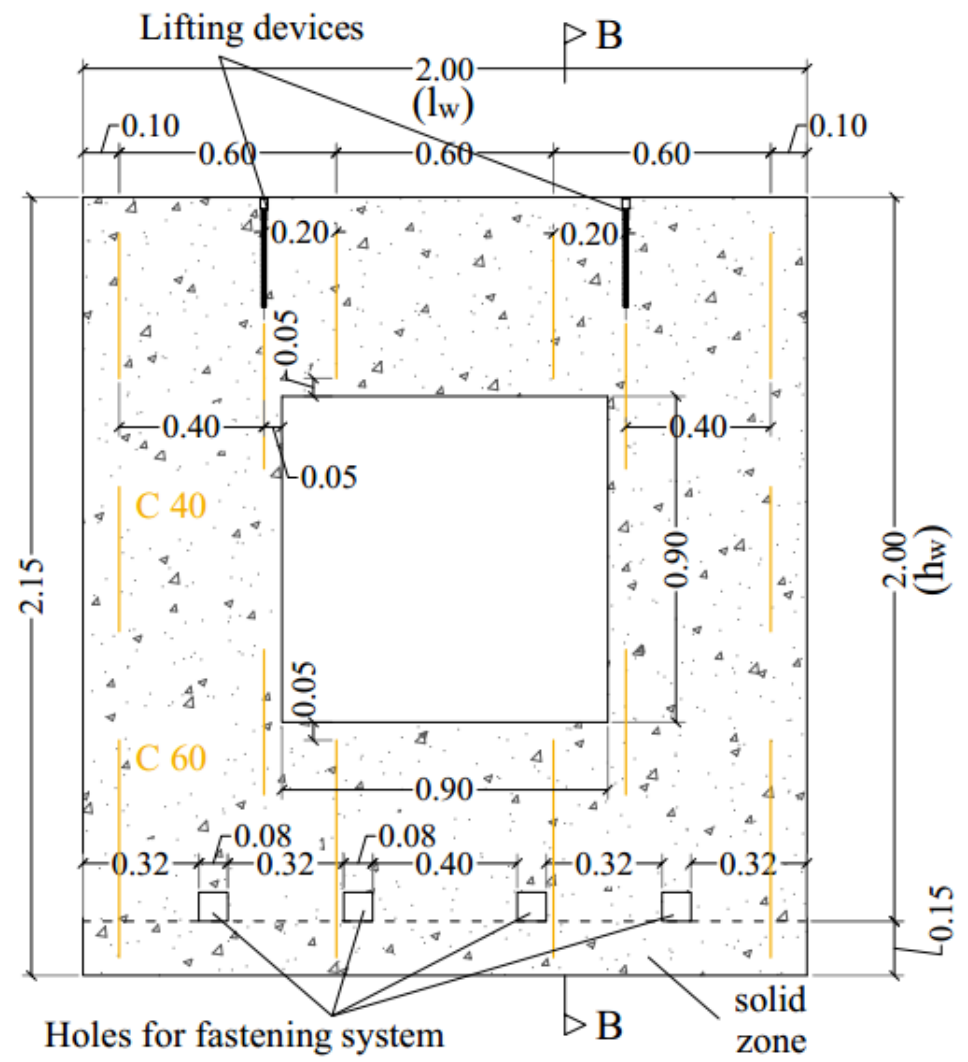

Section B-B

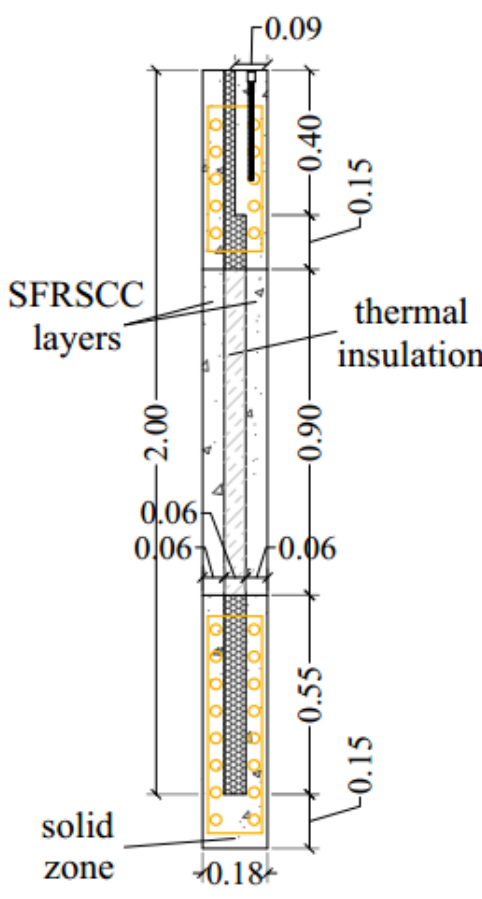

(b)

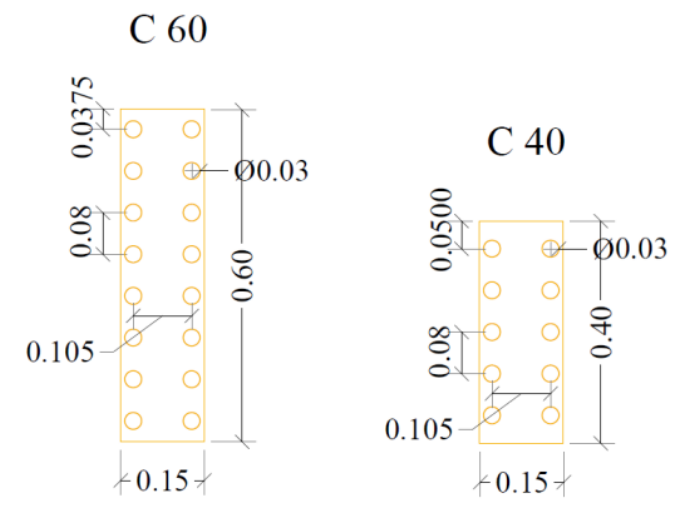

(c)

Figure 6: Details of the prototype: (a) without opening; (b) with opening; (c) connectors (dimensions in m). 


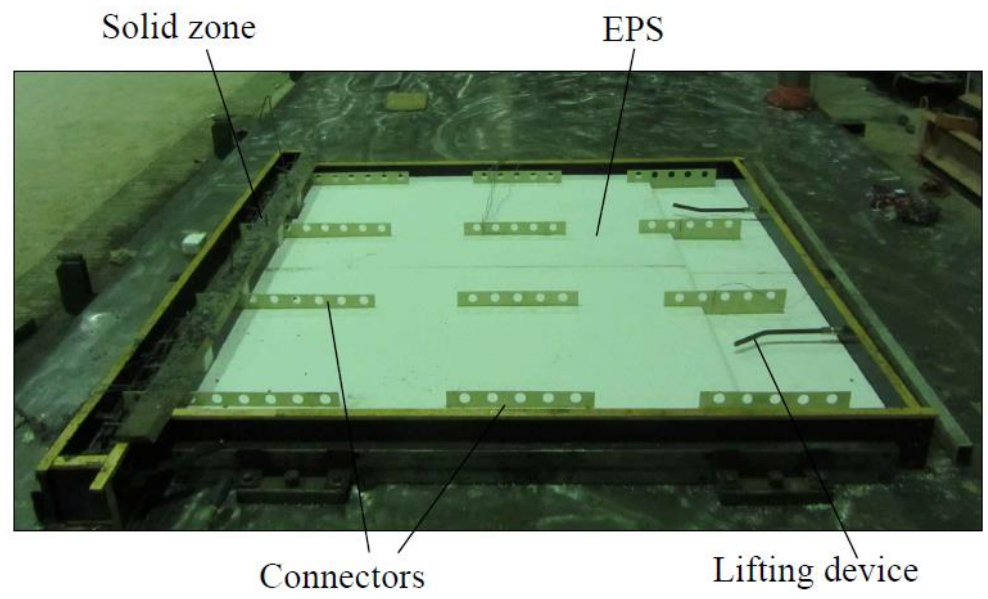

(a)

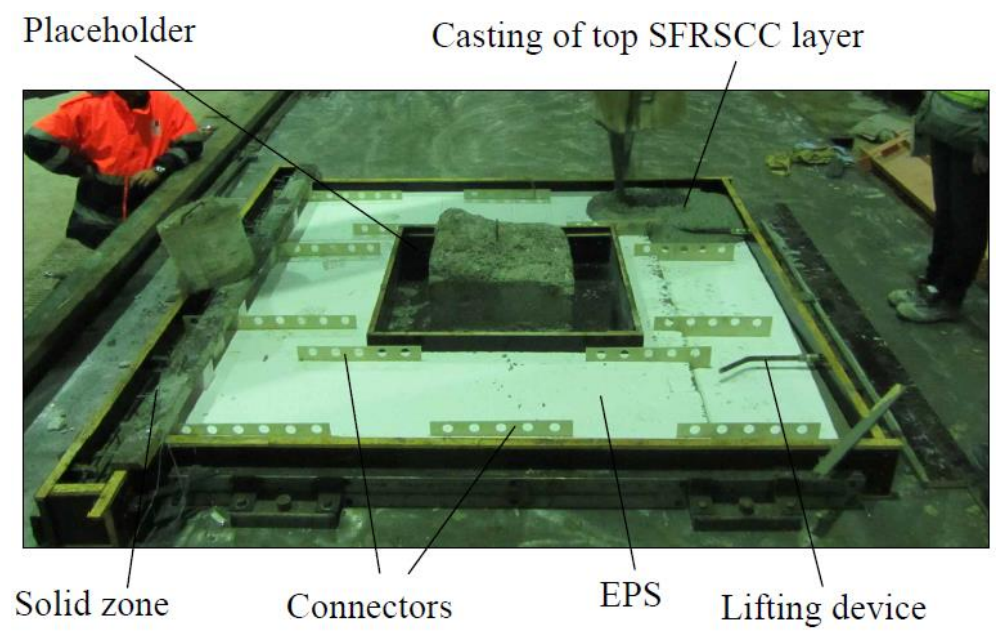

(b)

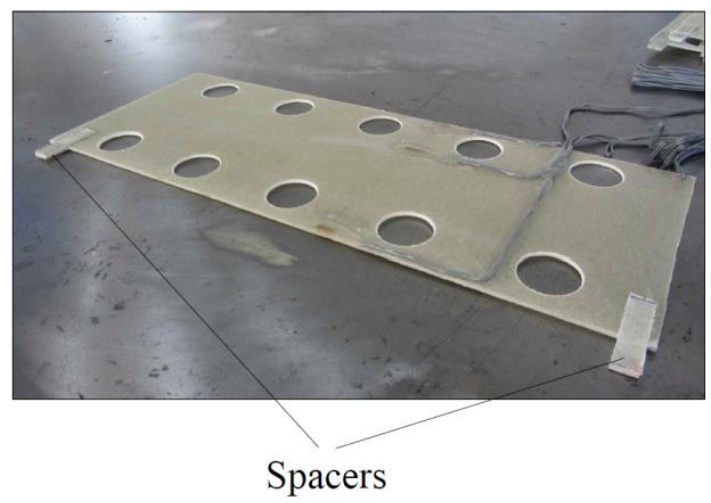

(c)

Figure 7: Manufacturing of prototypes: (a) without opening; (b) with opening; (c) detail of connector with spacer. 


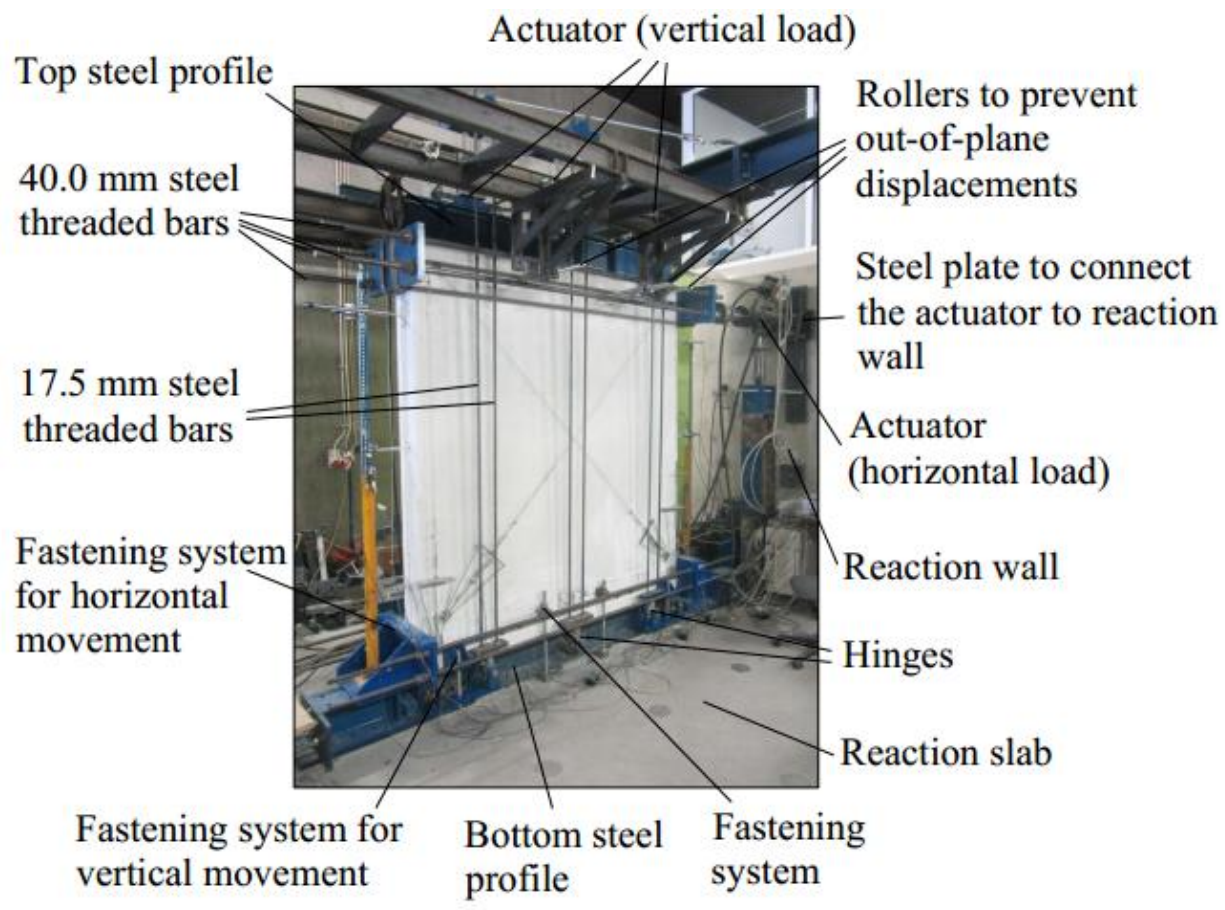

(a)

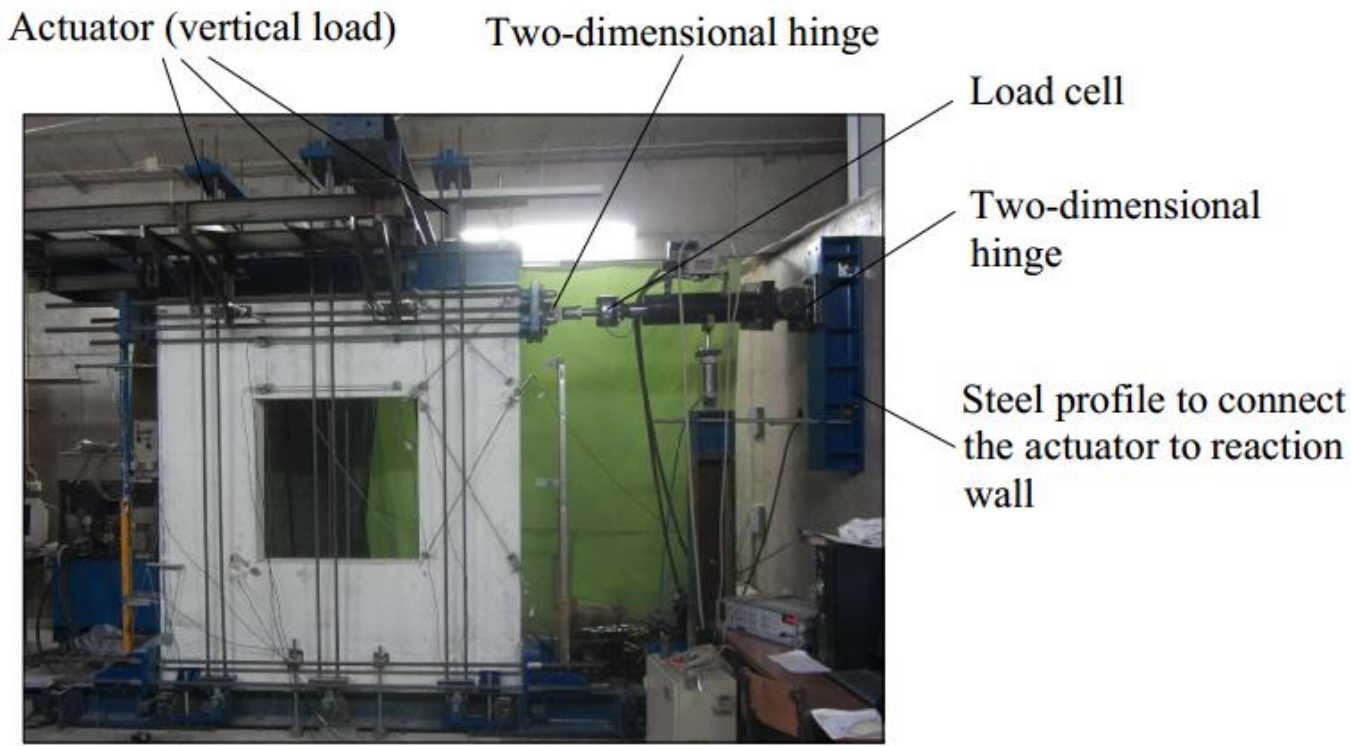

(b) 


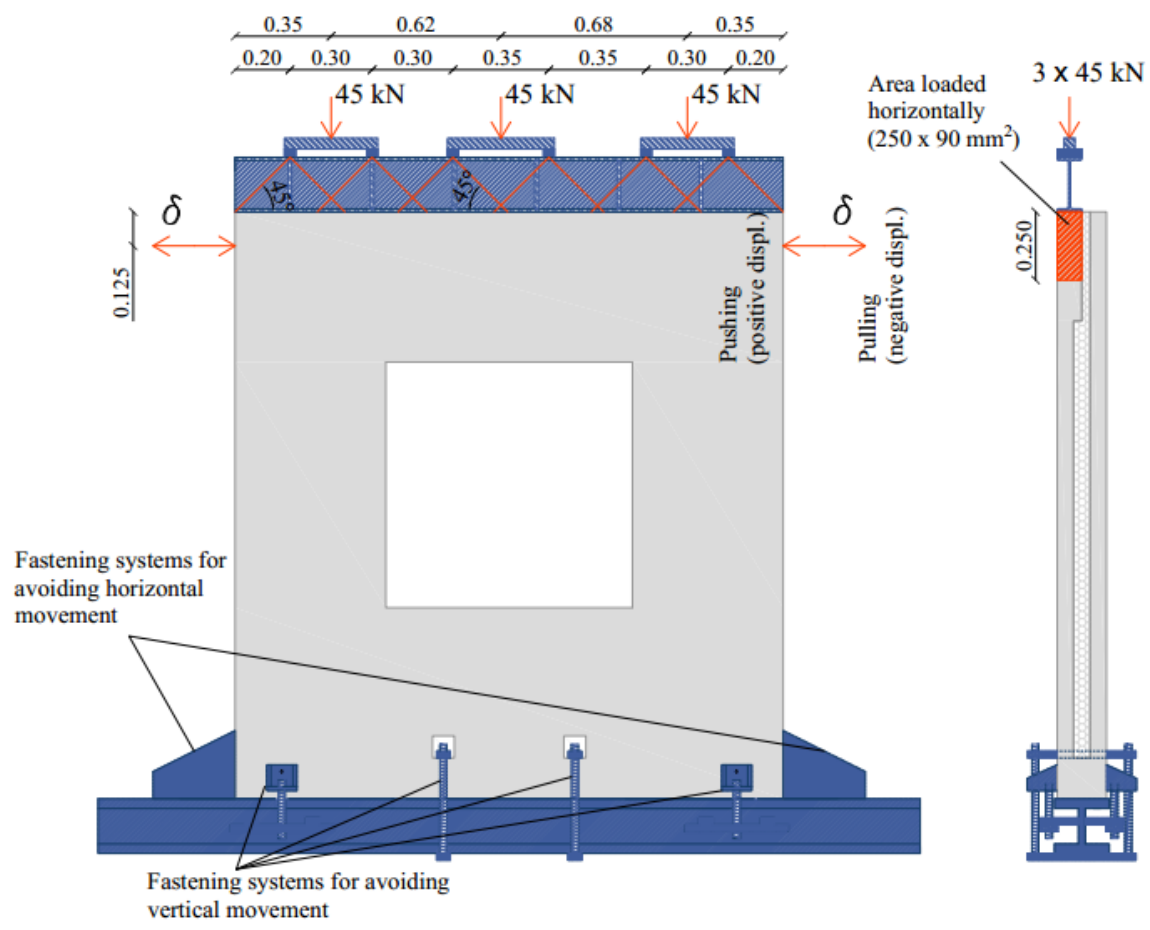

(c)

Figure 8: Experimental test setup: (a) perspective view of NO 01 panel; (b) front view of NO 02, OP 01 and OP 02 specimens; (c) schematic representation of loading system (dimensions in m). 


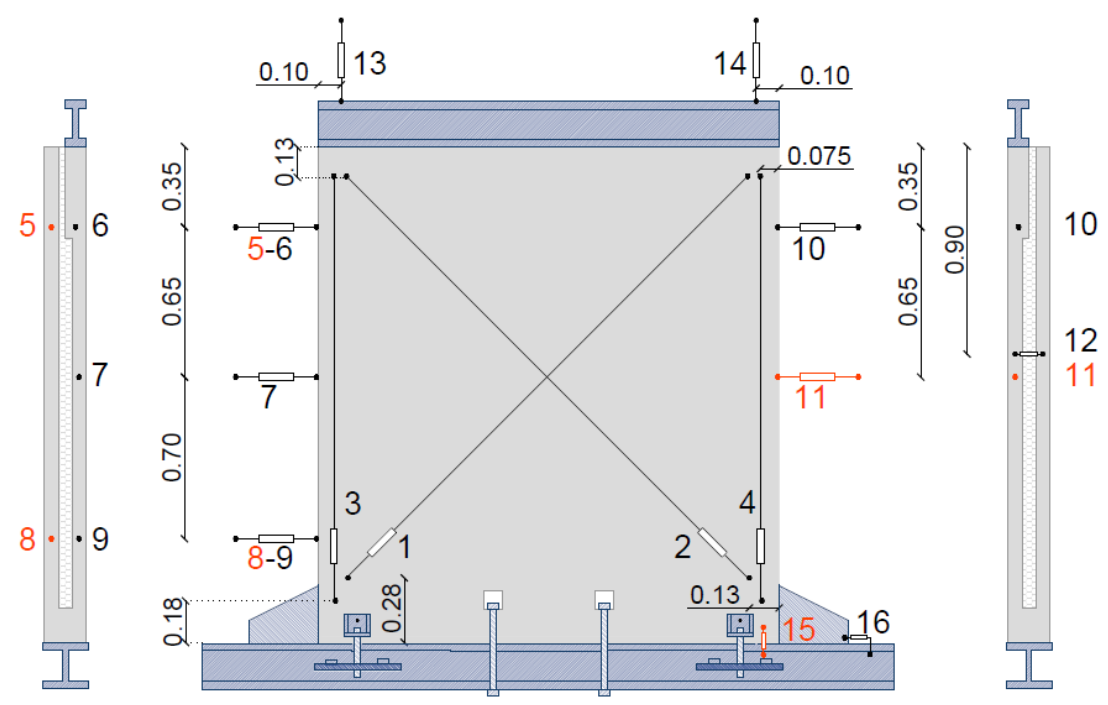

(a)

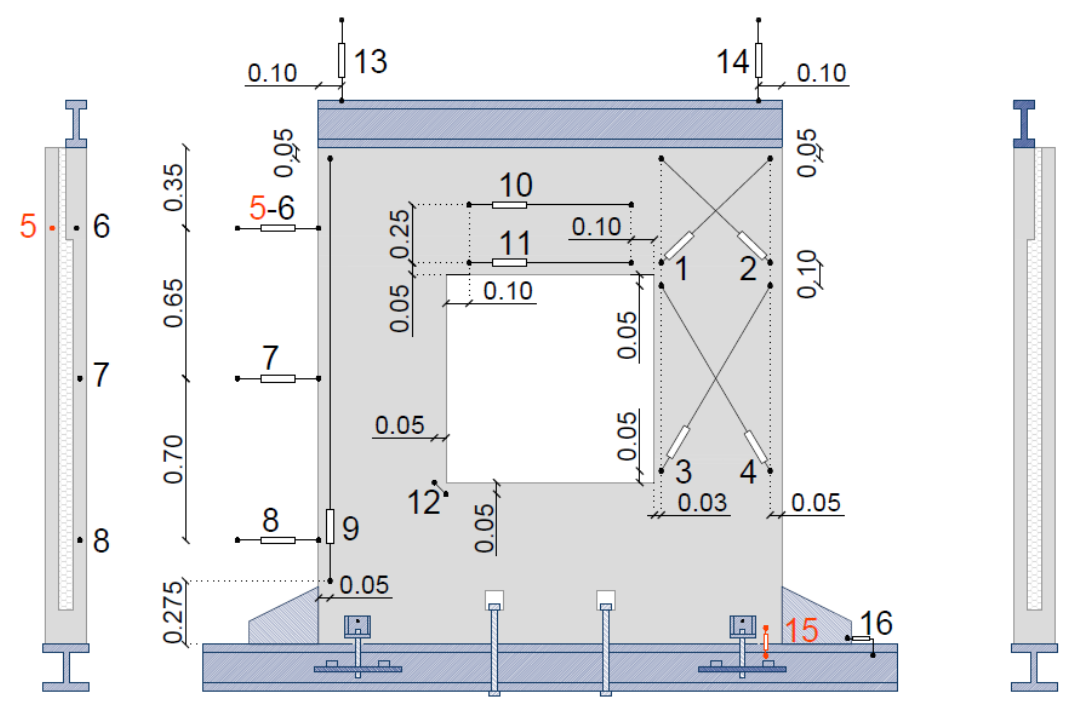

(b)

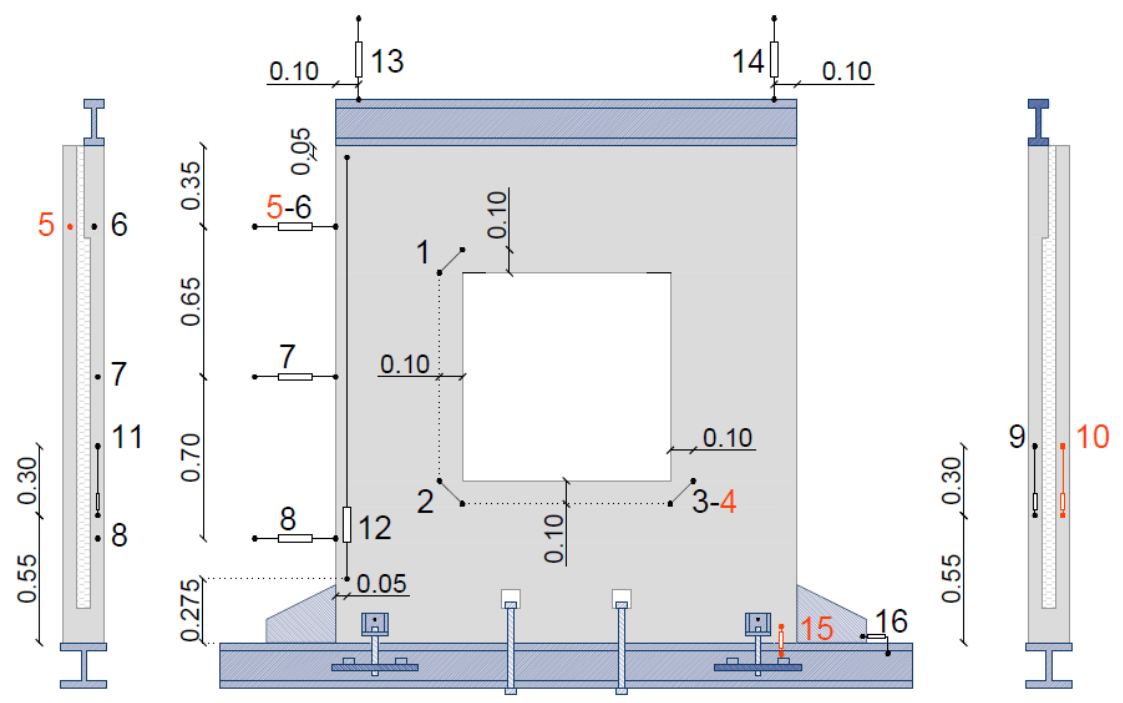


(c)

Figure 9: Schematic representation of instrumentation adopted: (a) prototypes without opening (NO); (b) and (c) prototypes with opening (OP). (dimensions in $\mathrm{m})$. 


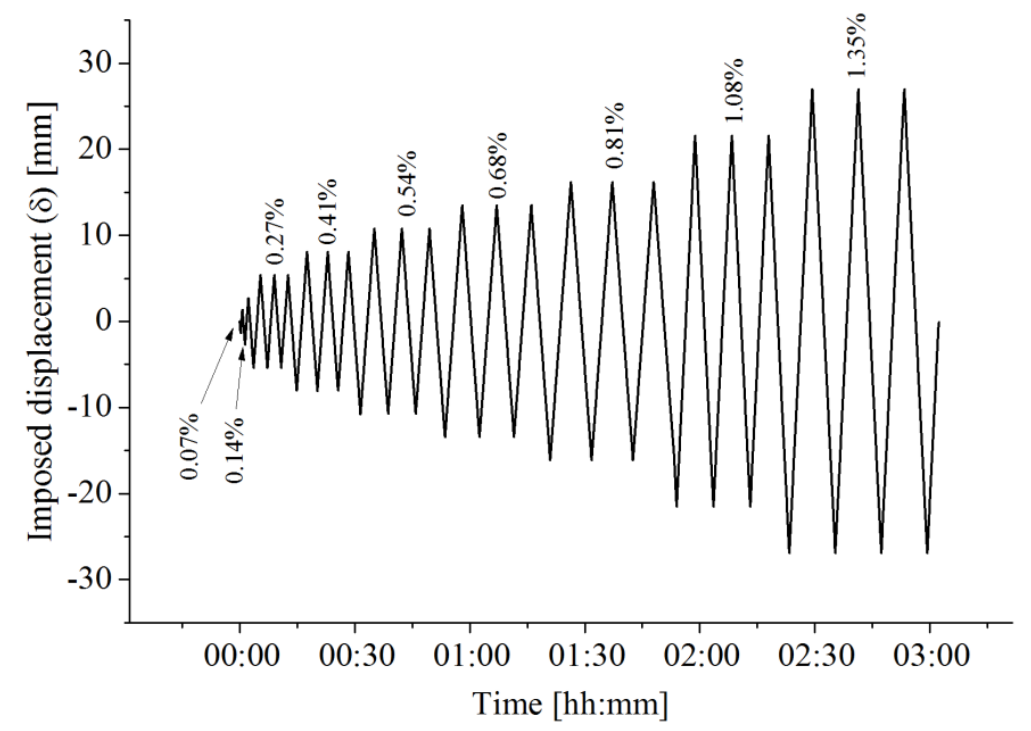

Figure 10: Test procedure used (pushing corresponds to a positive displacement, see Figure 7c). 
Panel: NO 02 / Drift: 1.35\% (front view)

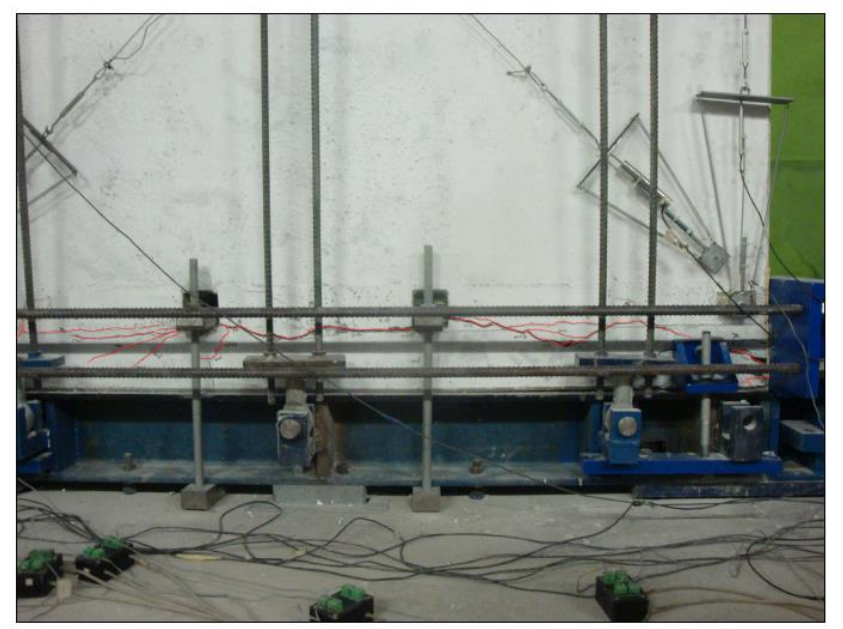

Figure 11: Typical cracking pattern of prototypes without opening (NO). 
Panel: OP 02 / Drift: $0.54 \%$ (front view)

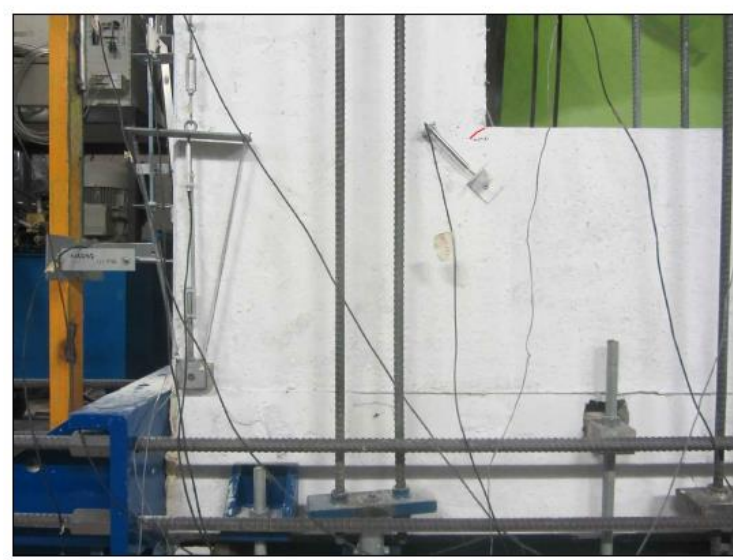

Panel: OP 02 / Drift: $0.81 \%$ (front view)

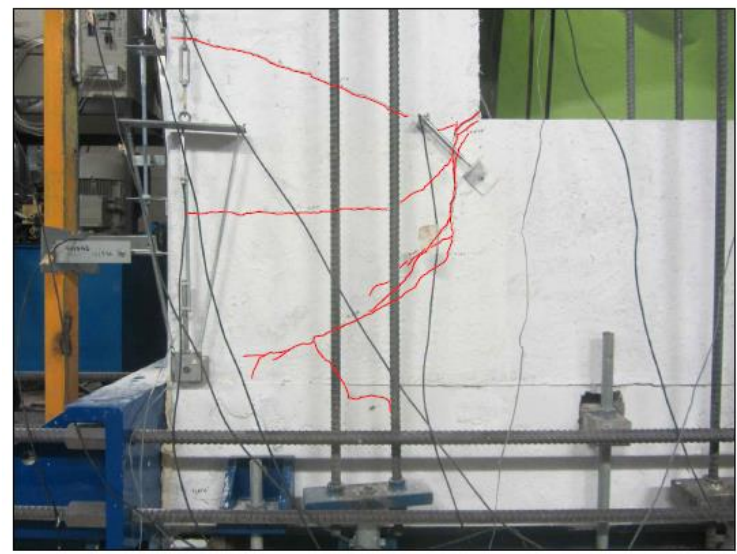

Panel: OP 02 / Drift: $0.68 \%$ (front view)

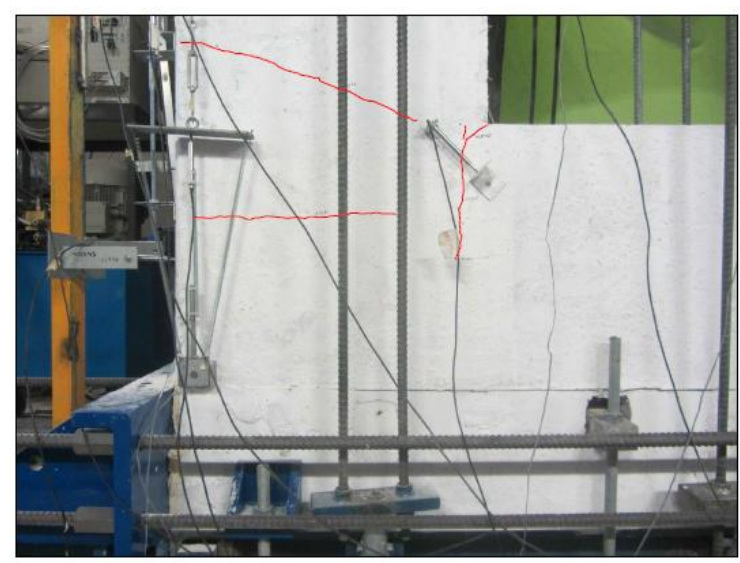

Panel: OP 02 / Final aspect (back view)

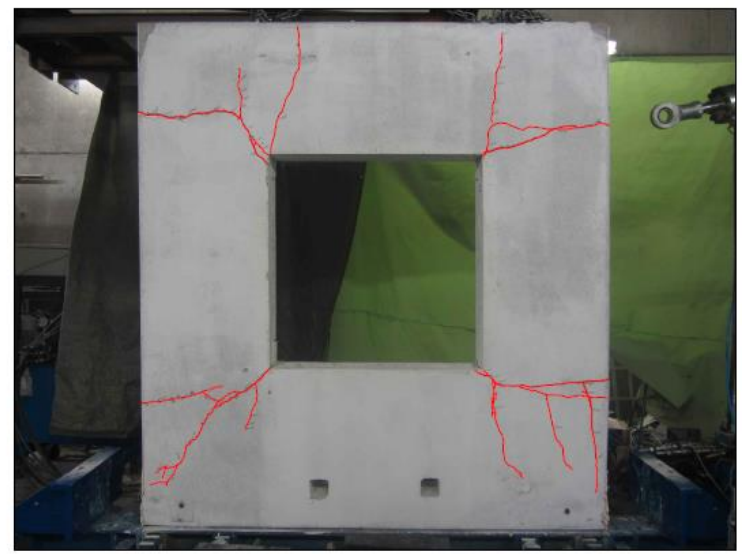

Figure 12: Typical cracking pattern of prototypes with opening (OP). 


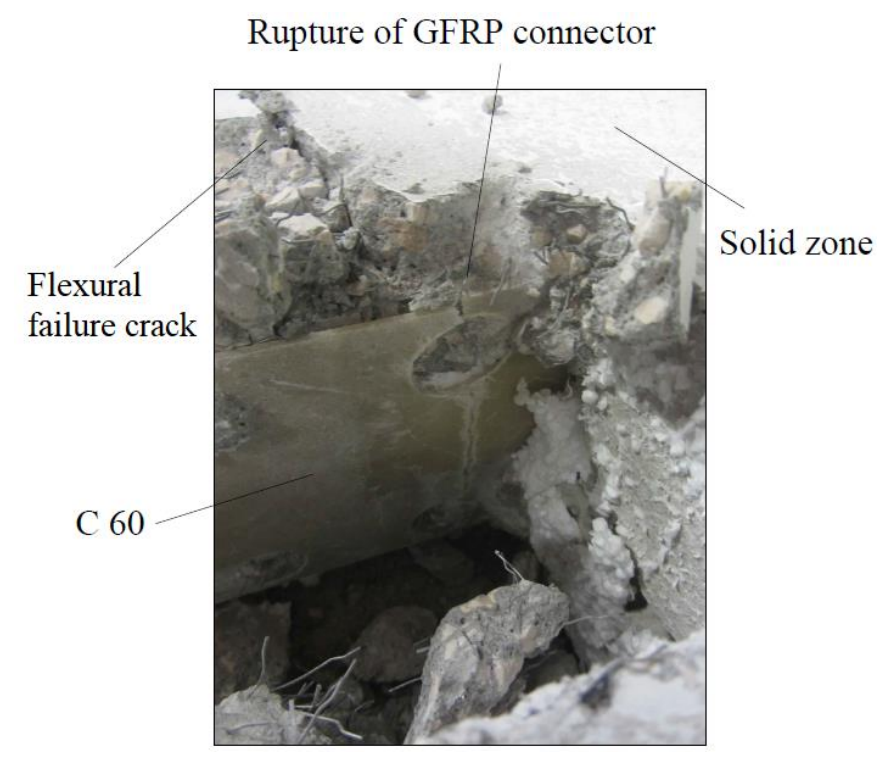

(a)

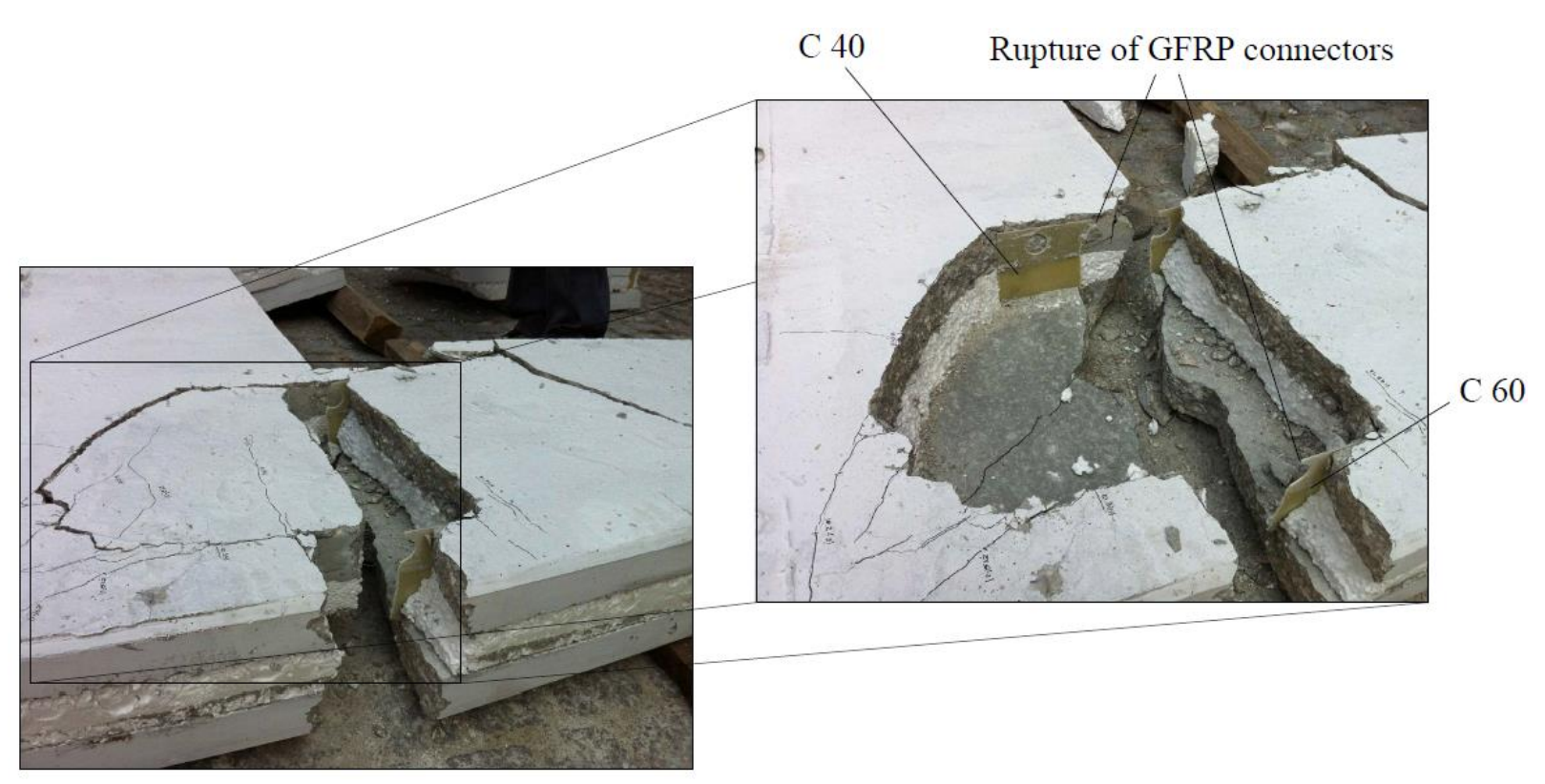

(b)

Figure 13: Damaged prototypes: (a) NO 02, (b) OP 02. 


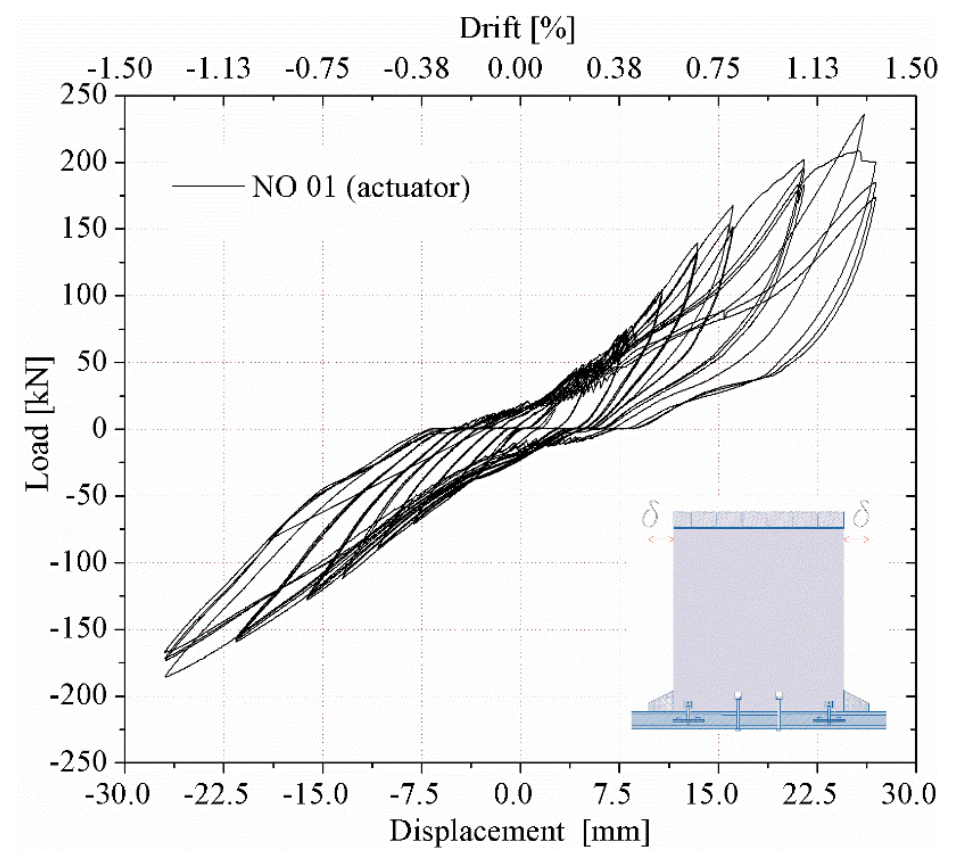

(a)

Drift [\%]

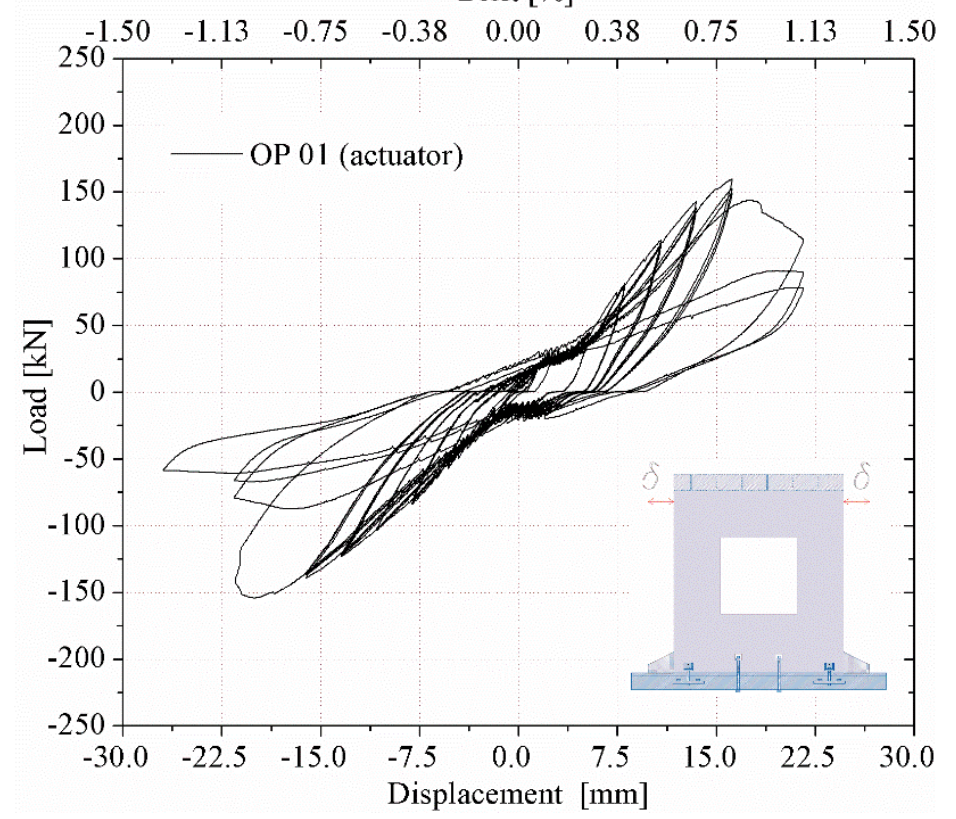

(c)

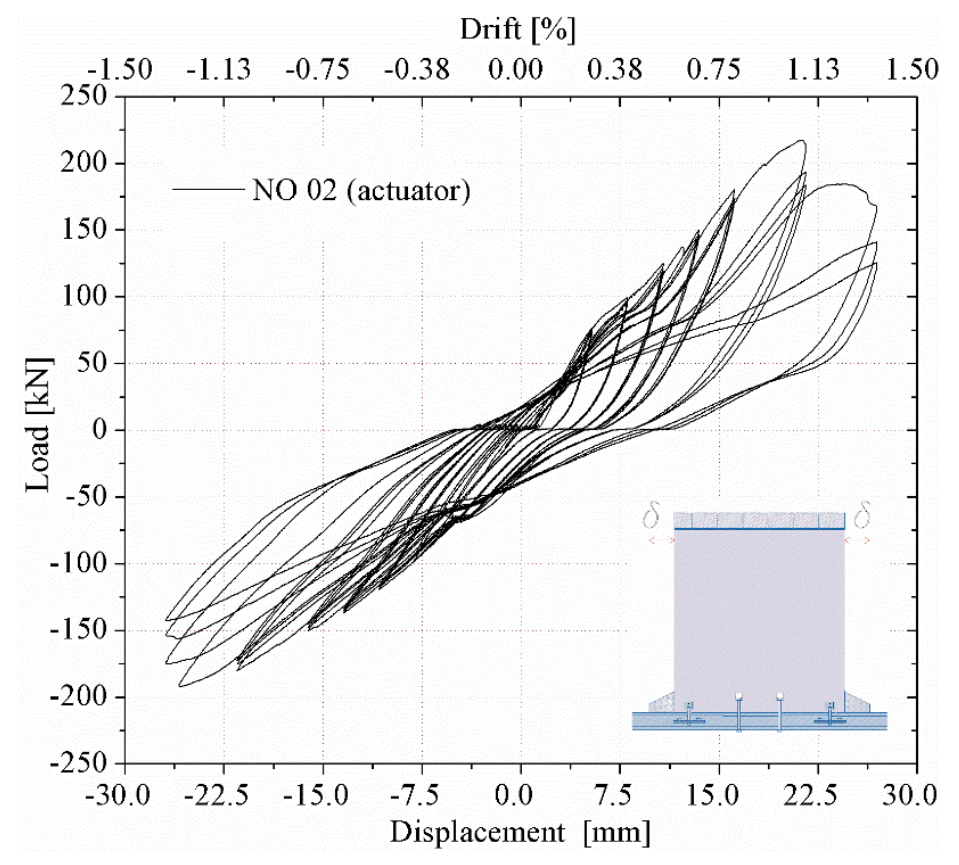

(b)

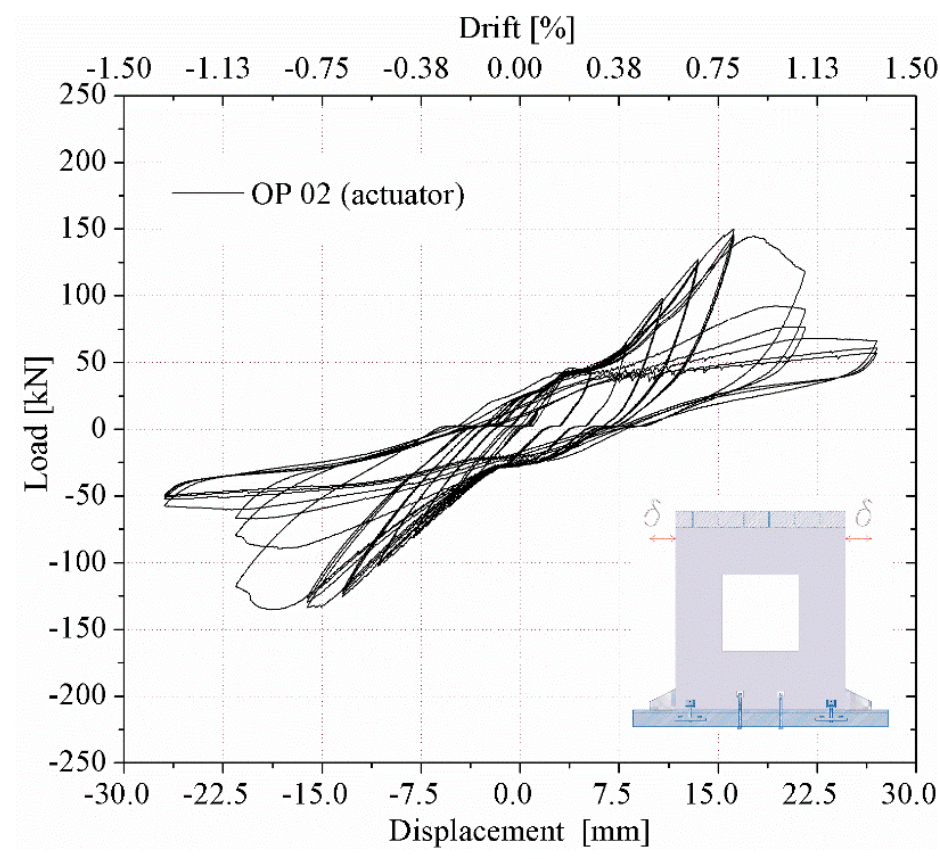

(d)

Figure 14: Hysteretic curves for: (a) NO 01; (b) NO 02; (c) OP 01; (d) OP 02. 


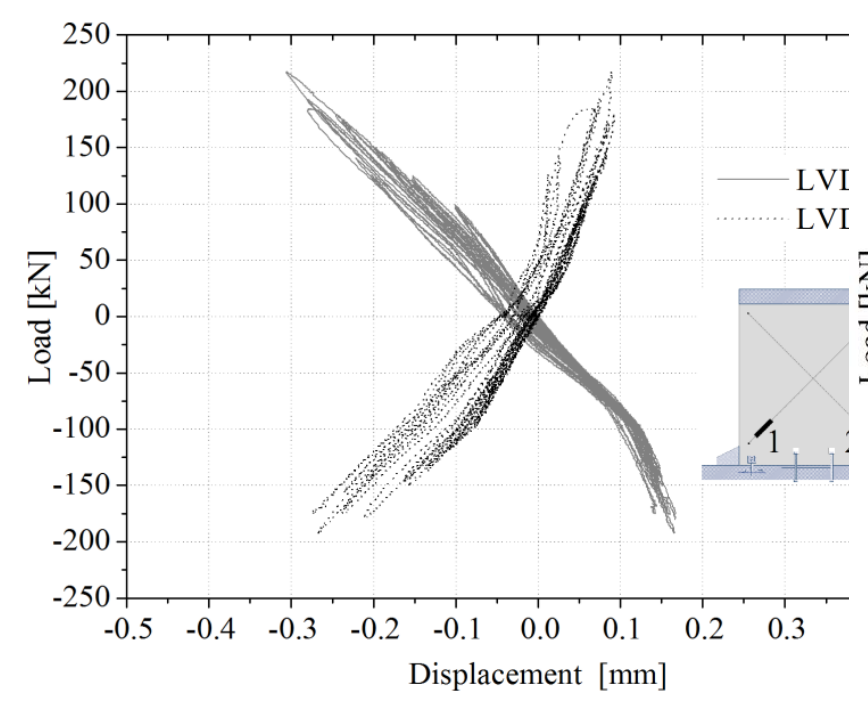

(a)

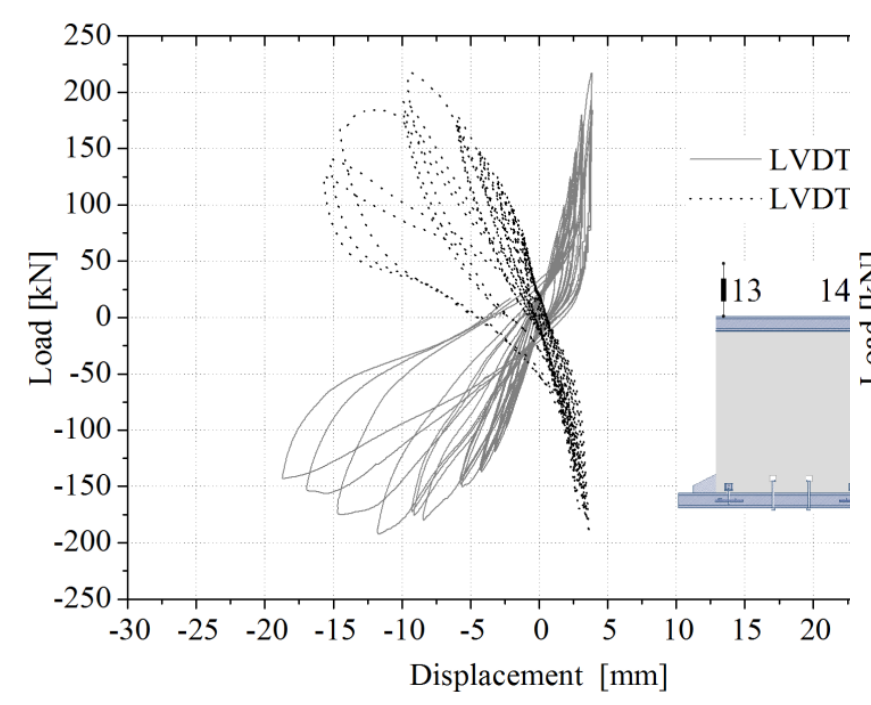

(c)

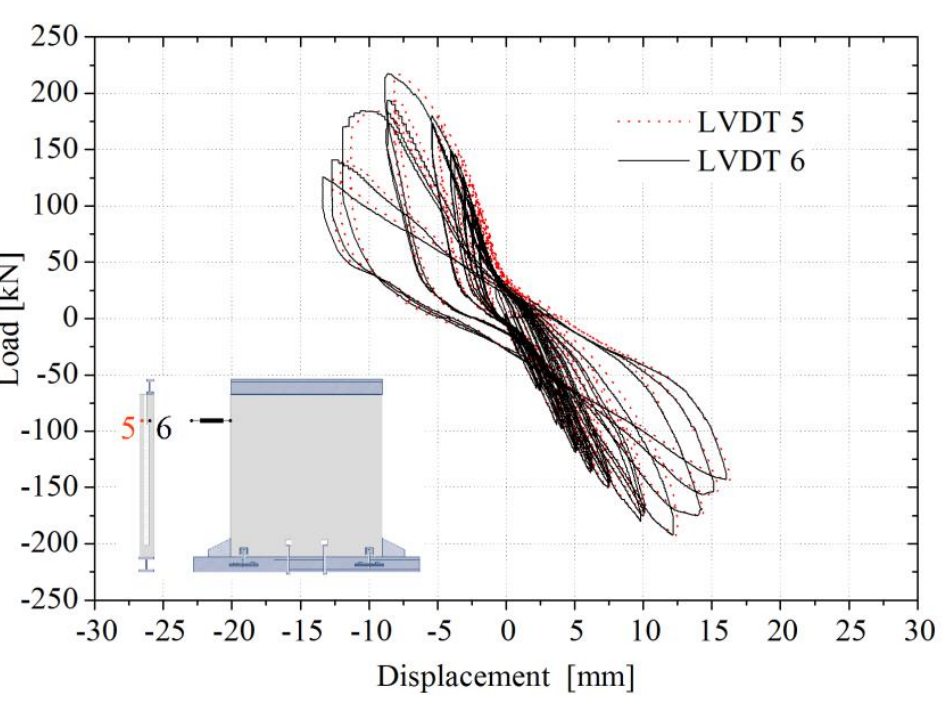

(b)

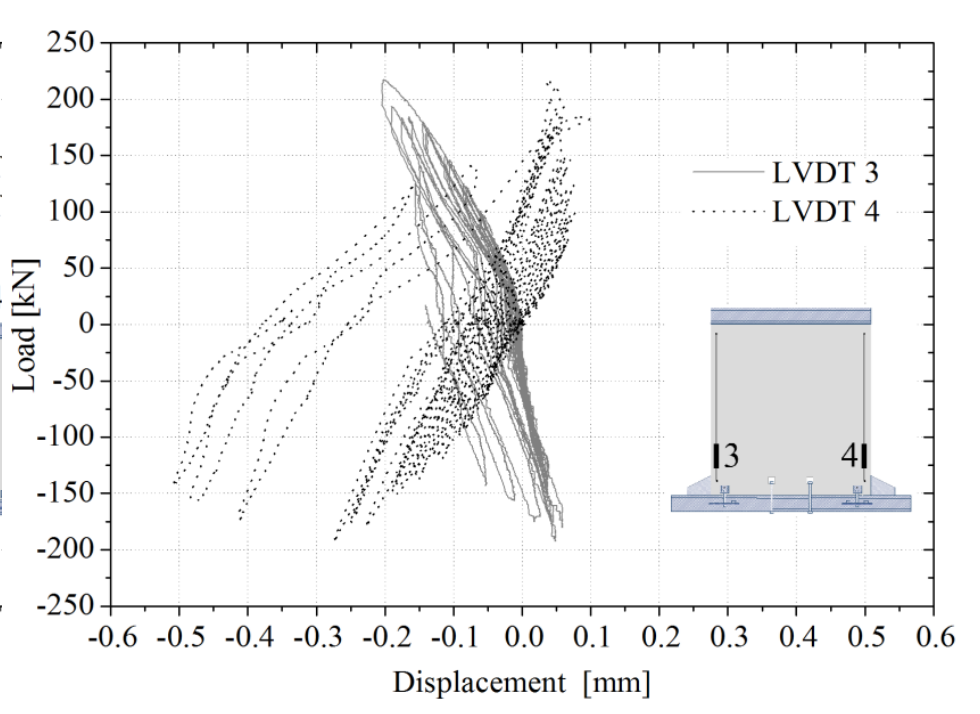

(d)

Figure 15: Force versus displacements for NO 02 panel: (a) diagonal shear displacements; (b) lateral displacements in both SFRSCC layers; (c) rocking displacements; (c) vertical displacements. 


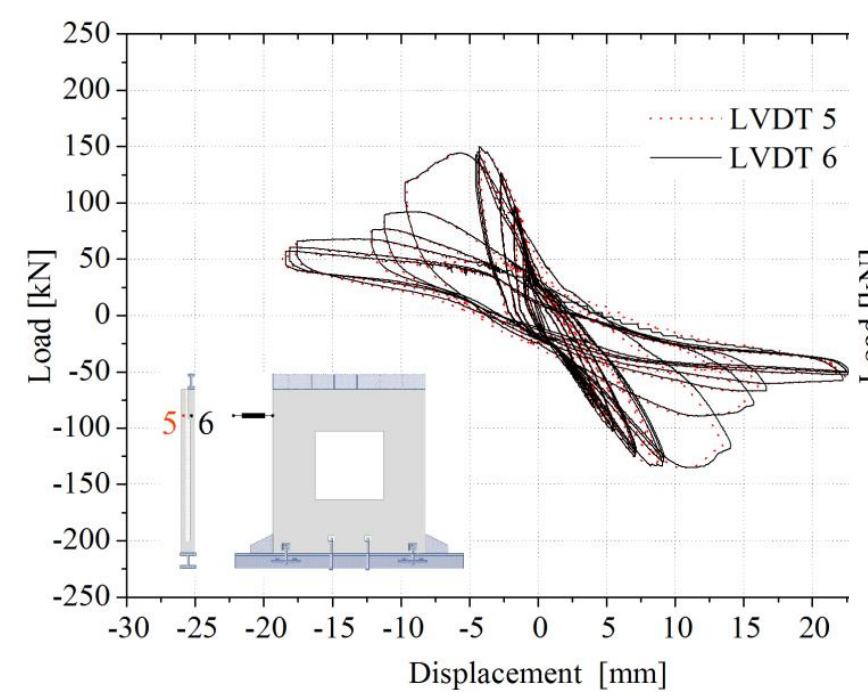

(a)

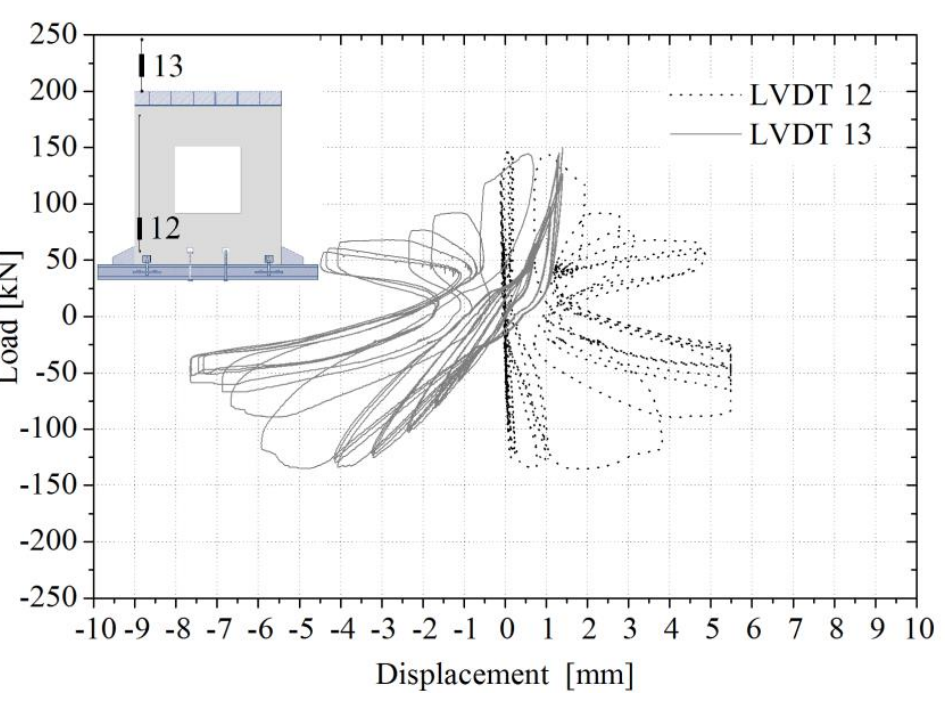

(b)

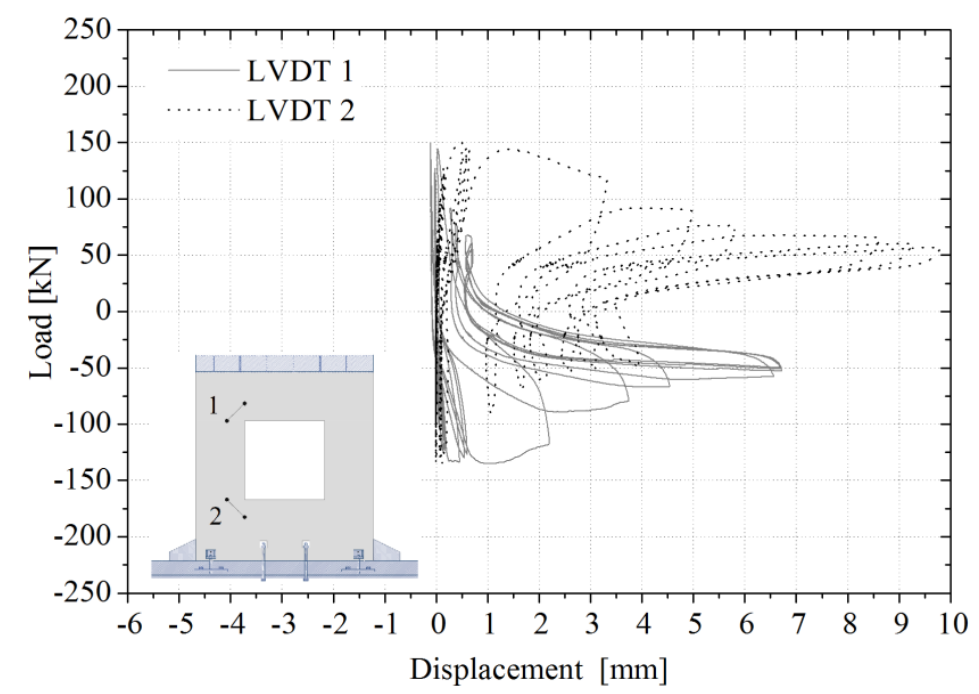

(c)

Figure 16: Force versus displacements for OP 02 panel: (a) lateral displacements in both SFRSCC layers; (b) vertical and rocking displacements; (c) cracking opening width in the corners of opening. 


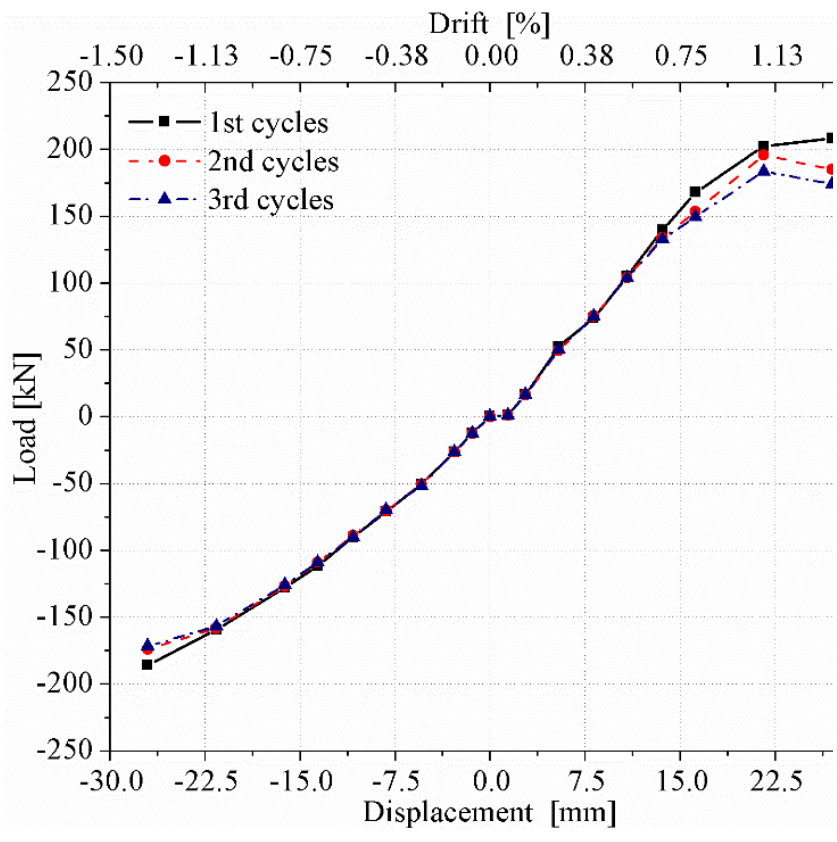

(a)

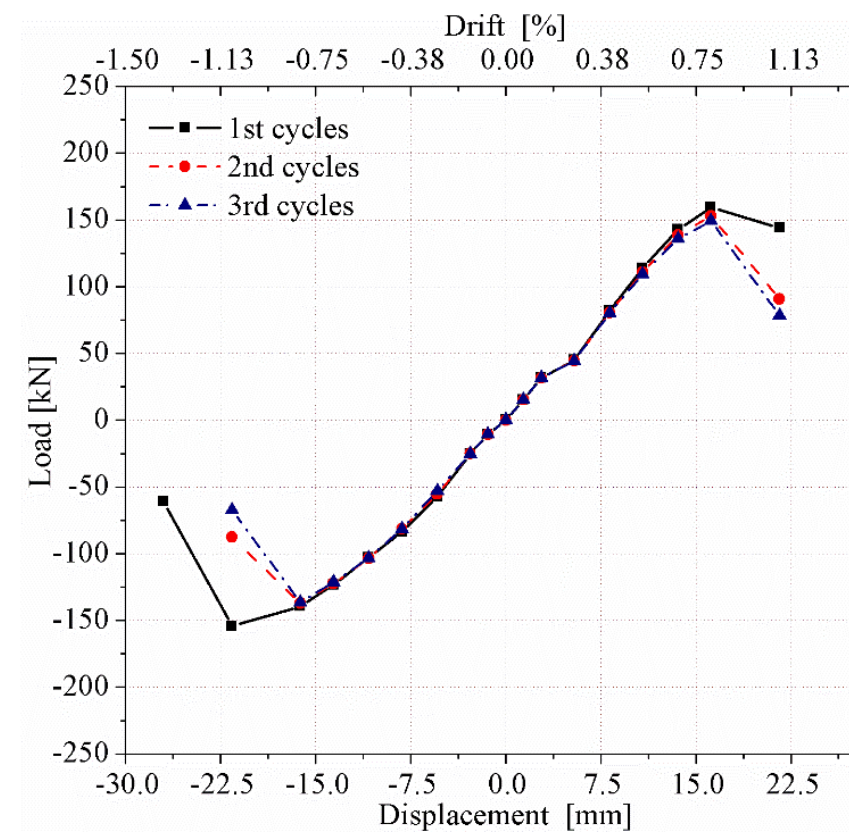

(c)

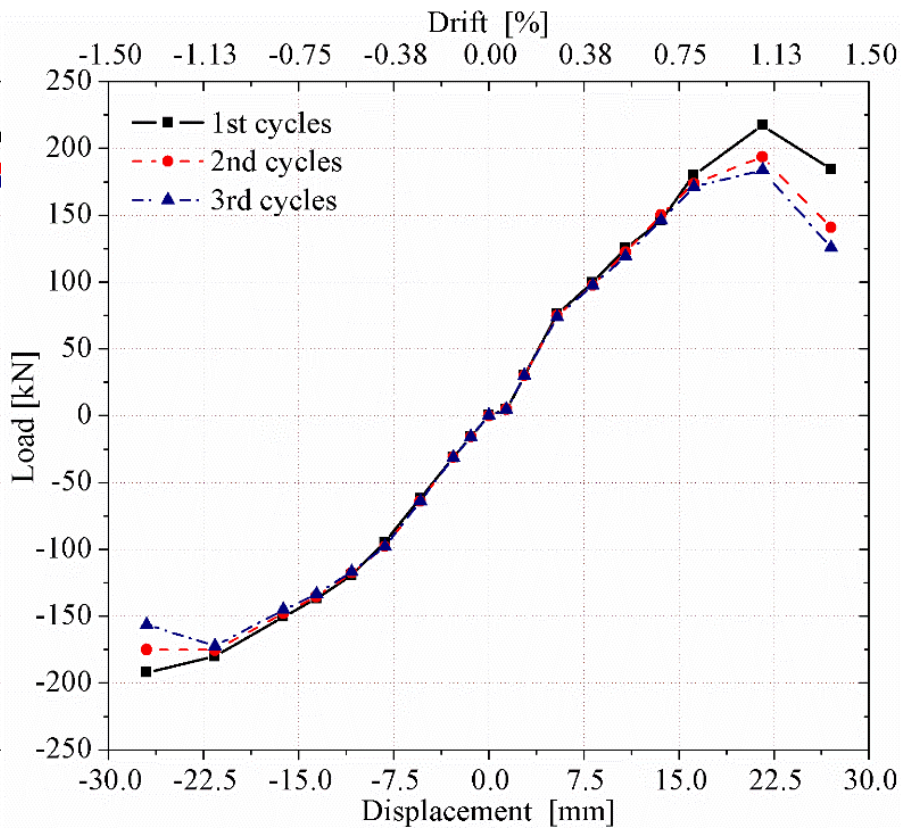

(b)

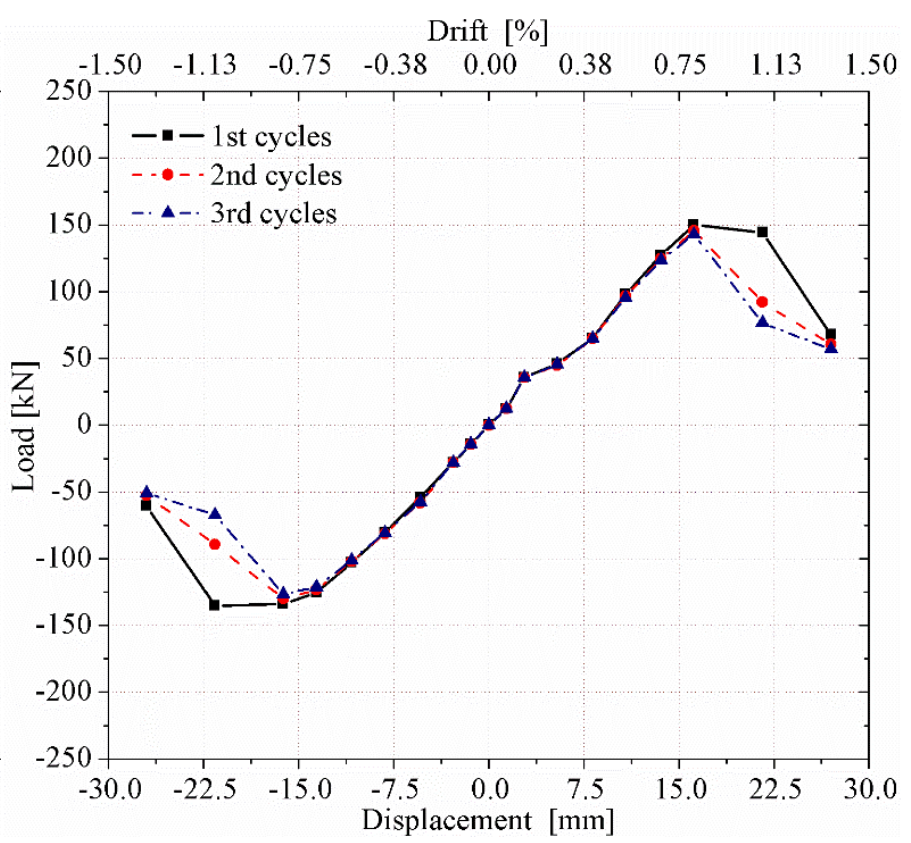

(d)

Figure 17: Envelopes of the force versus displacement responses: (a) NO 01; (b) NO 02; (c) OP 01; (d) OP 02. 


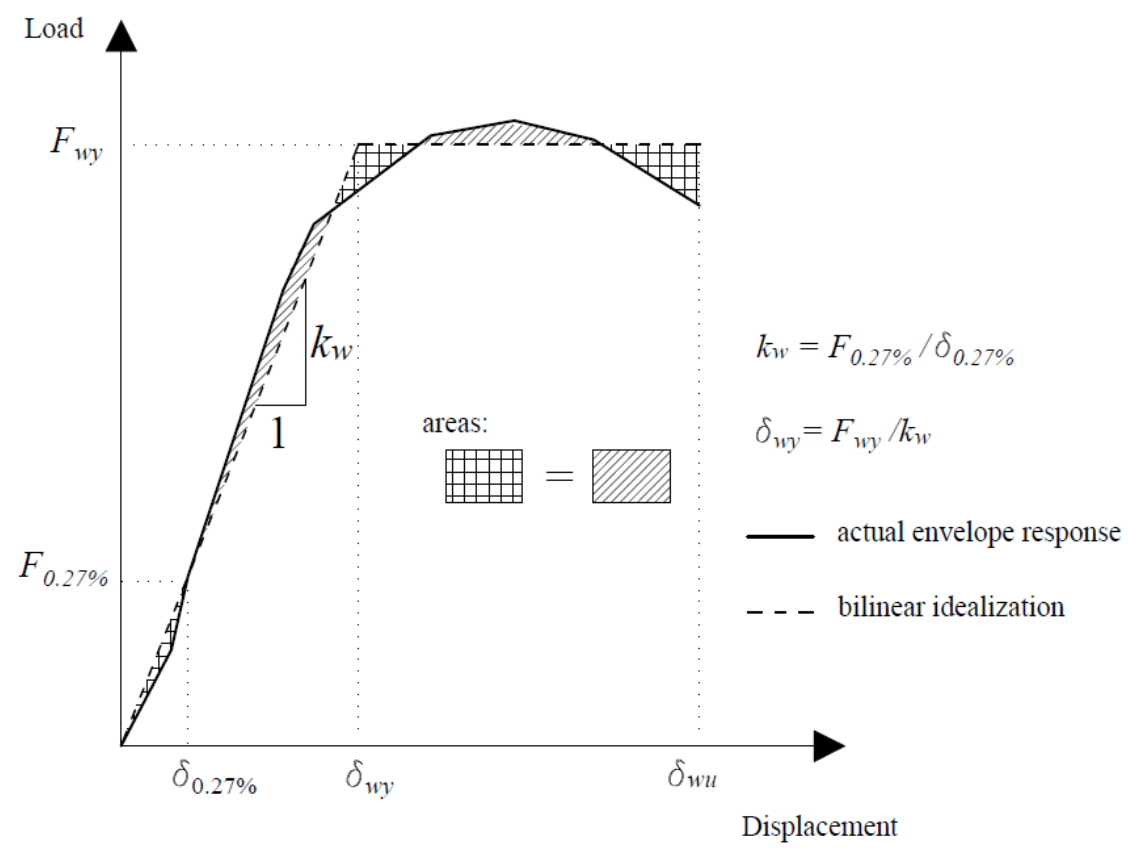

Figure 18: Schematic representation of equivalent energy method used to obtain the equivalent bilinear curve. 


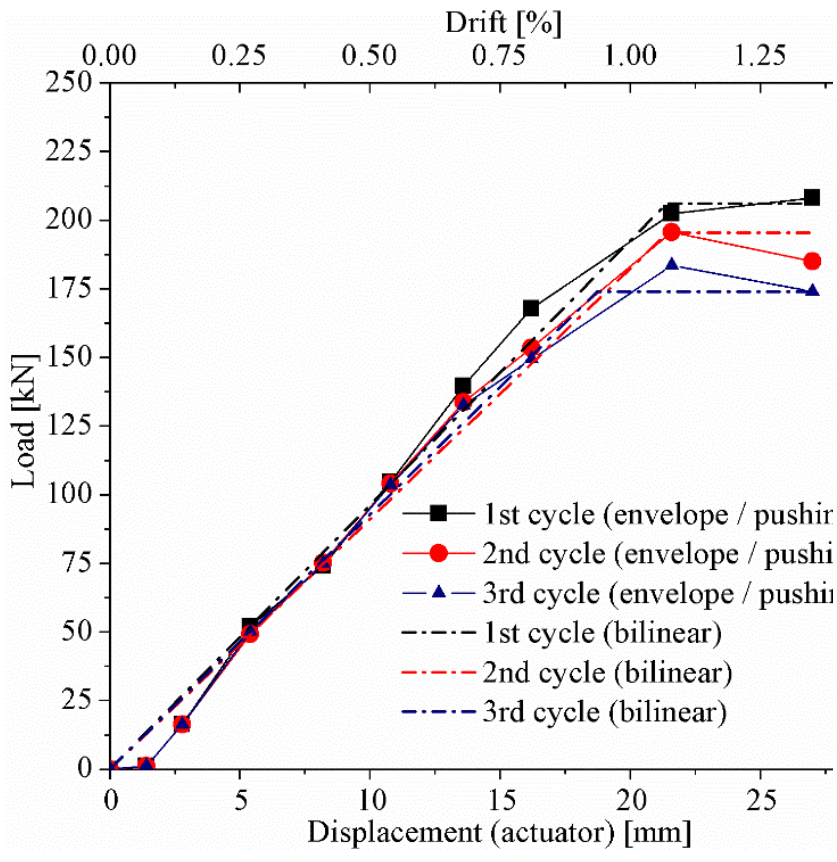

(a)

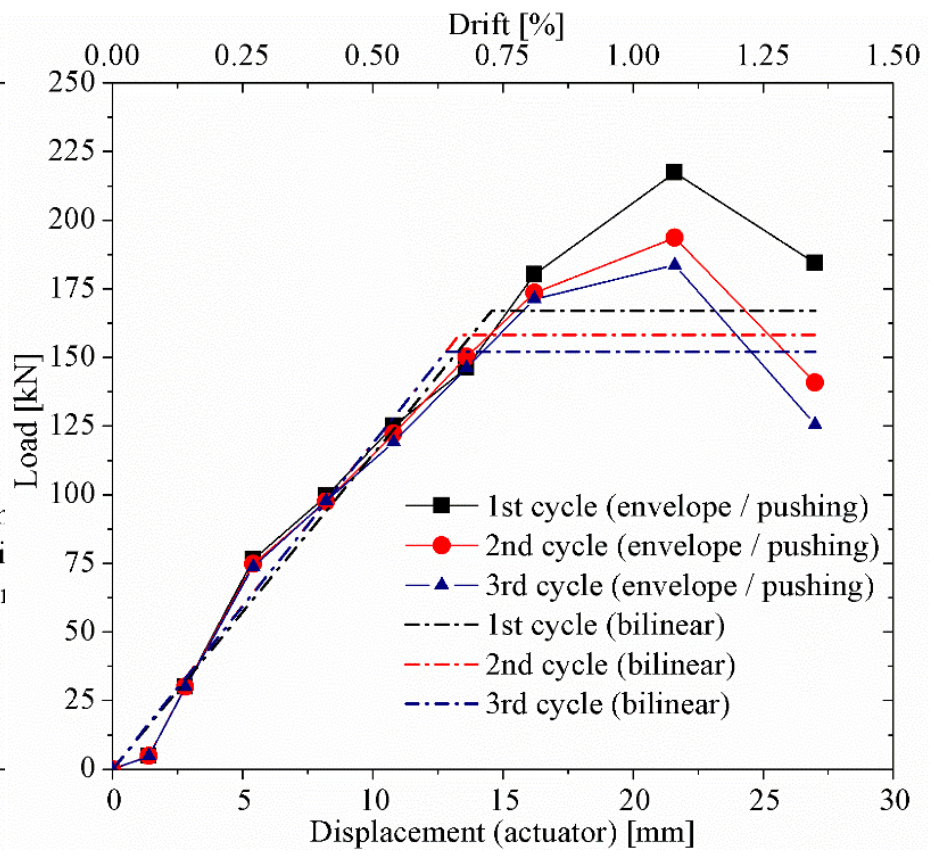

(b)

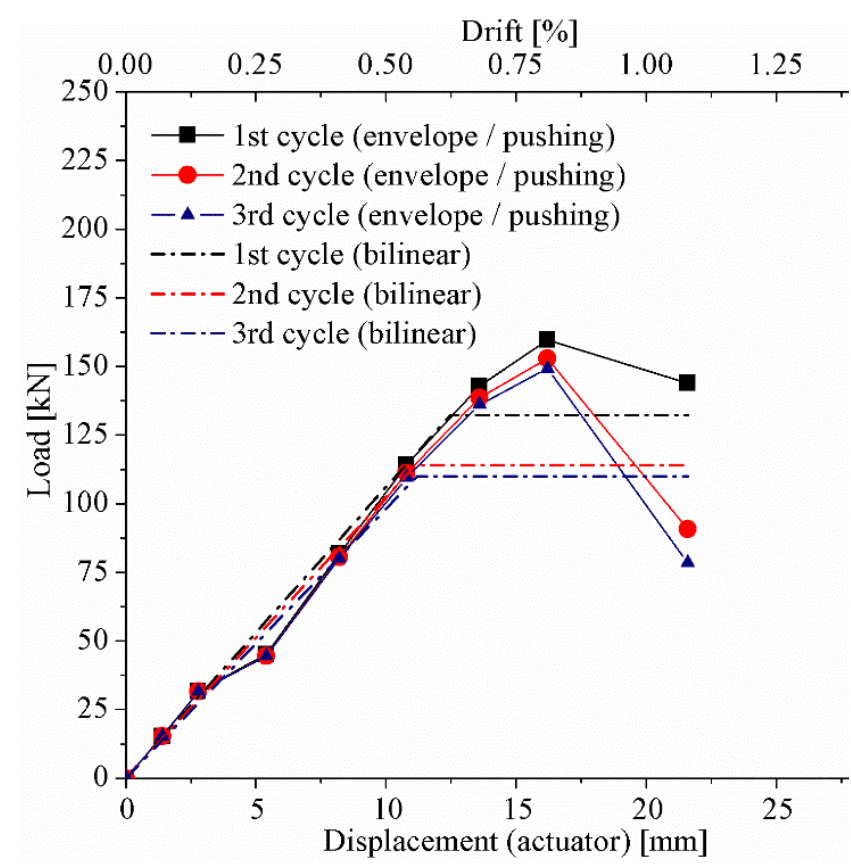

(c)

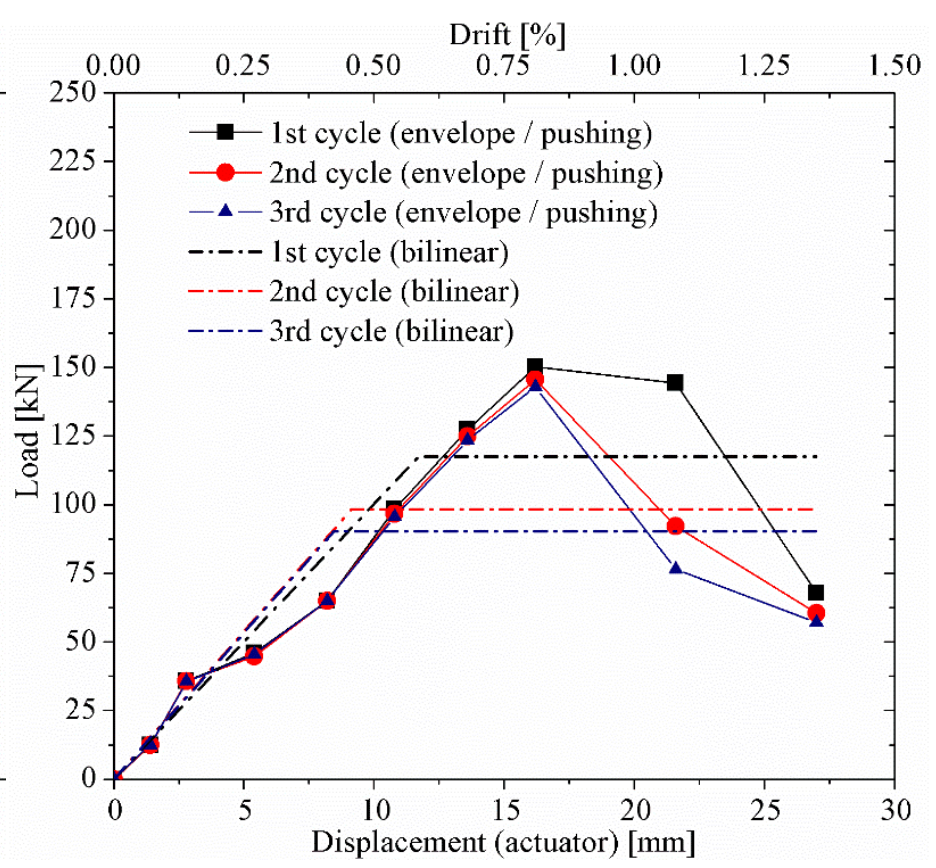

(d)

Figure 19: Equivalent bilinear curves: (a) NO 01; (b) NO 02; (c) OP 01; (d) OP 02. 


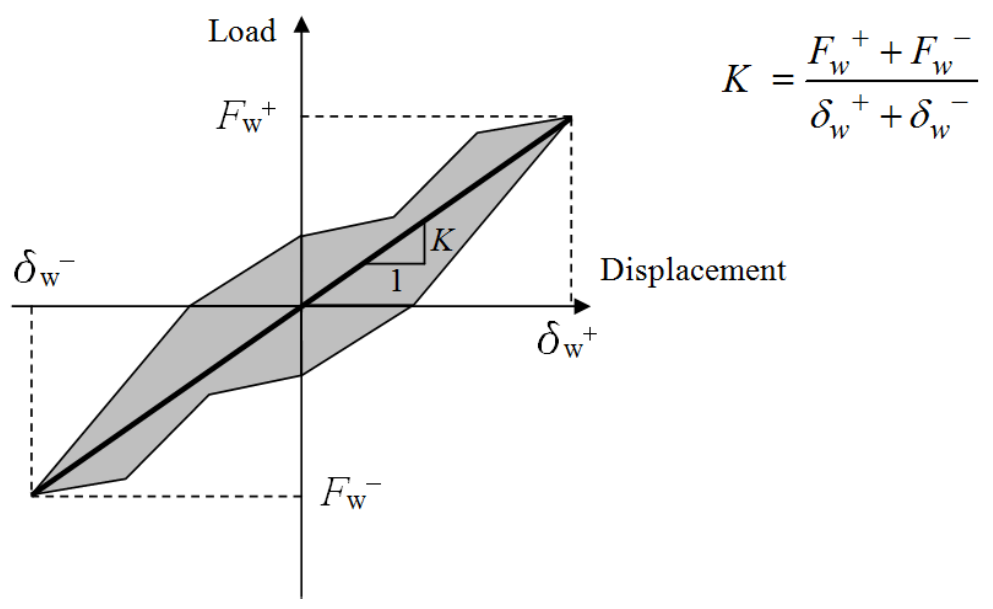

(a)
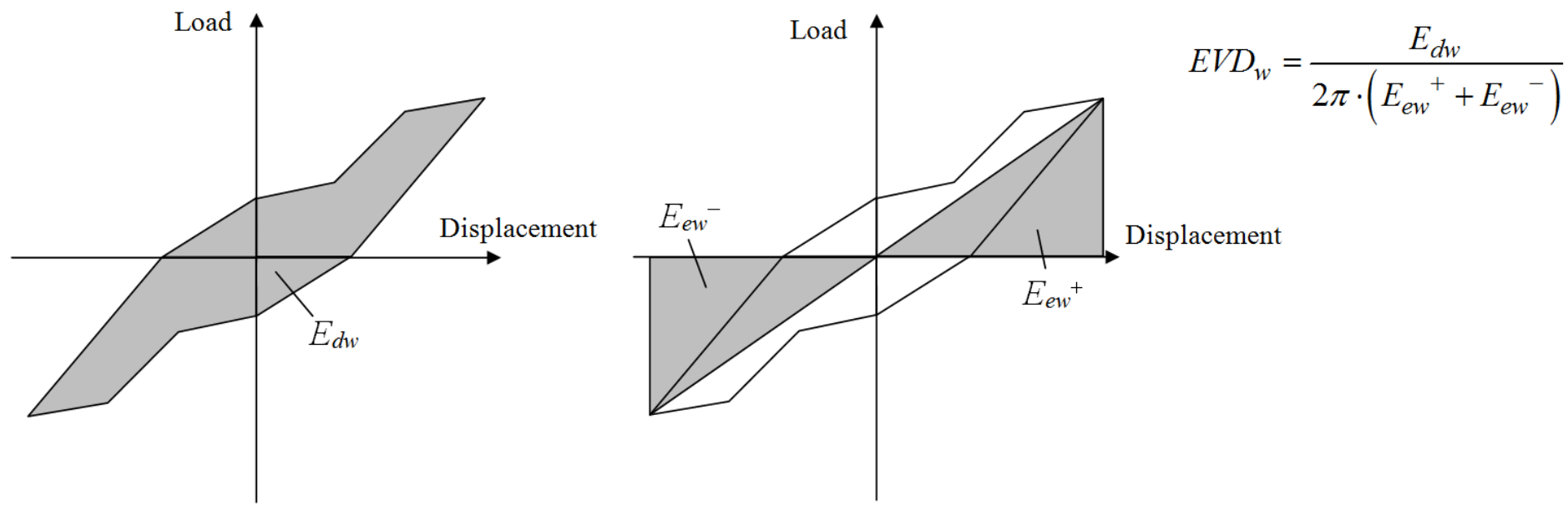

Figure 20: Evaluation of parameters: (a) overall stiffness $(K)$; (b) Equivalent Viscous Damping $\left(E V D_{w}\right)$. 


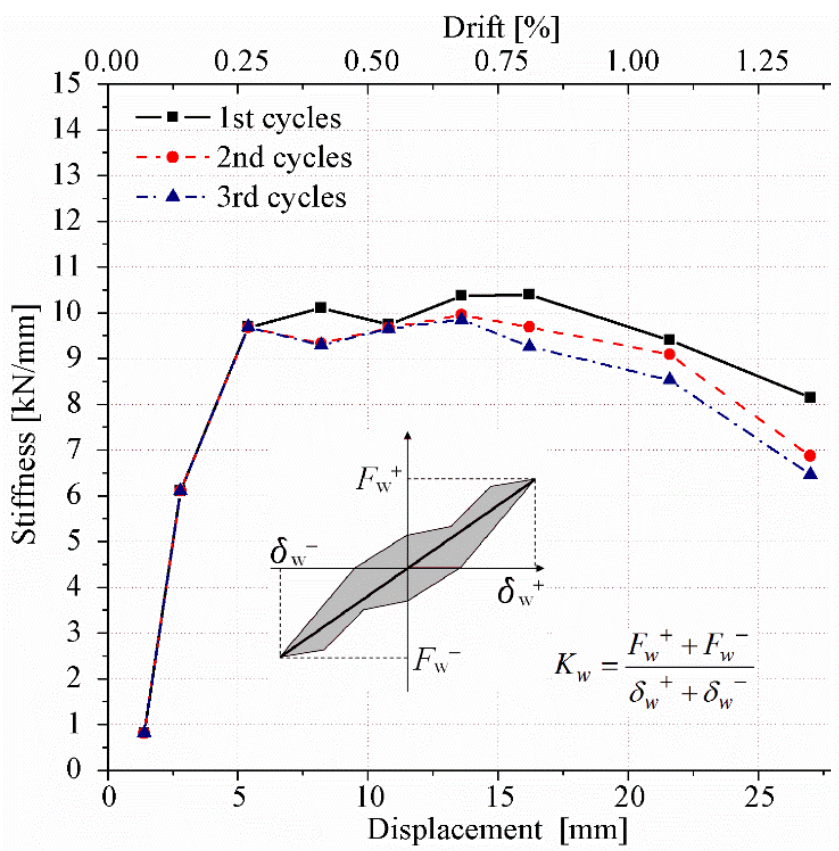

(a)

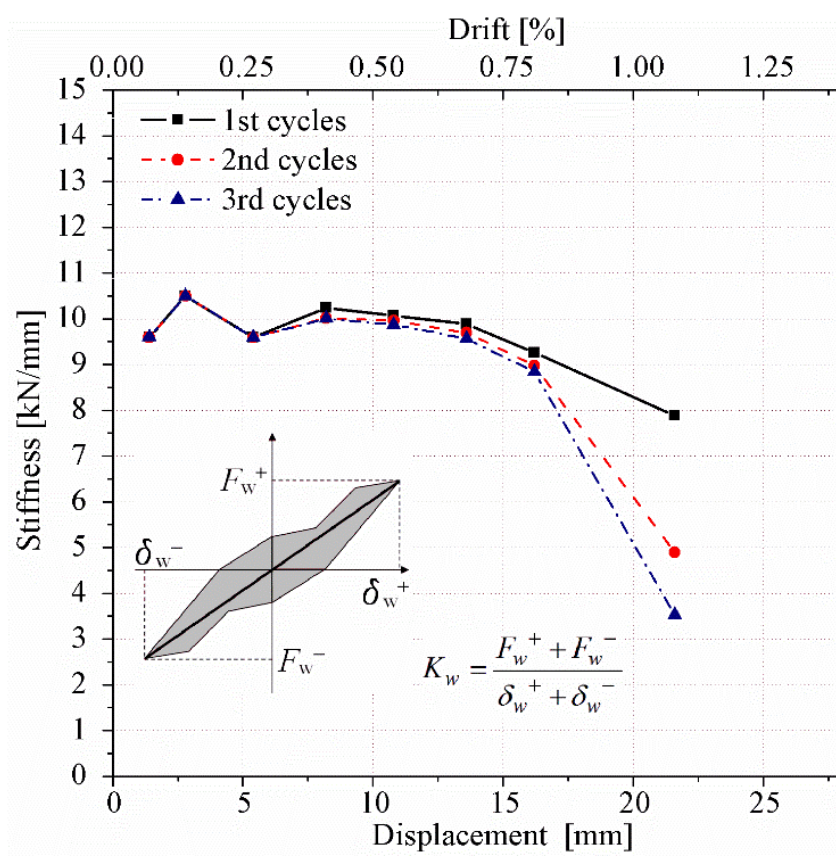

(c)

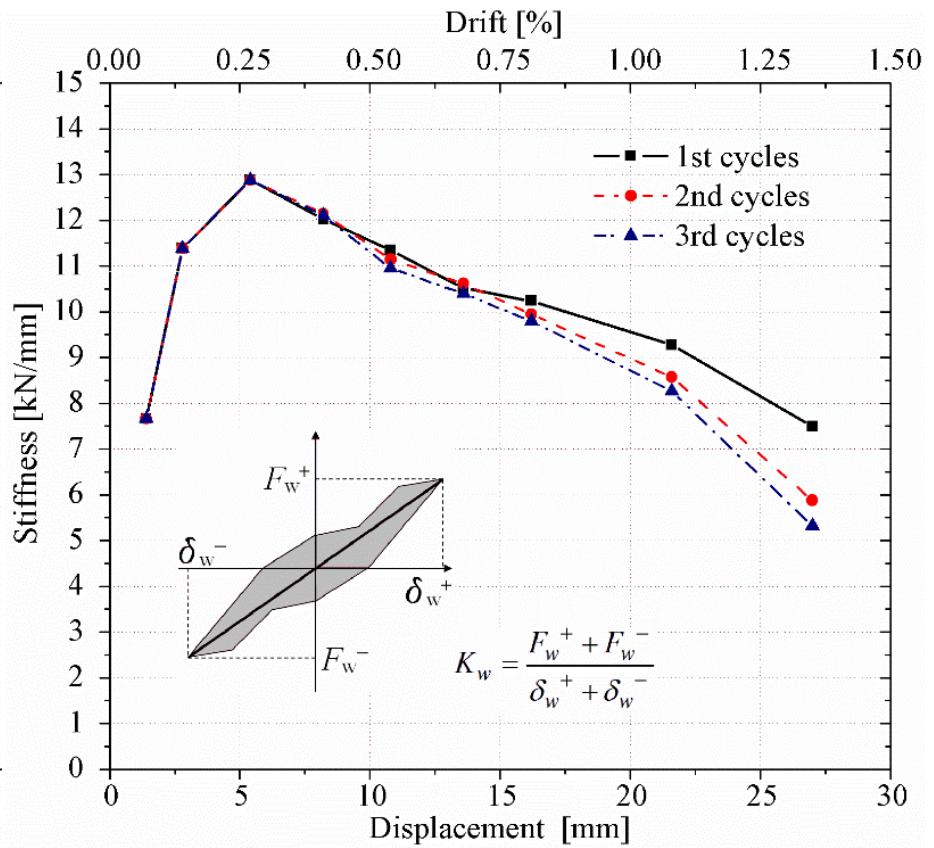

(b)

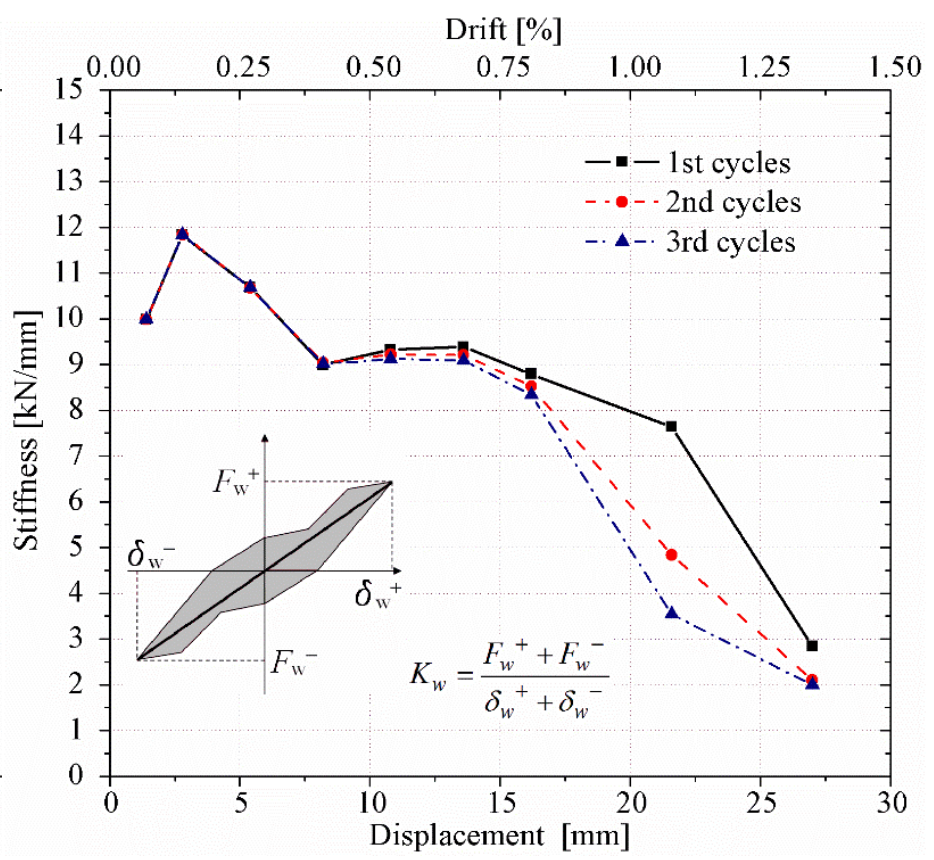

(d)

Figure 21: Overall stiffness degradation: (a) NO 01; (b) NO 02; (c) OP 01; (d) OP 02. 


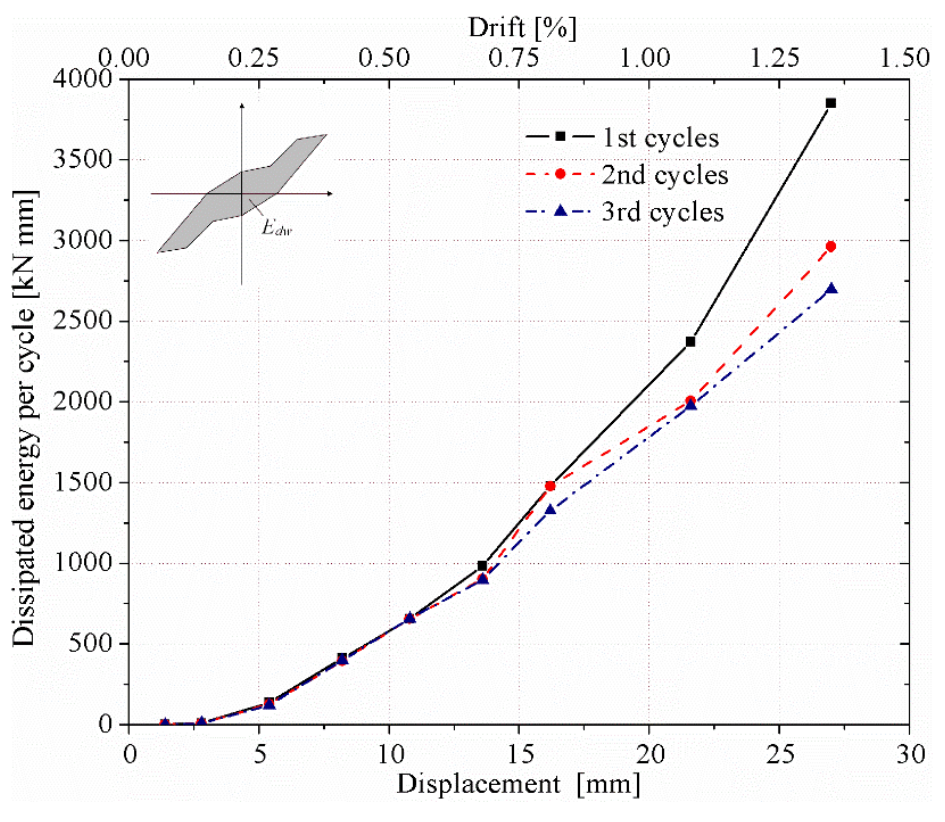

(a)

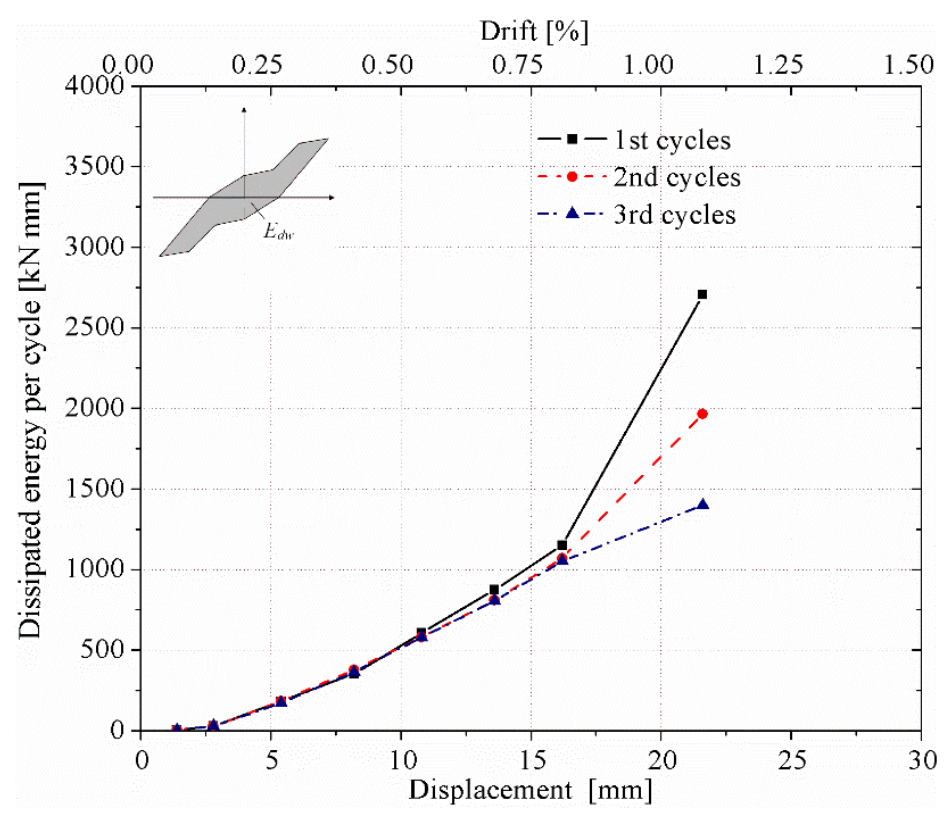

(c)

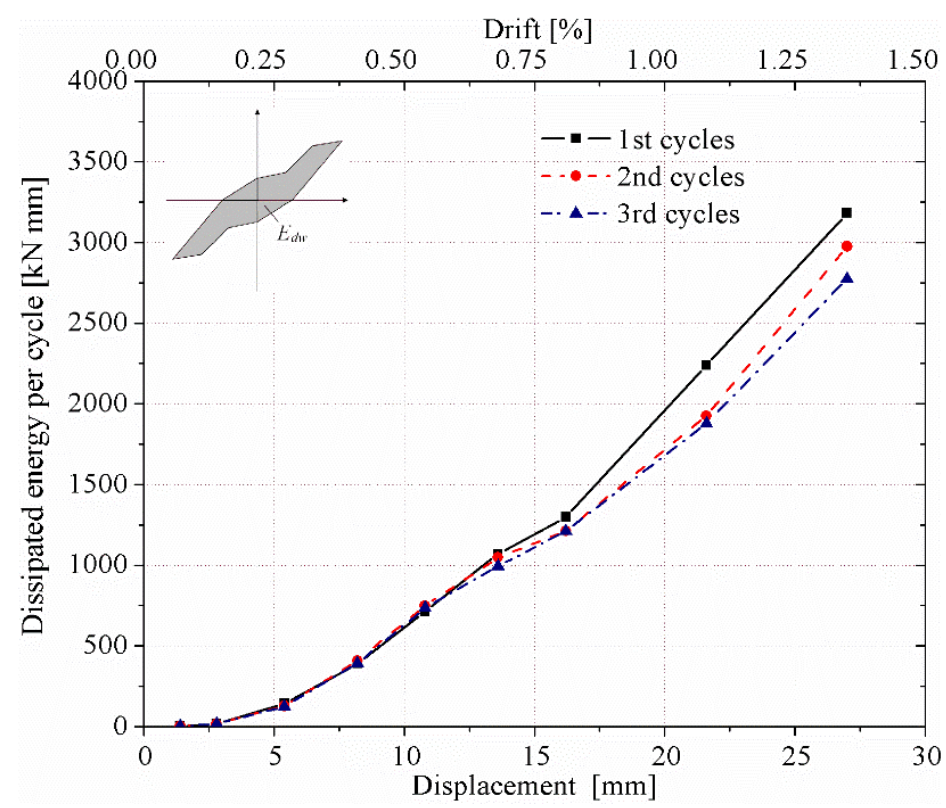

(b)

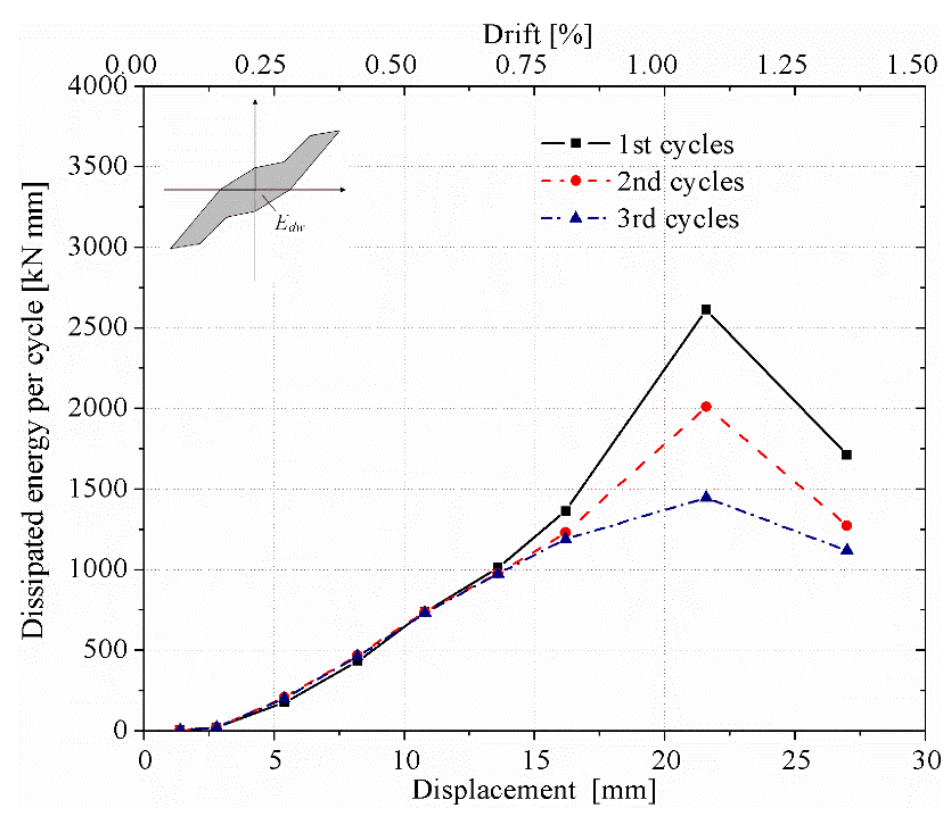

(d)

Figure 22: Dissipated energy per cycle: (a) NO 01; (b) NO 02; (c) OP 01; (d) OP 02. 


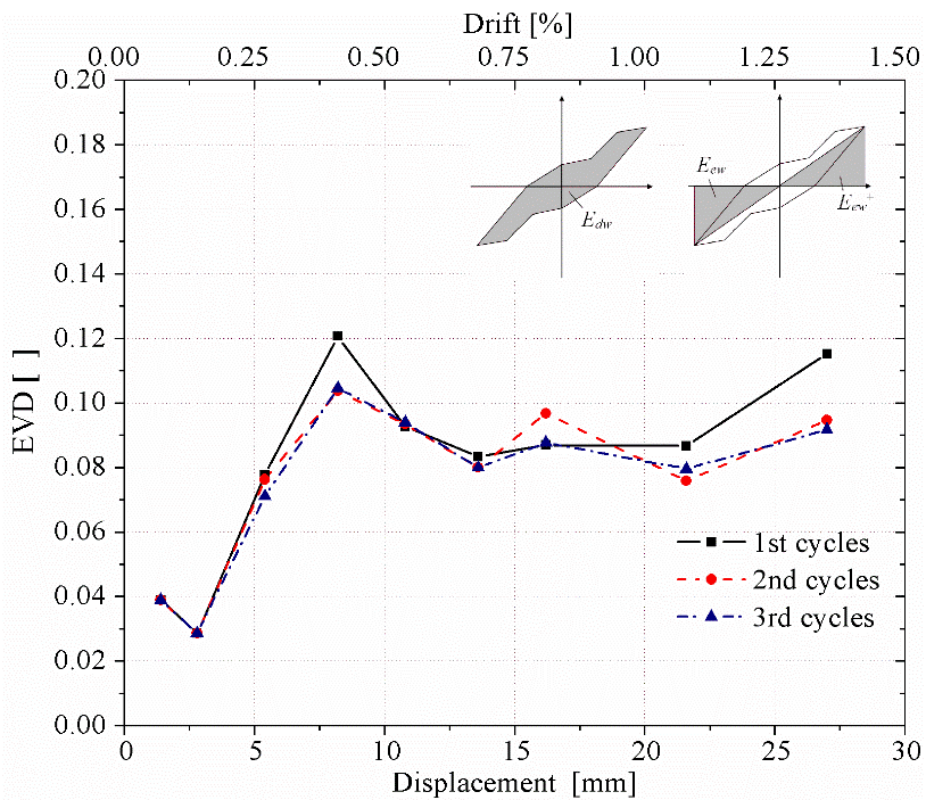

(a)

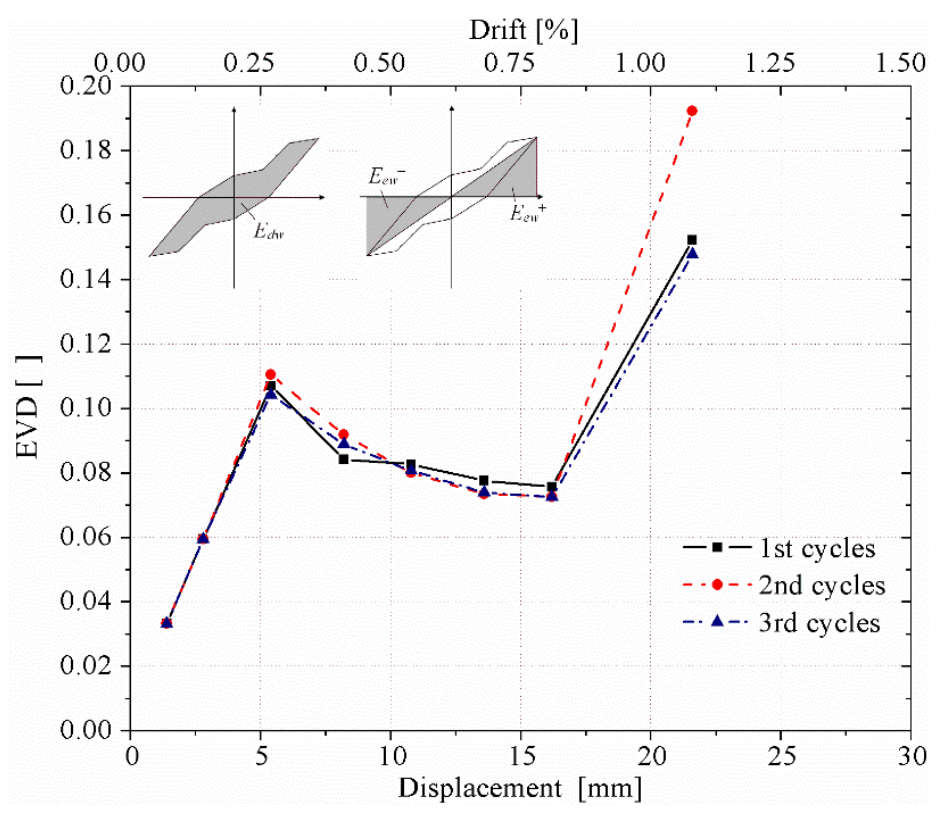

(c)

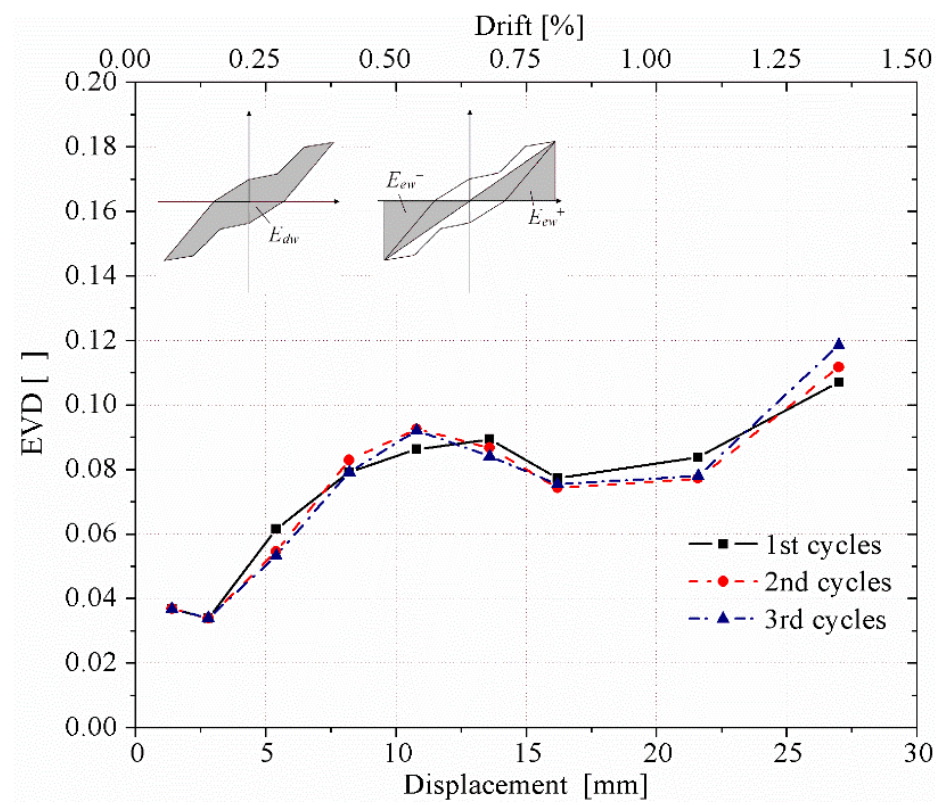

(b)

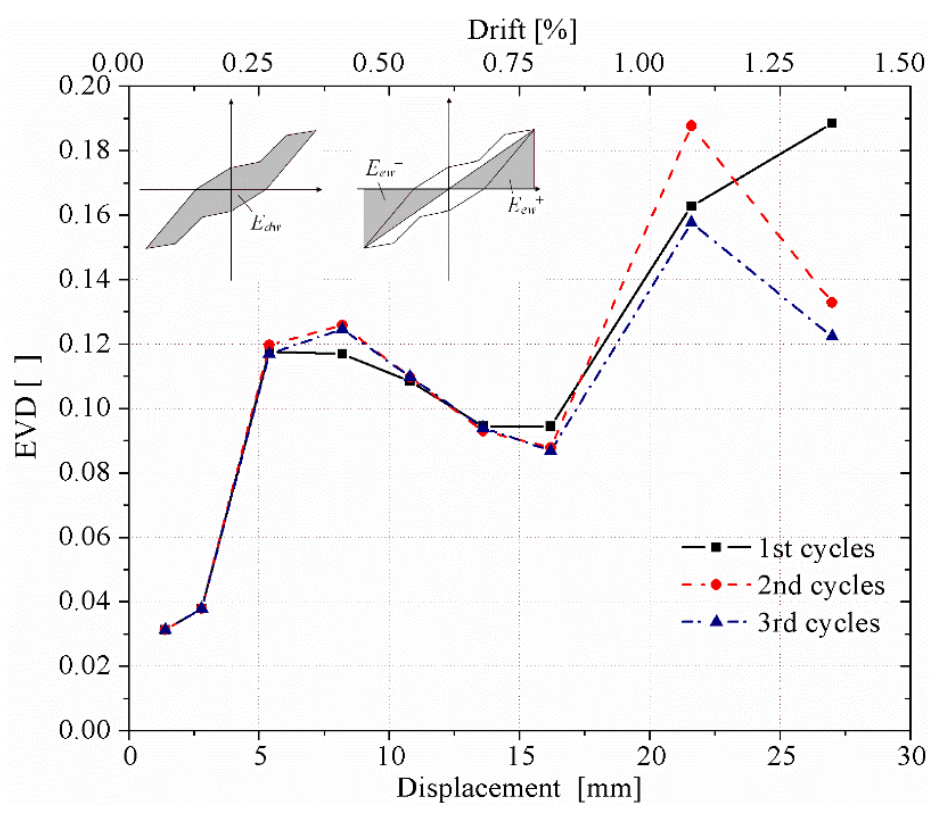

(d)

Figure 23: Equivalent viscous damping: (a) NO 01; (b) NO 02; (c) OP 01; (d) OP 02. 
